University of Louisville ThinkIR: The University of Louisville's Institutional Repository

Electronic Theses and Dissertations

$12-2015$

\title{
Meta-analyses of cardiovascular responses to rumination : exploring mechanisms linking depression and hostility to cardiovascular disease.
}

Lorna Y. Busch

University of Louisville

Follow this and additional works at: https://ir.library.louisville.edu/etd

Part of the Student Counseling and Personnel Services Commons

\section{Recommended Citation}

Busch, Lorna Y., "Meta-analyses of cardiovascular responses to rumination : exploring mechanisms linking depression and hostility to cardiovascular disease." (2015). Electronic Theses and Dissertations. Paper 2304.

https://doi.org/10.18297/etd/2304

This Doctoral Dissertation is brought to you for free and open access by ThinkIR: The University of Louisville's Institutional Repository. It has been accepted for inclusion in Electronic Theses and Dissertations by an authorized administrator of ThinkIR: The University of Louisville's Institutional Repository. This title appears here courtesy of the author, who has retained all other copyrights. For more information, please contact

thinkir@louisville.edu. 
META-ANALYSES OF CARDIOVASCUAR RESPONSES TO RUMINATION:

EXPLORING MECHANISMS LINKING DEPRESSION AND HOSTILITY TO CARDIOVASCULAR DISEASE

\author{
By \\ Lorna Y. Busch \\ B.A., State University of New York at Buffalo, 1995 \\ M.S., University of Baltimore, 2002 \\ M.Ed., University of Louisville, 2011

\begin{abstract}
A Dissertation
Submitted to the Faculty of the

College of Education and Human Development

of the University of Louisville

in Partial Fulfillment of the Requirements

for the Degree of
\end{abstract} \\ Doctor of Philosophy \\ in Counseling and Personnel Services \\ Department of Educational and Counseling Psychology \\ University of Louisville \\ Louisville, Kentucky
}

December 2015 
Copyright (C) 2015 by Lorna Y. Busch

All rights reserved 

META-ANALYSES OF CARDIOVASCUAR RESPONSES TO RUMINATION: EXPLORING MECHANISMS LINKING DEPRESSION AND HOSTILITY TO CARDIOVASCULAR DISEASE

\author{
By \\ Lorna Y. Busch \\ B.A., State University of New York at Buffalo, 1995 \\ M.S., University of Baltimore, 2002 \\ M.Ed., University of Louisville, 2011
}

A Dissertation Approved on

November 30, 2015

by the following Dissertation Committee

\begin{tabular}{c}
\hline $\begin{array}{c}\text { Dissertation Director } \\
\text { Patrick Pössel, Dr. rer. soc. } \\
\text { University of Louisville }\end{array}$ \\
\hline $\begin{array}{c}\text { Jeffrey C. Valentine, Ph.D. } \\
\text { University of Louisville }\end{array}$ \\
\hline Patrick Hardesty, Ph.D. \\
University of Louisville \\
\hline Amelia Aldao, Ph.D. \\
Ohio State University
\end{tabular}




\section{ABSTRACT \\ META-ANALYSES OF CARDIOVASCUAR RESPONSES TO RUMINATION: EXPLORING MECHANISMS LINKING DEPRESSION AND HOSTILITY TO CARDIOVASCULAR DISEASE \\ Lorna Y. Busch}

November 30, 2015

Rumination intensifies and prolongs cardiovascular responses to stress. This emotion regulation strategy is characteristic of depression and hostility and may be a mechanism linking these dispositions to cardiovascular disease (CVD). The current meta-analyses investigate the magnitude of cardiovascular responses to rumination and the effectiveness of distraction in curtailing these responses. A literature search identified studies with rumination conditions and corresponding cardiovascular measures. A random effects model was applied to calculate heart rate (HR), diastolic blood pressure (DBP), and systolic blood pressure (SBP) weighted effect sizes for reactivity and recovery to angry rumination, sadness rumination, and rumination on positive emotion; heart rate variability (HRV) responses to angry rumination; as well as differences in cardiovascular reactivity to rumination vs. distraction conditions. Large and significant reactivity effect sizes were found for all cardiovascular variables to all rumination subtypes. For angry rumination, DBP and SBP reactivity were significantly greater than HR reactivity. Recovery to sadness and angry rumination yielded significant effect sizes for SBP. There was a significant DBP effect size difference between angry rumination 
and distraction conditions. Sex and race/ethnicity did not moderate any calculated effect sizes; while a few study factors did. Results suggest that rumination contributes to CVD vulnerability and that distraction is not particularly effective at decreasing the magnitude of cardiovascular responses to induced rumination. Additionally, blood pressure may be of greater concern than HR when considering the cardiovascular implications of rumination, with angry rumination exerting the largest increases in blood pressure. 


\section{TABLE OF CONTENTS}

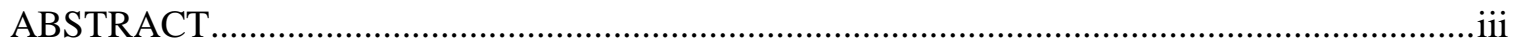

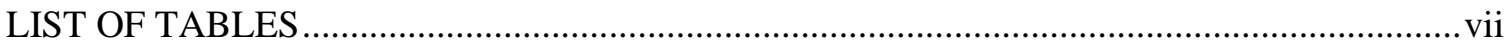

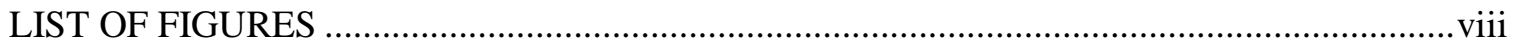

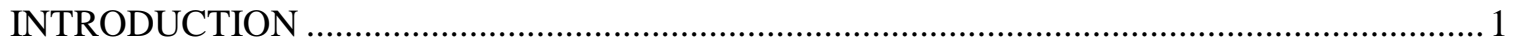

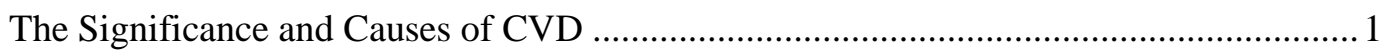

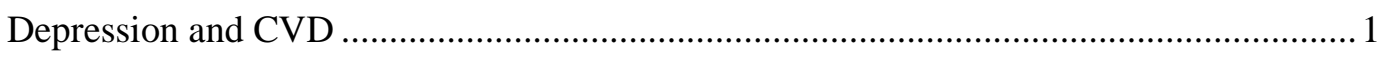

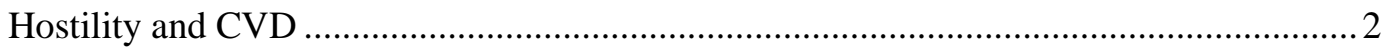

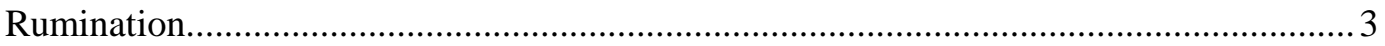

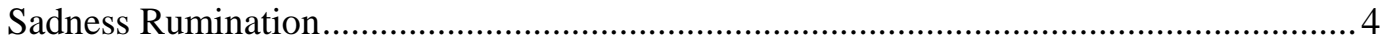

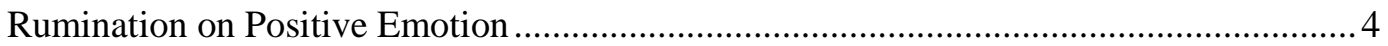

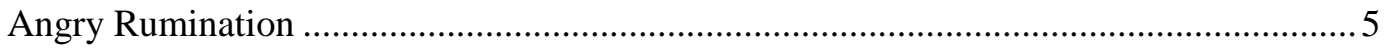

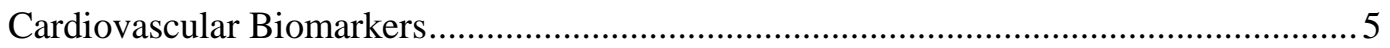

Rumination and Cardiovascular Biomarkers ............................................................. 7

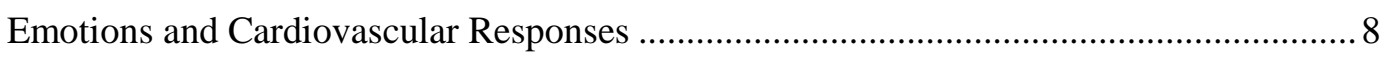

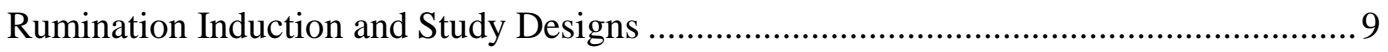

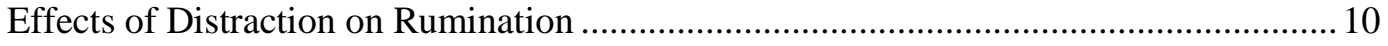

Possible Moderators of Cardiovascular Responses to Rumination ................................... 11

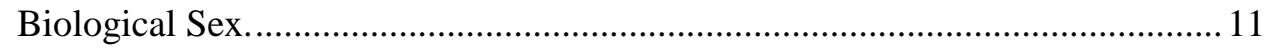

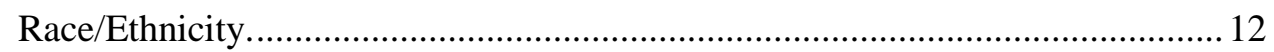

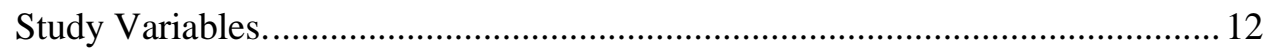

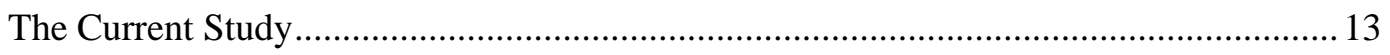

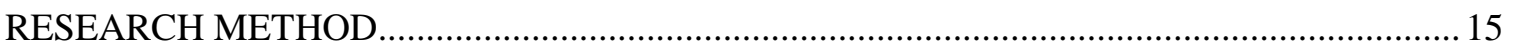

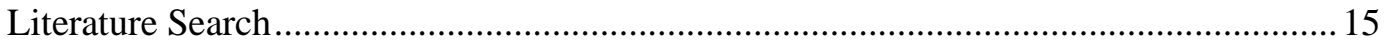

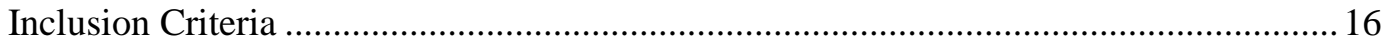

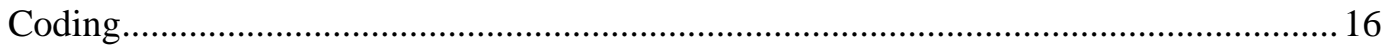

Data Extraction and Effect Size Calculation.................................................................. 17

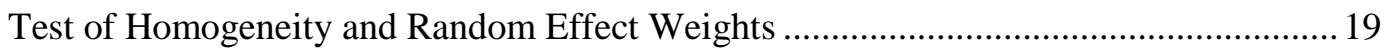

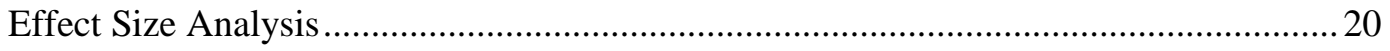

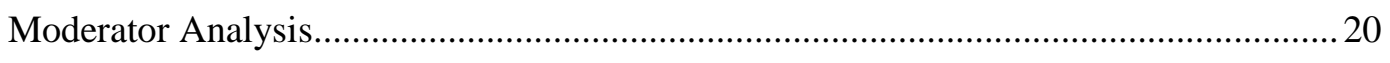

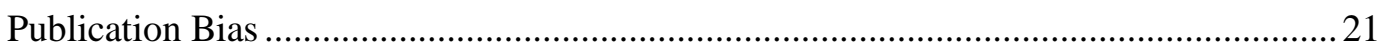




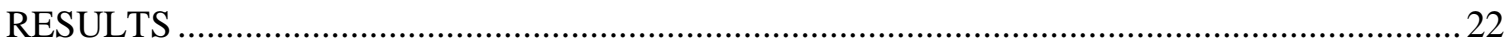

Literature Search and Study Characteristics ……..........................................................22

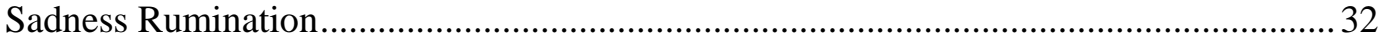

Sadness Rumination Reactivity and Recovery. …............................................. 32

Sadness Rumination Publication Bias. ................................................................ 35

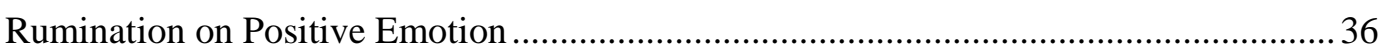

Rumination on Positive Emotion Reactivity.........................................................36

Rumination on Positive Emotion Publication Bias............................................... 39

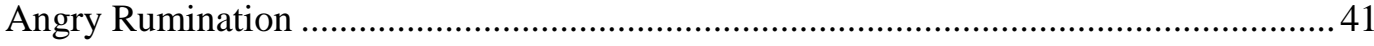

Angry Rumination Reactivity and Recovery................................................. 41

Angry Rumination Reactivity and Recovery Publication Bias..........................51

Reactivity and Recovery Effect Sizes within and across Rumination Types. .....54

Cardiovascular Reactivity for Angry Rumination vs. Distraction.......................56

Angry Rumination vs. Distraction Publication Bias......................................... 61

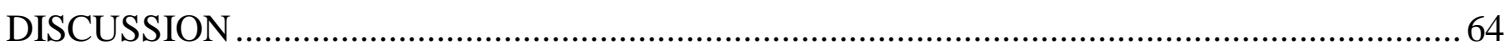

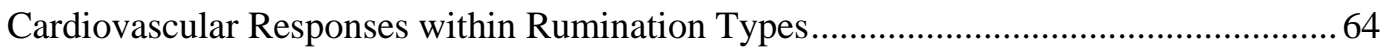

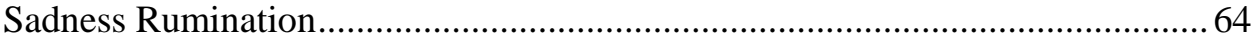

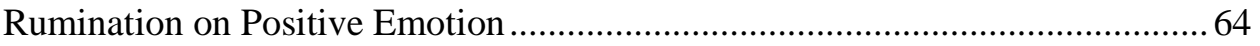

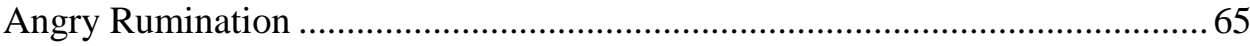

Cardiovascular Response Comparisons across Rumination Types ..................................66

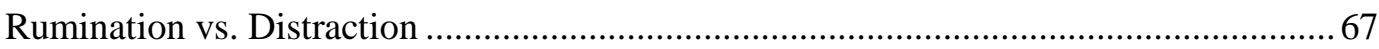

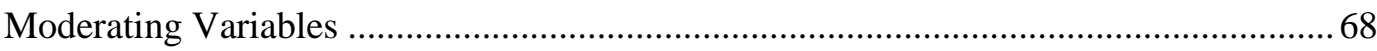

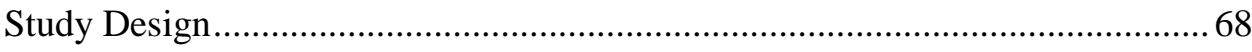

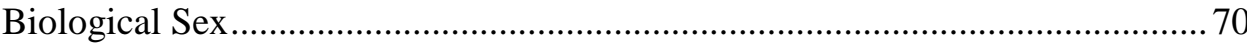

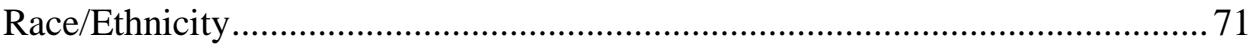

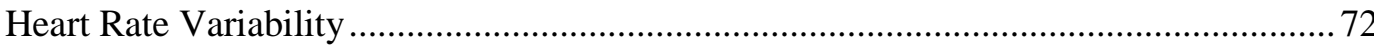

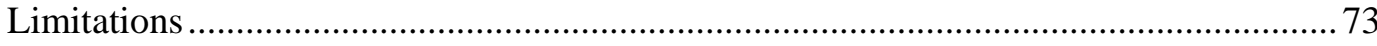

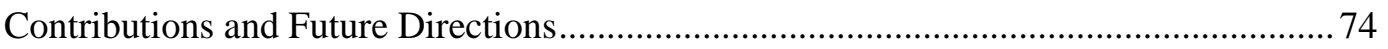

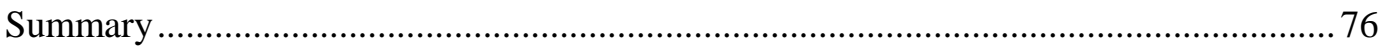

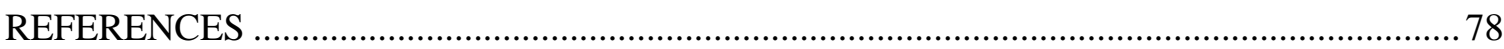

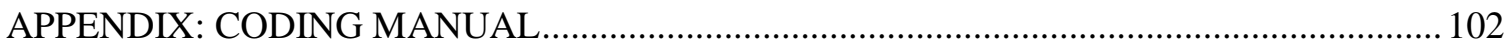

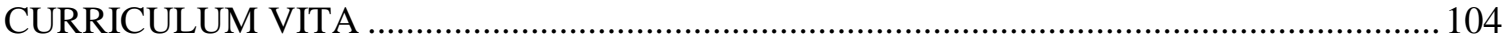




\section{LIST OF TABLES}

TABLE

PAGE

Table 1. Characteristics of Studies Included in Reactivity and Recovery Analyses............... 24

Table 2. Characteristics of Studies Included in Distraction vs. Rumination Analyses.............. 30

Table 3. Sadness Rumination Reactivity and Recovery Effect Sizes.......................... 32

Table 4. Sadness Rumination Reactivity Moderator Analyses................................... 33

Table 5. Rumination on Positive Emotion Reactivity Effect Sizes.............................. 36

Table 6. Rumination on Positive Emotion Reactivity Effect Size Moderator Analyses........... 37

Table 7. Moderators of Rumination on Positive Emotion Reactivity Effect Sizes................. 37

Table 8. Angry Rumination Reactivity and Recovery Effect Sizes.......................... 41

Table 9. Angry Rumination Reactivity and Recovery Moderator Analyses................... 42

Table 10. Moderators for angry rumination reactivity effect sizes............................. 43

Table 11. Moderators of angry rumination recovery effect sizes.............................. 43

Table 12. Angry Rumination Cardiovascular Reactivity Beta Weights ......................... 44

Table 13. Angry Rumination Cardiovascular Recovery Beta Weights ....................... 45

Table 14. Cardiovascular Reactivity and Recovery Effect Sizes across Types of Rumination...... 55

Table 15. Rumination vs. Distraction Effect Sizes..................................... 56

Table 16. Rumination vs. Distraction Reactivity Subgroup Moderator Analyses.............. 57

Table 17. Rumination vs. Distraction HR Subgroup Moderators......................... 57

Table 18. Angry Rumination vs. Distraction Comparison across Variables................. 57

Table 19. Angry Rumination vs. Distraction vs. Beta Weights...........................58 


\section{LIST OF FIGURES}

FIGURE

PAGE

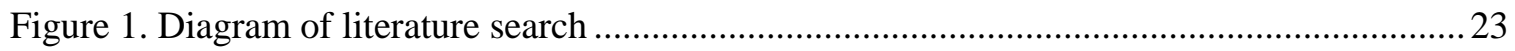

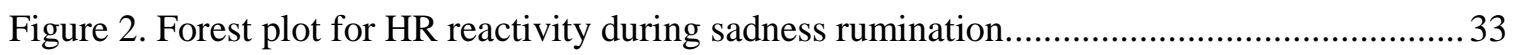

Figure 3. Forest plot for DBP reactivity during sadness rumination. .......................................... 34

Figure 4. Forest plot for SBP reactivity during sadness rumination............................................ 34

Figure 5. Funnel plot for HR sadness rumination reactivity................................................. 35

Figure 6. Funnel plot for DBP sadness rumination reactivity .................................................. 35

Figure 7. Funnel plot for SBP sadness rumination reactivity................................................... 36

Figure 8. Forest plot for HR reactivity during positive rumination........................................... 38

Figure 9. Forest plot for DBP reactivity during positive rumination.......................................... 38

Figure 10. Forest plot for SBP reactivity during positive rumination.......................................... 39

Figure 11. Funnel plot for HR rumination on positive emotion reactivity. ...............................40

Figure 12. Funnel plot for DBP rumination on positive emotion reactivity. ................................ 40

Figure 13. Funnel plot for SBP rumination on positive emotion reactivity ............................... 41

Figure 14. Forest plot for HR reactivity during angry rumination........................................... 46

Figure 15 . Forest plot for DBP reactivity during angry rumination. ....................................... 47

Figure 16. Forest plot for SBP reactivity during angry rumination........................................ 48

Figure 17. Forest plot for HRV reactivity during angry rumination....................................... 49

Figure 18. Forest plot for HR recovery following angry rumination....................................... 49

Figure 19. Forest plot for DBP recovery following angry rumination. ....................................50

Figure 20. Forest plot for SBP recovery following angry rumination. .....................................51

Figure 21. Funnel plot for HR angry rumination reactivity....................................................52

Figure 22. Funnel plot for DBP angry rumination reactivity ..................................................52 


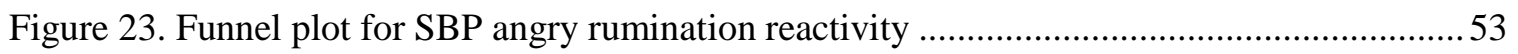

Figure 24. Funnel plot for HR angry rumination recovery.....................................................53

Figure 25. Funnel plot for DBP angry rumination recovery ...................................................54

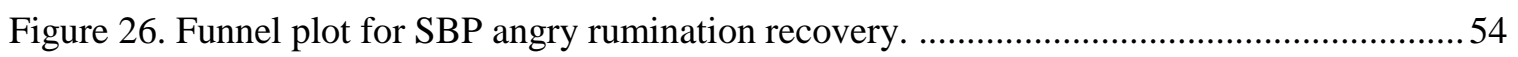

Figure 27. Forest plot for HR reactivity of angry rumination vs. distraction. ..............................59

Figure 28. Forest plot for DBP reactivity of angry rumination vs. distraction. ...........................60

Figure 29. Forest plot of SBP reactivity of angry rumination vs. distraction. .............................. 61

Figure 30. Funnel plot for HR angry rumination vs. distraction............................................... 62

Figure 31. Funnel plot for DBP angry rumination vs distraction. ............................................ 62

Figure 32. Funnel plot for SBP angry rumination vs. distraction. ............................................63 


\section{INTRODUCTION}

\section{The Significance and Causes of CVD}

Cardiovascular disease (CVD), which includes diseases of the heart and blood vessels, is a major cause of death worldwide (Ford \& Capewell, 2007), the number one cause of death in the United States (Lloyd-Jones et al., 2010), and is one of the main causes of disability (Zhang \& Hayward, 2006), costing the nation billions of dollars annually (American Heart Association, 2013). Certain variables predispose individuals to CVD, including health behaviors (e.g., smoking), genetics (e.g., family history of disease), and socioeconomic factors (e.g., low levels of education; Eaton, 2005; Kaplan \& Keil, 1993). However, these classic risk factors account for less than 50 percent of the variance in the onset of CVD (Futterman \& Lemberg, 1998). To explain the missing etiological variance, researchers are turning their attention to psychological constructs, with growing evidence supporting a link between cognitive and emotional factors, such as depressive and hostile dispositions, to cardiovascular health outcomes (Barefoot \& Schroll, 1996; Chida \& Steptoe, 2009). These associations have similar effect sizes to those of traditional risk factors, including smoking or obesity (Yusuf et al., 2004). Therefore, understanding mechanisms connecting depression and hostility to physical health has significant implications for targeting specific risk factors of CVD.

Depression and CVD

The association between depression and CVD has long been recognized given 
cardiac patients' high depression rates; up to $34 \%$ are clinically depressed (Rutledge, Reis, Linke, Greenberg, \& Mills, 2006) and close to one third of myocardial infarction (heart attack) patients develop depression within a year (Lespérance, FrasureSmith, \& Talajic, 1996). This startling prevalence cannot be attributed solely to factors pertaining to patients' medical conditions since research shows that depression often precedes the onset of CVD; those who are depressed are at a significantly higher risk for developing poor cardiovascular outcomes (Glassman \& Shapiro; 1998; Strike \& Steptoe, 2004). Even subclinical levels of depression pose a risk for CVD, particularly coronary heart disease (CHD; Haas et al., 2005; Pratt et al., 1996). This relationship persists despite controlling for the abovementioned classic risk variables (Barefoot \& Schroll, 1996; Pössel et al., 2013). Therefore, depressed individuals' susceptibility to CHD appears not to be merely through overt maladaptive coping behaviors characteristic of traditional CVD risk (e.g., sedentary lifestyle or smoking), but exists via some other mechanism. Furthermore, the association appears to be dose-responsive, supporting the notion of a causal relationship (Rugulies, 2002). Consequently, depression is now considered an independent risk-factor for CVD (Van der Kooy et al., 2007). Furthermore, depression rates are on the rise and this mental health issues has been considered an epidemic (Hidaka, 2012). As the fourth leading cause of disease burden in the world (Meyer, 2004), the prevalence and dire health implications of depression warrants an urgency to understand its link to fatal CVD.

\section{Hostility and CVD}

Hostility has also been implicated as an independent risk factor for CVD (Miller, Smith, Turner, Guijarro, \& Hallet, 1996) with a dose responsive relationship to CHD 
(Kawachi, Sparrow, Spiro, Vokonas, \& Weiss, 1996). Hostility is characterized by persistent negative attitudes towards others that lead to intense and prolonged anger (Chida \& Steptoe, 2009), which is a negative feeling state associated with specific cognitive appraisals, physiological arousal, and behavioral inclinations (Kassinove \& Sukhodolsky, 1995). The intensity of anger depends on how an event is mentally processed (Mauss, Cook, Cheng, \& Gross, 2007). Due in part to the propensity to perceive situations as unjust and others as antagonistic (Miller, Dolgoy, Friese, \& Sita, 1996), hostile individuals are more inclined to interpret events as threatening. This tendency to experience anger frequently and in a wide range of situations, referred to as trait anger, is associated with certain cognitive processes (Wilkowski \& Robinson, 2010) and has been consistently linked to CVD (Chida \& Steptoe, 2009). Therefore, it is largely recognized that physiological arousal from repeated and prolonged anger is likely responsible for the increased cardiovascular risk for hostile individuals, especially since anger has been found to precede sudden cardiovascular-related deaths (Adler, Macritchie, \& Engle, 1971). Despite this well-established association, as well as the nationwide prevalence of anger in presenting clinical concerns (Eckhardt, Norlander, \& Deffenbacher, 2004), research investigating specific pathways of this relationship is lacking. One possible venue to understand this connection is to identify cognitive emotion regulation strategies of hostile individuals that prolong and intensify anger, and to investigate associated cardiovascular implications.

\section{Rumination}

Considerable research reveals that both depressed and hostile individuals tend to engage in a perseveratory process called rumination (Balsamo, 2010). This emotion 
regulation strategy is defined as repetitively thinking about the causes and consequences of negative events and feelings (Rusting \& Nolen-Hoeksema, 1998) in the absence of environmental stimuli requiring the recurrent thoughts (Martin \& Tesser, 1996), and is experienced in a first-person perspective (Kross, Ayduk, \& Mischel, 2005). It is now understood that there are subtypes of rumination that have unique emotional, cognitive, and behavioral components (Peled \& Moretti, 2010)

\section{Sadness Rumination}

Initially, rumination was extensively studied in relation to depression, providing substantial evidence for Nolen-Hoeksema's Response Styles Theory (RST, 1991); in which rumination intensifies and prolongs dysphoric mood (Denton, Rieckmann, Davidson, \& Chaplin, 2012) and plays a role in the development of clinical depression (Abela \& Hankin, 2011). This type of rumination (known as sadness or depressive rumination) is associated with withdrawn behaviors (Dickson, Ciesla, \& Reilly, 2012), self-critical and self-blaming thoughts (Rimes \& Watkins, 2005), and other depressogenic cognitions (Winkeljohn Black \& Pössel, 2013).

\section{Rumination on Positive Emotion}

While rumination has traditionally been conceptualized in terms of negative emotion, some researchers have recently applied this emotion regulation strategy to positive affect (e.g., Feldman, Joormann, \& Johnson, 2008; Raes, Daems, Feldman, Johnson, \& Van Gucht, 2009). Gruber, Eidelman, Johnson, Smith, and Harvey (2011), who coined the phrase ruminating on positive emotion, had individuals ruminate about a happy personal experience. Results revealed that extensive rumination on positive events was a distinguishing feature of individuals diagnosed with bipolar disorder; a mental 
health condition characterized by difficulty regulating both positive and negative emotions, in which an individual experiences separate episodes of intense depression and mania. To date, no research exists comparing the cardiovascular health implications of ruminating on negative and positive emotional events.

\section{Angry Rumination}

A proliferation of studies on rumination led to the recognition that this repetitive cognitive process also intensifies and prolongs other affective responses, notably anger (Bushman, 2002). For most people, angry feelings dissipate relatively quickly, usually within a few minutes (Averill, 1983). However, some individuals (such as those with hostile dispositions) have difficulty letting go of anger-inducing stimuli, extending psychological and physiological reactions well beyond a perceived transgression. Such angry rumination (also known as provocation-focused rumination) increases aggression and often includes thoughts of revenge (Bushman, 2002; Pedersen et al., 2011).

\section{Cardiovascular Biomarkers}

Cardiovascular biomarkers are measurable aspects of cardiovascular health that are known risk factors for CVD. These variables are sometimes observed in response to laboratory tasks, revealing important information about reactivity (increases in cardiac activity from baseline during a task) and recovery (cardiac activity relative to baseline following a task) to stimuli that elicit particular cognitive functions or affective states.

Common cardiovascular measures include heart rate (HR), or beats per minute, and blood pressure, which is comprised of two readings: systolic and diastolic. Systolic blood pressure (SBP) refers to pressure on the arteries caused by the contraction of the heart muscle, while diastolic blood pressure (DBP) represents pressure on the arteries 
between beats. While elevated resting HR, DBP, and SBP are considered important predictors of CVD (Palatini, 2011; Lewington \& MacMahon, 1999), empirical evidence reveals that exaggerated responses (i.e., intense reactivity and prolonged recovery) to stress may be better indicators of poor cardiovascular outcomes (Carroll et al., 2012; Treiber et al., 2003). For example, a recent meta-analysis by Chida and Steptoe (2010) revealed that heightened reactivity increased one's risk of developing hypertension by 23\%. These findings support the cardiovascular reactivity hypothesis, in which exaggerated heart rate and blood pressure responses to stress over time lead to system deregulation, tissue damage, and disease (Lovallo, 2010). This over-reactivity becomes particularly problematic when it continues long after the source of a stressor is no longer present (Pieper, Brosschot, van der Leeden, \& Thayer, 2010).

Heart rate variability (HRV) is a comparatively new cardiovascular measure and represents variations in the interval between heart beats. Although an indication of cardiac activity, HRV provides a window into autonomic nervous system (ANS) functioning, which is critical to physical health by adjusting the body's level of homeostasis. The ANS consists of two branches: the sympathetic ("fight or flight") and parasympathetic ("rest and relax"). Healthy functioning allows parasympathetic control following a stressor, returning the body to baseline homeostatic functioning. Otherwise, the sympathetic system would remain aroused, sustaining a high level of physiological activation beyond homeostasis; a condition termed allostatic load (McEwen, 1998). Return to pre-stress functioning according to the Polyvagal Theory (Porges, 2009), an emerging model explaining the psychological-physical health relationship, is accomplished by slowing down the heart's pacemaker (the sinoatrial node) through the 
myelinated vagus nerve's (one of the twelve pairs of cranial nerves that originate in the brain) inhibitory influence over primitive sympathetic-inducing unmyelinated nerves. Such dampening of the sympathetic system, enhanced by cognitive self-soothing processes, is indicative of high vagal tone, good health, and high HRV. Meanwhile, low HRV, or difficulty regulating healthy beat-to-beat functioning in response to stress, is associated with poor health outcomes, including CVD (Haensel, Mills, Nelesen, Ziegler, \& Dimsdale, 2008). Taken together, excessive cardiovascular stress responses as measured by HR, SBP, DBP, and HRV can be considered indicators of poor cardiac function and biomarkers for CVD.

\section{Rumination and Cardiovascular Biomarkers}

Mounting evidence indicates that rumination about negative events plays a role in exaggerated cardiovascular stress responses (Gerin et al., 2012; Radstaak, Geurts, Brosschot, Cillessen, \& Kompier, 2011). This relationship is explained by the perseveratory cognition hypothesis (Brosschot, Gerin, \& Thayer, 2006), in which rumination and other thought processes involving repetitive cognitions maintain sympathetic activation. Specifically, rumination serves to keep distressing mental representations of an event active in one's mind, prolonging stress-related affective and physiological responses. Research suggests that such ongoing biological activation is more damaging than normal short-lived spikes in response to stress (Glynn, Christenfeld, \& Gerin, 2002), and therefore poor recovery associated with rumination may be a stronger indicator of disease risk than acute stress reactivity.

A key aspect of the perseveratory cognition model is the recognition that physiological activation associated with rumination comprises both a prolonged recovery 
immediately following stressors and a tendency to re-experience these events at a later time. This re-experiencing entails re-living an event through cognitive representations that activate corresponding physiological stress responses (Neumann \& Waldsein, 2001). These delayed reactivated responses are rarely examined in rumination research, which tends to focus on recovery directly following a stressor without considering harmful effects days, weeks, or months later. However, research demonstrates that mentally reexperiencing an event can be just as physiological arousing as immediate post-stress reactions. In a study by Gerin, Davidson, Christenfeld, Goyal, and Schwartz (2006), ruminating about an event both one hour and one week later elicited similar levels of physiological arousal, showing that negative effects of a stressor may occur long after the incident itself. Therefore, repeated re-experienced stress responses may be a critical component linking rumination to cardiovascular health.

\section{Emotions and Cardiovascular Responses}

Since rumination serves to sustain and intensify emotions (Ray, Wilhelm, \& Gross, 2008), understanding the biological basis of emotion may help explain physiological mechanisms associated with affective rumination subtypes. Physiological stress responses seem to differ depending on emotional context (Herrald \& Tomka, 2002). Personally-relevant events (those prone to ruminative thoughts) lead to increased physiological arousal compared to non-emotional stressors (Glynn et al., 2002; Waldstein et al., 2000). Additionally, some studies have shown cardiovascular responses to be greater for negative than positive emotions (Brosschot \& Thayer, 2003; James, Yee, Harshfield, Blank, \& Pickering, 1986), and that negative affect in particular prolongs cardiovascular recovery from stress (Brosschot \& Thayer, 2003; Chida \& Hamer, 2008). 
However, studies directly examining physiological responses to different types of emotion-focused rumination are scarce. In one study by Prkachin, Williams-Avery, Zwaal, \& Mills (1999), negative emotions (e.g., sadness and anger) elicited via emotional imagery of personally relevant events (a technique used in rumination research) resulted in greater SBP, DBP, and HR reactions than that of positive (happiness) imagery. Therefore, it seems that reliving negative events results in more extensive cardiovascular responses relative to reliving positive events. Furthermore, negative emotions within themselves have been shown to elicit differential cardiac responses (e.g., Sinha, Lovallo, \& Parsons, 1992; Rainville, Bechara, Naqvi, \& Damasio, 2006), suggesting that sadness and angry rumination may have different cardiovascular implications. By independently analyzing the magnitude of cardiovascular responses to distinct emotional recall, important information concerning their relative risk for cardiovascular damage may be investigated.

\section{Rumination Induction and Study Designs}

Studies investigating the effects of rumination use various techniques to prompt this perseveratory process and typically fall into one of two study designs. "Immediate post-stress" studies analyze rumination immediately following a stressor or emotioninduction (e.g., Nolen-Hoeksema \& Morrow, 1993; Rusting \& Nolen-Hoeksema, 1998). These studies often assign participants to a rumination or distraction condition following a stressor (e.g., Cohen, 2010) and hence, are used to gauge the effectiveness of distraction at preventing ruminative thoughts. The other type of design are "recall" studies that examine the later (e.g., weeks to months) mental recreation of prior emotional events (e.g., Gruber et al., 2011). While the examination of cardiovascular responses is not 
typical in both types of rumination studies, some anger-focused recall studies employ a re-experiencing technique, known as the anger recall interview (Ironson et al., 1992) that is effective at evoking ruminative thoughts (Ottaviani, Shapiro, \& Fitzgerald, 2011).

The rumination research also incorporates different conceptualizations of reactivity and recovery. In the current analysis, reactivity refers to cardiovascular responses during rumination, and recovery corresponds to cardiovascular responses postrumination.

\section{Effects of Distraction on Rumination}

Research shows that distraction from rumination is an effective method of lowering maladaptive affective, cognitive, and behavioral reactions following a stressor (Lyubomirsky Caldwell, \& Nolen-Hoeksema, 1998; Bushman, 2002). However, limited studies have assessed the physiological implications of distracting from rumination. Evidence reveals that distraction following angry rumination or an angering situation can accelerate return to baseline cardiovascular levels (Gerin et al., 2006; Ottaviani, Shapiro, \& Fitzgerald, 2011). This effect was not found in the limited experimental studies involving cardiovascular implications of rumination following other types of emotion induction, such as sadness or anxiety (Cui \& Huang, 2007; Key, 2011; Vaughn, 2008). The conflicting results may be due to the wide variation in study design, including participants (e.g., clinical vs. non-clinical status) and study methodology. For example, methods of distraction differ across experiments (e.g., reading or looking at pictures), as do the stressful events to which participants are induced to ruminate about (e.g., labinduced or personally-experienced). The current analysis will allow for the study of overall effect sizes in the difference in cardiovascular activity between rumination and 
distraction conditions, and investigate whether variations in experimental conditions contribute to variability in outcomes. These results will provide important information about possible benefits of distraction.

\section{Possible Moderators of Cardiovascular Responses to Rumination}

Biological Sex. Substantial literature supports the notion that women ruminate more than men when sad (Nolen-Hoeksema, Larson, \& Grayson, 1999; Nolen-Hoeksema \& Jackson, 2001; Grant et al., 2004). These studies have been thought to help explain why women are almost twice more likely to be depressed than men (Kessler, Petukhova, Sampson, Zaslavsky, \& Wittchen, 2012; Nolen-Hoeksema \& Jackson, 2001). In response to anger, it was found that women were more likely to distract themselves rather than ruminate relative to men, while men were more likely to engage in rumination than women (Rusting \& Nolen-Hoeksema, 1998). Therefore, a sex difference seems to exist in the tendency to engage in the two subtypes of rumination. However, there has been a lack of attention on sex differences in cardiovascular responses to rumination. One study by Vogeltanz-Holm and Vickers (2003) found that men had higher SBP responses to sadness rumination than women. While it is unknown whether this sex difference holds for angry rumination, research indicates that men tend to have greater physiological responses to recall of angry events (Lawler, Wilcox, \& Anderson, 1995). These elevated responses to anger may play a role in men's higher rates of CVD (Möller-Leimkühler, 2007), in which chronic exaggerated cardiovascular reactions exert physical damage over time. Examining the moderating effect of biological sex on both sadness and angry rumination may shed light on whether these subtypes of rumination have different health implications for men and women. 
Race/Ethnicity. Research reveals that African Americans develop many forms of CVD at earlier ages and at higher rates than European Americans (Falkner, 1993). Similar trends of increased risk compared to European Americans have been found for Latino populations (Fryar, Hirsch, Eberhardt, Yoon, \& Wright, 2010). It has been proposed that heightened sympathetic reactivity to psychological stressors in minorities may contribute to this difference (Carroll, Ring, Hunt, Ford, \& Macintyre, 2003; Merritt, Bennett, Williams, Edwards, \& Sollers, 2006). For example, in response to laboratoryinduced stress, African Americans were found to have greater DBP reactivity than European Americans (Huisman et al., 2013), as well as longer DBP recovery (Anderson, Lane, Taguchi, Williams, \& Houseworth, 1989). Additionally, African-American women had larger cardiovascular responses to imagining a hypothetical social stressor than their European American counterparts (Lepore et al., 2006). Thus, it appears that both actual and mentally-created stress results in overall higher cardiovascular responses for some minorities. Research suggests that rumination potentially mediates the relationship between race/ethnicity and psychological distress (Borders \& Liang, 2011). These findings raise the question of whether rumination plays a role in heightened physiological stress responses for racial/ethnic minorities. Therefore, the current study investigated race/ethnicity as moderator on cardiovascular reactions to rumination.

Study Variables. Variations in research design may also affect the magnitude of cardiovascular reactions. For example, a within-subjects design introduces the possibility of order-effects, in which exposure to previous experimental conditions could lead to inflated or deflated cardiovascular responses. Additionally, some recall methods include the articulation of ruminative thoughts, and it has been shown that vocalization alone may 
increase autonomic responses (Girdler, Turner, Sherwood, \& Light, 1990). Finally, a few studies include participants over the age of 60 and advanced age is associated with decreases in blood pressure and heart rate reactivity to stress (Faucheux et al., 1989). To determine if these study variables could influence study outcomes, they were coded for analysis.

\section{The Current Study}

Based on existing literature indicating that perseveratory processes both prolong and reactivate physiological stress-reactions, in addition to the evidence suggesting poor cardiovascular recovery to negative compared to positive emotions, it was hypothesized that both sadness and angry rumination would have significantly larger cardiovascular response effect sizes (i.e., increases in HR, SBP, DBP, and HRV from baseline during reactivity and recovery) compared to ruminating on positive events. It was also hypothesized that for studies in which participants are assigned to rumination vs. distraction conditions following an angering task, angry rumination would have significantly greater cardiovascular reactivity effect sizes (i.e., increases in HR, SBP, DBP, and HRV from baseline during rumination) than those in distraction conditions, aligning with the evidence that distraction can aid in cardiovascular recovery from stressors (Pedersen et al., 2011). Moderator variables that were analyzed include biological sex, race/ethnicity, and variations in study design. It was hypothesized that biological sex and race/ethnicity would contribute to the variance explained in reactivity and recovery effect sizes (i.e., increases in HR, SBP, DBP, and HRV from baseline) for both sadness and angry rumination. The study design moderator variables (e.g., withinvs. between-groups, type of rumination induction, and participants over the age of 60) 
were exploratory in nature and therefore it was not hypothesized whether they have a significant effect on the magnitude of effect sizes. 


\section{RESEARCH METHOD}

\section{Literature Search}

The relevant literature (both published and unpublished) was searched in PsycInfo and MEDLINE from January 1983 to July 2015 to gather all studies that include an experimental rumination condition along with measures of cardiovascular reactivity and/or recovery. The studies of interest typically compare cardiovascular responses to rumination induction, such as a recall task, with those of other lab tasks or a distraction task. The literature search strategy was developed with a professional research librarian and pilot tested. This process resulted in the following search terms: Ruminat*, Persev*, Recall, Self Reflect* Emotional State*, Brood*, Repetitive Thought*, Repetitive Think*, Ponder*, Self-Focus*, Automatic Think*, and Automatic Thought*. These terms were combined (using "and") with the following cardiovascular terms to locate studies that assess blood pressure, heart rate, or heart rate variability: Blood Pressure, Cardiovascular, Vagal, Systolic, Diastolic, and Heart Rate. Additionally, references of the following reviews and key studies specifically investigating the relationship between perseveratory thought and cardiovascular variables were examined for relevant articles: Brosschot et al., 2006; Brosschot, Peiper, \& Thayer, 2005; Gerin et al., 2012; Larsen \& Christenfeld, 2009; Ottaviani, Shapiro, Davydov, Goldstein, \& Mills, 2009; Verkuil, Brosschot, Gebhardt, \& Thayer, 2010. A forward citation search (using Google Scholar) was also 
performed on these pertinent articles. Emails were sent to subject experts who are actively researching the connection between rumination and cardiovascular implications (Bacon, Brosschot, Campbell, Christenfeld, Davidson, Gerin, Glynn, Key, Ottavianni, Pieper, Thayer, and Verkuil) in an attempt to access relevant data not accessible by other means. Results of the search were stored and organized in citation management software (EndNote) and in a spreadsheet.

\section{Inclusion Criteria}

The titles and abstracts of studies obtained through the electronic search were screened for the following inclusion criteria: (a) an empirical study, (b) written in the English language, (c) on humans, (d) who are adults (i.e., over the age of 17), (e) conducted on at least one group of healthy participants (i.e., no self-reported current or past physical or psychiatric clinical diagnosis, which could affect cardiovascular function), (f) a rumination condition or recall of a personal emotional event, (g) a cardiovascular measure (HR, SBP, DBP, or HRV) taken during or after rumination or recall, and (h) inclusion of baseline cardiovascular data or cardiovascular change scores from baseline. For studies that appeared to be eligible, full text articles were retrieved and further evaluated to ensure the inclusion criteria were met. Among studies that investigated populations with mental health or physical diagnoses, only the data from healthy control groups were included.

\section{Coding}

During the pilot testing phase, a coding manual was created to allow for the identification of experiment characteristics that could potentially moderate study outcomes. Two coders independently coded the following study characteristics: method 
of rumination induction (e.g., verbal recall or imagery recall); whether a between- or within-subjects design was used, type(s) of emotion (e.g., anger, sadness, joy) elicited, whether the study assessed for reactivity or recovery, or both; what outcome measures were assessed (e.g., diastolic blood pressure, heart rate); length of baseline, rumination, and recovery periods; if any intrusive measures were taken that could affect physiological activation (e.g., blood draw); composition of sample (e.g., participants over the age of 60); and publication status. There were three discrepancies between coders, which were resolved via discussion and resulted in updating the coding manual with greater detail to clarify the identified ambiguities. The coding manual is provided in Appendix A. Percentage of female and minority participants in each study were also recorded. For any studies with missing data, primary authors were contacted electronically in attempt to retrieve the omitted information.

\section{Data Extraction and Effect Size Calculation}

Baseline, rumination, and post-rumination HR, DBP, SBP, and HRV data, or corresponding change scores, were extracted from each study to compute effect sizes according to established procedures (Lipsey \& Wilson, 2001). For studies in which these data were not provided, the primary author was contacted in an attempt to retrieve the information. When data was not furnished, but either $t$-values or $F$-values were reported, an effect size conversion (Lipsey \& Wilson, 2001, p.174) was applied. Effect sizes and standard errors were entered into a software program, Comprehensive Meta-Analysis (CMA), to compute overall and subgroup analysis, run meta-regression, and to create forest plots and funnel plots. The comparisons of cardiovascular reactions to sadness, angry, and positive rumination required multiple effect sizes generated from single 
samples (e.g., distinct effect sizes for each of the cardiovascular measures for reactivity and recovery). However, only one effect size per variable was calculated for each sample being analyzed, which eliminates any concern for a violation of the statistical assumption of independence. A few studies used a repeated design with multiple sequential baseline and rumination conditions. In these cases, the first pre- and post- measures were used since subsequent pre- and post- cardiovascular measures could be contaminated by the initial experimental reactions. Therefore, each construct has only one effect size per sample.

The effect sizes reported for comparisons of cardiovascular reactions to anger, sadness, and positive rumination reflects the standardized mean change statistic, $d$, for single group designs. The formula for this statistic is:

$$
E S=d=\left(x_{2}-x_{1}\right) / s_{1}
$$

Where $x_{2}$ is the mean cardiovascular measure during reactivity or recovery, $x_{1}$ is the mean cardiovascular measure at baseline, and $s_{1}$ is the standard deviation at baseline. Weighted effect sizes (in which studies are weighted for their approximate precision) for each of the single group design studies were calculated using the mean gain effect size formula (Lipsey \& Wilson, 2001), which accounts for the correlation between pre- (baseline) and post- (reactivity/recovery) measures:

$$
1 / s^{2}=w_{i}=2 n / 4(1-r)+d^{2}
$$

The effect sizes reported for comparisons of cardiovascular reactions to rumination vs. distraction conditions reflect the standardized mean change statistic, $d$, for between group designs. The formula for this statistic is:

$$
E S=d=\left(x_{2}-x_{1}\right) / s_{p}
$$


Where $x_{2}$ represents the mean cardiovascular change score (from baseline) for the rumination condition, $x_{1}$ represents the mean cardiovascular change score (from baseline) for the distraction condition, and $s_{p}$ is the pooled standard deviation of the rumination and distraction conditions. This raw effect size for the difference between groups is known to be upwardly biased in small samples. Therefore, a correction for small sample size bias was applied using the following formula (Hedges, 1981):

$$
d_{\text {corrected }}=[1-(3 / 4 N-9)] d
$$

The weighted effect of each study was determined by the inverse variance of the effect size, using the following formula:

$$
1 / s^{2}=w_{i}=\left[2 n_{1} n_{2}\left(n_{1}+n_{2}\right)\right] /\left[2\left(n_{1}+n_{2}\right)^{2}+n_{1} n_{2} d^{2}\right]
$$

The calculated weights for both the between and within study designs were used to calculate a weighted average effect size for each analysis:

$$
\text { Weighted Average } E S=\Sigma\left(w_{\mathrm{i}} E S_{\mathrm{i}}\right) / \Sigma w_{\mathrm{i}}
$$

95\% confidence intervals were calculated for each overall mean effect size:

$$
95 \% \mathrm{CI}=-1.96\left(S E_{d}\right) \text { to }+1.96\left(S E_{d}\right)
$$

\section{Test of Homogeneity and Random Effect Weights}

Heterogeneity of the studies was tested by means of a $Q$ statistic (which is approximately distributed as a chi-square). The presence of significant heterogeneity suggests that study-level factors other than sampling error contribute to the difference in outcome measures across studies. Due to the variation in population samples within the current analysis, which include differences in gender, age, ethnicity, socioeconomic status, and overall health of participants; between-study heterogeneity was expected, in which true effect sizes vary across studies. 
Since it was postulated that a distribution of effect sizes, rather than a single effect size, is being estimated, a random effects model was used. Tau squared $\left(\tau^{2}\right)$ was calculated to determine the estimate of between-study variance in addition to the withinstudies variance:

$$
\tau^{2}=Q-(k-1) /\left[\sum w_{1}-\left(\Sigma w_{1}^{2} / \Sigma w_{1}\right)\right]
$$

While this computation provides an approximation of between-study variance, it is generally considered to be an acceptable method for analysis (Lipsey \& Wilson, 2001). A new set of weights that are a function of sampling error were created by adding $\tau^{2}$ to the effect size variance in the denominator of the fixed effects weight computation. Using this procedure, meta-analytic results account for both within and between study variability.

\section{Effect Size Analysis}

Overall effect sizes for cardiovascular reactivity and recovery (change scores from baseline for HR, DBP, SBP, and HRV) to the different subtypes of rumination were assessed for statistical significance. The overall reactivity and recovery effect sizes for angry rumination, sadness rumination, and rumination on positive events was compared using an analysis of variance for each of the cardiovascular variables. Comparisons of reactivity and recovery effect sizes for $\mathrm{HR}, \mathrm{SBP}$, and $\mathrm{DBP}$ in response to rumination vs. distraction conditions were also compared using this method.

\section{Moderator Analysis}

A regression model was used to determine if the continuous moderator variables (percentage of female and minority participants) explain a significant amount of variance in each analysis. Categorical moderator variables (e.g., type of rumination induction) 
were examined using an analysis of group comparisons, which analogous to an analysis of variance (ANOVA).

\section{Publication Bias}

Publication bias refers to the tendency for statistically significant findings or large effect sizes to be published leading to selection bias that can inflate results. Despite attempts in the current analysis to obtain unpublished literature, it is important to assess if bias might exist and if so to what extent. A funnel plot was used to detect the presence of publication bias in each analysis by graphically displaying the symmetry of included studies (illustrating the relationship between effect size and sample size). Larger studies, depicted on top, are expected to have less sampling error and hence, greater accuracy and less asymmetry. The resulting image is an inverted funnel, with smaller studies that have a wider array of effect sizes on the bottom. A trim and fill procedure (Taylor \& Tweedie, 2000) was used to remove the most extreme smallest studies until symmetry was attained, and then replace these studies along with their mirror images. A corrected effect size was

then calculated based on the symmetrical funnel that includes estimated results of missing studies. Since this procedure could be thrown off by one or two atypical studies, it is important to have enough studies to compensate for this effect. 


\section{RESULTS}

\section{Literature Search and Study Characteristics}

The literature search revealed 2,170 studies for consideration after deletion of duplicates. Figure 1 outlines the screening process. Forward citation searches (a total of 865 citations), emails to key authors, and reference harvesting from key review articles did not yield additional studies for inclusion. A total of 48 studies (average sample size $=$ 76) were included in the analyses; six of which are unpublished studies. Forty-four were recall study designs (i.e., participants prompted to ruminate about a prior personal emotional event), which were used to calculate cardiovascular reactivity and recovery effect sizes for sadness, angry, and positive rumination. Four studies included HRV as an outcome variable. Ten studies included distraction vs. rumination components in which participants underwent an angering condition and then assigned to a rumination and/or distraction condition. These latter studies were used to calculate cardiovascular reactivity effect sizes for the difference in angry rumination and distraction conditions. Studies consisted of 3,647 participants (age range $18-96$ years). Thirty-one percent of participants were reported as ethnic or racial minority and 53 percent were reported as female. Table 1 displays the included recall studies (in which participants are prompted to recall an emotional event) and Table 2 displays the included rumination vs. distraction studies (in which participants are randomly assigned to a rumination or distraction 
condition following an angering task).

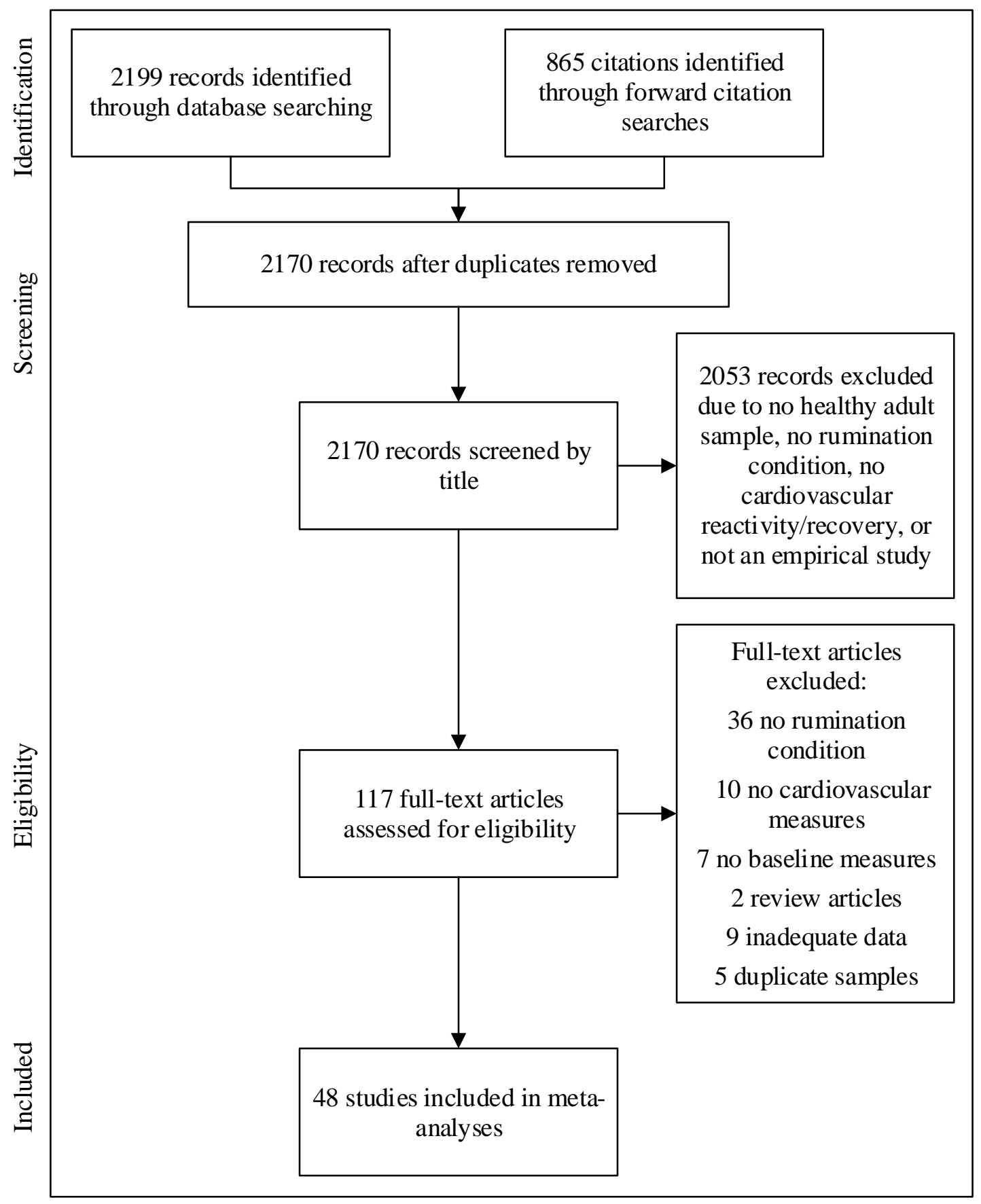

Figure 1. Diagram of literature search identifying studies qualifying for inclusion in analyses. 
Table 1

Studies for which Participants are Prompted to Ruminate/Recall a Prior Emotional Event

\begin{tabular}{|c|c|c|c|c|c|c|c|c|c|c|c|c|}
\hline Study & $\mathbf{N}$ & Age & Pub & $\begin{array}{l}\text { RUM } \\
\text { Type }\end{array}$ & $\begin{array}{l}\text { RUM } \\
\text { Time }\end{array}$ & $\begin{array}{l}\text { REC } \\
\text { Time }\end{array}$ & Exclusion Criteria & $\begin{array}{l}\text { Outcome } \\
\text { Variables }\end{array}$ & $\begin{array}{l}\text { REA } \\
\text { or } \\
\text { REC }\end{array}$ & $\begin{array}{c}\text { Task } \\
\text { Preceding } \\
\text { Recall } \\
\end{array}$ & $\begin{array}{l}\text { Anxiety- } \\
\text { Provoking } \\
\text { Procedure } \\
\end{array}$ & $\begin{array}{c}\text { Recall } \\
\text { Emotion }\end{array}$ \\
\hline $\begin{array}{l}\text { Ayduk \& } \\
\text { Kross (2008) }\end{array}$ & 90 & $\begin{array}{l}20.71 \\
(4.24)\end{array}$ & Yes & 1 & $1+$ & 22 & None reported & $\begin{array}{l}\text { DBP } \\
\text { SBP }\end{array}$ & $\begin{array}{l}\text { REA } \\
\text { REC }\end{array}$ & No & No & A \\
\hline $\begin{array}{l}\text { Beckham et } \\
\text { al. (2002) }\end{array}$ & 53 & $\begin{array}{l}50.3 \\
(5.17)\end{array}$ & Yes & 1 & 1.5 & $2-3$ & $\begin{array}{l}\text { PTSD or psychotic disorder; } \\
\text { alcohol or substance abuse }\end{array}$ & $\begin{array}{l}\text { HR } \\
\text { DBP } \\
\text { SBP }\end{array}$ & $\begin{array}{l}\text { REA } \\
\text { REC }\end{array}$ & No & No & $A$ \\
\hline $\begin{array}{l}\text { Benight et al. } \\
\text { (1997) }\end{array}$ & 9 & $\begin{array}{c}64 \\
(18.17)\end{array}$ & Yes & v & 6 & 5 & $\begin{array}{l}<5 \% \text { probability of } \mathrm{CHD} \text { via the } \\
\text { Coronary Risk Handbook } \\
\text { criteria }\end{array}$ & $\begin{array}{l}\text { HR } \\
\text { DBP } \\
\text { SBP }\end{array}$ & REA & $\begin{array}{l}\text { (C) } \\
\text { Desperation } \\
\text { Recall }\end{array}$ & $\begin{array}{l}\text { Blood } \\
\text { Draw }\end{array}$ & A \\
\hline Brown (1999) & 80 & NG & No & V & 3 & None & $\begin{array}{l}\text { Smoked in past year, alcohol } \\
\text { consumption > } 21 \\
\text { ounces/week, medications or } \\
\text { medical conditions that would } \\
\text { influence CV reactivity }\end{array}$ & $\begin{array}{l}\text { HR } \\
\text { DBP } \\
\text { SBP }\end{array}$ & REA & $\begin{array}{l}(F) \\
\text { Speech } \\
\text { Task }\end{array}$ & No & A \\
\hline $\begin{array}{l}\text { Brummett et } \\
\text { al. (2009) }\end{array}$ & 328 & $\begin{array}{l}31.41 \\
(8.8)\end{array}$ & Yes & v & 5 & 5 & $\begin{array}{l}\text { Major medical condition } \\
\text { (cancer, heart disease, arthritis, } \\
\text { diabetes) or psychiatric } \\
\text { disorder; pregnancy }\end{array}$ & $\begin{array}{l}\text { HR } \\
\text { DBP } \\
\text { SBP }\end{array}$ & $\begin{array}{l}\text { REA } \\
\text { REC }\end{array}$ & $\begin{array}{c}(\mathrm{F}) \\
\text { Anger } \\
\text { Recall before } \\
\text { Sadness } \\
\text { Recall }\end{array}$ & $\begin{array}{l}\text { Blood } \\
\text { Draw }\end{array}$ & $A, S$ \\
\hline Burns (2006) & 79 & $\begin{array}{l}27.2 \\
(4.2)\end{array}$ & Yes & v & 5 & 5 & $\begin{array}{l}\text { CVD, medications affecting CV } \\
\text { function, chronic pain from } \\
\text { malignant conditions, } \\
\text { alcohol/substance abuse, hx of } \\
\text { bipolar disorders, daily use of } \\
\text { narcotic analgesic medication, } \\
\text { limited English proficiency }\end{array}$ & $\begin{array}{l}\text { HR } \\
\text { DBP } \\
\text { SBP }\end{array}$ & $\begin{array}{l}\text { REA } \\
\text { REC }\end{array}$ & $\begin{array}{l}\text { (C) } \\
\text { Sadness } \\
\text { and Anger } \\
\text { Recall }\end{array}$ & No & A, S \\
\hline $\begin{array}{l}\text { Burns et al. } \\
\text { (2003) }\end{array}$ & 21 & $\begin{array}{l}25.1 \\
(3.4)\end{array}$ & Yes & v & 5 & 10 & $\begin{array}{l}\text { Hx of urticaria, CV disorder, } \\
\text { medications that affect } \mathrm{CV} \\
\text { function, pregnancy, } \mathrm{hx} \text { of } \\
\text { chronic pain, limited English } \\
\text { proficiency }\end{array}$ & $\begin{array}{l}\text { HR } \\
\text { DBP } \\
\text { SBP }\end{array}$ & REA & No & $\begin{array}{c}\text { Pain } \\
\text { Condition }\end{array}$ & $A, S, P$ \\
\hline $\begin{array}{l}\text { Carels et al. } \\
\text { (1998) }\end{array}$ & 50 & $\begin{array}{l}33.94 \\
(5.98)\end{array}$ & Yes & v & 5 & 10 & $\begin{array}{l}\text { High or low } \mathrm{BP} \text { (must be } \\
\text { normotensive) }\end{array}$ & $\begin{array}{l}\text { HR } \\
\text { DBP } \\
\text { SBP }\end{array}$ & REA & $\begin{array}{c}\text { (C) } \\
\text { Serial } \\
\text { Subtraction } \\
\text { Task }\end{array}$ & No & $A$ \\
\hline Cohen (2010) & 100 & $\begin{array}{c}22 \\
(3.1)\end{array}$ & No & v & 4 & 14 & $\begin{array}{l}\text { Medical condition that could } \\
\text { interfere with CV functioning or } \\
\text { that requires continuous } \\
\text { medical attention; pregnancy }\end{array}$ & $\begin{array}{l}\text { HR } \\
\text { DBP } \\
\text { SBP }\end{array}$ & $\begin{array}{l}\text { REA } \\
\text { REC } \\
\text { (D) }\end{array}$ & No & No & A \\
\hline
\end{tabular}




\begin{tabular}{|c|c|c|c|c|c|c|c|c|c|c|c|c|}
\hline Study & $\mathbf{N}$ & Age & Pub & $\begin{array}{l}\text { RUM } \\
\text { Type }\end{array}$ & $\begin{array}{l}\text { RUM } \\
\text { Time }\end{array}$ & $\begin{array}{l}\text { REC } \\
\text { Time }\end{array}$ & Exclusion Criteria & $\begin{array}{l}\text { Outcome } \\
\text { Variables }\end{array}$ & $\begin{array}{l}\text { REA } \\
\text { or } \\
\text { REC }\end{array}$ & $\begin{array}{c}\text { Task } \\
\text { Preceding } \\
\text { Recall } \\
\end{array}$ & $\begin{array}{l}\text { Anxiety- } \\
\text { Provoking } \\
\text { Procedure }\end{array}$ & $\begin{array}{c}\text { Recall } \\
\text { Emotion }\end{array}$ \\
\hline $\begin{array}{l}\text { Cooper et al. } \\
(2014)\end{array}$ & 81 & $\begin{array}{l}19.81 \\
(2.10)\end{array}$ & Yes & $v$ & 4 & 5 & $\begin{array}{l}\text { Hypertension, obesity, hx of } \\
\text { CVD, diabetes, chronic medical } \\
\text { or psychological illness, } \\
\text { smoking, pregnancy, } \\
\text { cardioactive medications, or > } \\
14 \text { alcoholic drinks per week }\end{array}$ & $\begin{array}{l}\text { HR } \\
\text { DBP } \\
\text { SBP }\end{array}$ & $\begin{array}{l}\text { REA } \\
\text { REC }\end{array}$ & $\begin{array}{l}\text { (C) } \\
\text { Racial Recall } \\
\text { and Neutral } \\
\text { Speech } \\
\text { Task }\end{array}$ & No & A \\
\hline $\begin{array}{l}\text { Ditto et al. } \\
\text { (1987) }\end{array}$ & 42 & $18-96$ & Yes & 1 & 2 & 4 & $\begin{array}{l}\text { CVD or medications that can } \\
\text { affect CV function }\end{array}$ & $\begin{array}{l}\text { HR } \\
\text { DBP } \\
\text { SBP }\end{array}$ & REA & $\begin{array}{c}\text { (F) } \\
\text { Serial } \\
\text { Subtraction } \\
\text { Task and } \\
\text { Anxiety Recall }\end{array}$ & No & A \\
\hline $\begin{array}{l}\text { Foster et al. } \\
\text { (1997) }\end{array}$ & 16 & 22 & Yes & I & 2 & None & None Reported & $\mathrm{HR}$ & REA & $\begin{array}{c}\text { (C) } \\
\text { Fear, Anger, } \\
\text { Joy, Sadness, } \\
\text { and } \\
\text { Embarrassment } \\
\text { Recall }\end{array}$ & No & $A, S, P$ \\
\hline $\begin{array}{l}\text { Foster et al. } \\
\text { (1998) }\end{array}$ & 12 & 19.2 & Yes & I & $>1$ & None & None reported & $\mathrm{HR}$ & REA & No & No & A \\
\hline $\begin{array}{l}\text { Fredrickson } \\
\text { et al. (2000) }\end{array}$ & 66 & $\begin{array}{c}62 \\
(11.22)\end{array}$ & Yes & 1 & $<3$ & $1+$ & Use of medication for high BP & $\begin{array}{l}\text { HR } \\
\text { DBP } \\
\text { SBP }\end{array}$ & REA & No & No & A \\
\hline $\begin{array}{l}\text { Friedberg et } \\
\text { al. (2007) }\end{array}$ & 99 & $22-65$ & Yes & v & 4 & 20 & $\begin{array}{l}\text { Hx of hypertension or CVD, or } \\
\text { use of medicine that affects CV } \\
\text { health }\end{array}$ & $\begin{array}{l}\text { HR } \\
\text { DBP } \\
\text { SBP }\end{array}$ & REA & $\begin{array}{c}\text { (C) } \\
\text { Serial } \\
\text { Subtraction } \\
\text { Task }\end{array}$ & No & A \\
\hline $\begin{array}{l}\text { Gerin et al. } \\
\text { (2006) }\end{array}$ & 60 & $24-51$ & Yes & v & 5 & 12 & $\mathrm{Hx}$ of hypertension or $\mathrm{CHD}$ & $\begin{array}{l}\text { HR } \\
\text { DBP } \\
\text { SBP }\end{array}$ & $\begin{array}{l}\text { REA } \\
\text { REC } \\
\text { (D) }\end{array}$ & No & No & A \\
\hline $\begin{array}{l}\text { Glynn et al. } \\
\text { (2002) }\end{array}$ & 18 & $\begin{array}{l}20.3 \\
(3.7)\end{array}$ & Yes & v & 3 & 5 & $\begin{array}{l}\text { Poor health or medications that } \\
\text { might affect CV measurements }\end{array}$ & $\begin{array}{l}\text { HR } \\
\text { DBP } \\
\text { SBP }\end{array}$ & $\begin{array}{l}\text { REA } \\
\text { (D) }\end{array}$ & No & No & A \\
\hline $\begin{array}{l}\text { Greeson et al. } \\
\text { (2009) }\end{array}$ & 173 & $\begin{array}{l}26.7 \\
(7.7)\end{array}$ & Yes & V & 5 & 1 & $\begin{array}{l}\text { Smoking; hx of or current } \\
\text { chronic medical conditions that } \\
\text { influence inflammatory } \\
\text { biomarkers, psychiatric } \\
\text { conditions, and oral } \\
\text { contraceptive use }\end{array}$ & $\begin{array}{l}\text { HR } \\
\text { DBP } \\
\text { SBP }\end{array}$ & REC & $\begin{array}{c}\text { (F) } \\
\text { Neutral } \\
\text { Reading } \\
\text { Task }\end{array}$ & $\begin{array}{l}\text { Blood } \\
\text { Draw }\end{array}$ & A \\
\hline $\begin{array}{l}\text { Henninger } \\
\text { (2001) }\end{array}$ & 108 & NG & No & V & 5 & 5 & $\begin{array}{l}\text { High resting BP (> 140/90 mm } \\
\text { Hg), use of prescription } \\
\text { medications other than oral } \\
\text { contraceptives }\end{array}$ & $\begin{array}{l}\text { HR } \\
\text { DBP } \\
\text { SBP }\end{array}$ & REA & $\begin{array}{l}\text { (C) } \\
\text { Pain } \\
\text { Condition/ } \\
\text { Forearm } \\
\text { Ischemia } \\
\text { Procedure }\end{array}$ & $\begin{array}{c}\text { Pain } \\
\text { Condition }\end{array}$ & A \\
\hline
\end{tabular}




\begin{tabular}{|c|c|c|c|c|c|c|c|c|c|c|c|c|}
\hline Study & N & Age & Pub & $\begin{array}{l}\text { RUM } \\
\text { Type }\end{array}$ & $\begin{array}{l}\text { RUM } \\
\text { Time }\end{array}$ & $\begin{array}{c}\text { REC } \\
\text { Time }\end{array}$ & Exclusion Criteria & $\begin{array}{l}\text { Outcome } \\
\text { Variables }\end{array}$ & $\begin{array}{l}\text { REA } \\
\text { or } \\
\text { REC }\end{array}$ & $\begin{array}{c}\text { Task } \\
\text { Preceding } \\
\text { Recall } \\
\end{array}$ & $\begin{array}{l}\text { Anxiety- } \\
\text { Provoking } \\
\text { Procedure } \\
\end{array}$ & $\begin{array}{l}\text { Recall } \\
\text { Emotion }\end{array}$ \\
\hline $\begin{array}{l}\text { Ironson et al. } \\
\text { (1992) }\end{array}$ & 9 & NG & Yes & $\mathrm{V}$ & 6 & 15 & $\begin{array}{l}\text { Chest pain or } \mathrm{hx} \text { of } \mathrm{CHD},>5 \% \\
\text { chance of } \mathrm{CHD} \text { based on } \\
\text { treadmill test }\end{array}$ & $\begin{array}{l}\text { HR } \\
\text { DBP } \\
\text { SBP }\end{array}$ & REA & $\begin{array}{c}\text { (C) } \\
\text { Arithmetic } \\
\text { Task and } \\
\text { Speech Task }\end{array}$ & No & A \\
\hline $\begin{array}{l}\text { Jonassaint et } \\
\text { al. (2009) }\end{array}$ & 109 & $\begin{array}{l}27.31 \\
(6.17)\end{array}$ & Yes & $\mathrm{V}$ & 6 & None & $\begin{array}{l}\text { Hx of heart problems or } \\
\text { hypertension }\end{array}$ & $\begin{array}{l}\text { HR } \\
\text { DBP } \\
\text { SBP }\end{array}$ & REA & $\begin{array}{l}\text { (C) } \\
\text { Arithmetic } \\
\text { Task }\end{array}$ & No & A \\
\hline $\begin{array}{l}\text { Kario et al. } \\
(2002)\end{array}$ & 87 & $\begin{array}{c}40 \\
(7.5)\end{array}$ & Yes & v & 6 & 15 & $\begin{array}{l}<30 \text { or }>60 \text { years old; BP }> \\
160 / 105 \mathrm{mmHg} \text {; clinically overt } \\
\text { CVD; renal disease; diabetes; } \\
\text { use of antihypertensive } \\
\text { medication }\end{array}$ & $\begin{array}{l}\mathrm{HR} \\
\text { SBP }\end{array}$ & $\begin{array}{l}\text { REA } \\
\text { REC }\end{array}$ & $\begin{array}{l}\text { (F) } \\
\text { Mental } \\
\text { Arithmetic } \\
\text { Task }\end{array}$ & No & A \\
\hline $\begin{array}{l}\text { Lawler et al. } \\
\text { (1995) }\end{array}$ & 119 & NG & Yes & v & 4 & 5 & $\begin{array}{l}\text { Medications that could affect } \\
\text { CV response }\end{array}$ & $\begin{array}{l}\text { HR } \\
\text { DBP } \\
\text { SBP }\end{array}$ & REA & $\begin{array}{c}\text { (F) } \\
\text { Math } \\
\text { Task and } \\
\text { Videogame }\end{array}$ & No & A \\
\hline $\begin{array}{l}\text { Leon et al. } \\
\text { (2007) }\end{array}$ & 58 & $\begin{array}{l}21.3 \\
(2.1)\end{array}$ & Yes & v & 5 & 8 & $\begin{array}{l}\mathrm{Hx} \text { of } \mathrm{CHD} \text {, hypertension, or } \\
\text { diabetes; or use of medications } \\
\text { with } \mathrm{CV} \text { effects }\end{array}$ & $\begin{array}{l}\text { HR } \\
\text { DBP } \\
\text { SBP }\end{array}$ & $\begin{array}{l}\text { REA } \\
\text { REC }\end{array}$ & No & $\begin{array}{l}\text { Recall } \\
\text { Recorded } \\
\text { and } \\
\text { Evaluated }\end{array}$ & A \\
\hline $\begin{array}{l}\text { Lineberger, } \\
\text { M.D. (2005) }\end{array}$ & 49 & $\begin{array}{l}22.29 \\
(6.85)\end{array}$ & No & 1 & $1+$ & 5 & None stated & $\begin{array}{l}\text { HR } \\
\text { DBP } \\
\text { SBP }\end{array}$ & REA & No & No & A \\
\hline $\begin{array}{l}\text { Marci et al. } \\
(2007)\end{array}$ & 10 & $\begin{array}{c}33.9 \\
(11.9)\end{array}$ & Yes & 1 & 2 & 10 & $\begin{array}{l}\text { Neurological or medical } \\
\text { condition or AXIS I disorder }\end{array}$ & HRV & REA & No & No & $A, S, J$ \\
\hline $\begin{array}{l}\text { McLain } \\
(2010)\end{array}$ & 80 & $18-30$ & No & v & 4 & 10 & $\begin{array}{l}\text { Hx of CVD, diabetes, or } \\
\text { psychiatric } \mathrm{d} / \mathrm{o}^{\prime} \text { s.; smoking, BMI } \\
>30 \mathrm{~kg} / \mathrm{m}^{2} \text {, use of prescribed } \\
\text { medications }\end{array}$ & $\begin{array}{l}\text { HR } \\
\text { DBP } \\
\text { SBP }\end{array}$ & $\begin{array}{l}\text { REA } \\
\text { REC } \\
\text { (D) }\end{array}$ & No & No & A \\
\hline $\begin{array}{l}\text { Neumann et } \\
\text { al. (2004) }\end{array}$ & 80 & $18-30$ & Yes & v & 3 & 10 & $\begin{array}{l}\text { Smoking; hx of CVD, psychiatric } \\
\text { disorder, or use of medications } \\
\text { affecting CV function (including } \\
\text { oral contraceptives) }\end{array}$ & $\begin{array}{l}\text { HR } \\
\text { DBP } \\
\text { SBP } \\
\text { HRV }\end{array}$ & $\begin{array}{l}\text { REA } \\
\text { REC } \\
\text { (D) }\end{array}$ & No & No & A \\
\hline $\begin{array}{l}\text { Neumann \& } \\
\text { Waldstein } \\
\text { (2001) }\end{array}$ & 42 & $\begin{array}{l}19.25 \\
(2.5)\end{array}$ & Yes & v & 3 & 10 & $\begin{array}{l}\text { Hx of CVD, psychiatric } \mathrm{d} / \mathrm{o}^{\prime} \mathrm{s} \text { or } \\
\text { use of medications (including } \\
\text { oral contraceptives) affecting } \\
\text { CV function }\end{array}$ & $\begin{array}{l}\text { HR } \\
\text { DBP } \\
\text { SBP }\end{array}$ & REA & $\begin{array}{c}\text { (C) } \\
\text { Anger Recall, } \\
\text { Sadness Recall, } \\
\text { Happy Recall, } \\
\text { and Relaxation }\end{array}$ & No & $A, S, P$ \\
\hline
\end{tabular}




\begin{tabular}{|c|c|c|c|c|c|c|c|c|c|c|c|c|}
\hline Study & $\mathbf{N}$ & Age & Pub & $\begin{array}{l}\text { RUM } \\
\text { Type }\end{array}$ & $\begin{array}{l}\text { RUM } \\
\text { Time }\end{array}$ & $\begin{array}{l}\text { REC } \\
\text { Time }\end{array}$ & Exclusion Criteria & $\begin{array}{l}\text { Outcome } \\
\text { Variables }\end{array}$ & $\begin{array}{c}\text { REA } \\
\text { or } \\
\text { REC }\end{array}$ & $\begin{array}{c}\text { Task } \\
\text { Preceding } \\
\text { Recall } \\
\end{array}$ & $\begin{array}{c}\text { Anxiety- } \\
\text { Provoking } \\
\text { Procedure }\end{array}$ & $\begin{array}{l}\text { Recall } \\
\text { Emotion }\end{array}$ \\
\hline $\begin{array}{l}\text { Ottaviani \& } \\
\text { Shapiro } \\
\text { (2011) }\end{array}$ & 60 & $\begin{array}{l}33.4 \\
(9.5)\end{array}$ & Yes & v & 5 & 10 & $\begin{array}{l}\text { Psychiatric d/o's, significant } \\
\text { health problems, medications } \\
\text { that could affect CV function or } \\
\text { catecholamines, obesity, } \\
\text { hypertension, menopause, use } \\
\text { of oral contraceptives, } \\
\text { pregnancy or recent childbirth }\end{array}$ & HRV & $\begin{array}{l}\text { REA } \\
\text { REC }\end{array}$ & $\begin{array}{c}\mathrm{F} \\
\text { Neutral } \\
\text { Reading } \\
\text { Task }\end{array}$ & No & A \\
\hline $\begin{array}{l}\text { Ottaviani et } \\
\text { al. (2009) }\end{array}$ & 45 & $\begin{array}{c}34 \\
(7.5)\end{array}$ & Yes & 1 & 2.5 & 10 & $\begin{array}{l}\text { Psychiatric } \mathrm{d} / \mathrm{o}^{\prime} \mathrm{s} \text {, significant } \\
\text { health problems, medications } \\
\text { that could affect CV function, } \\
\text { obesity, hypertension, } \\
\text { menopause, use of oral } \\
\text { contraceptives, pregnancy or } \\
\text { recent childbirth }\end{array}$ & HRV & $\begin{array}{l}\text { REA } \\
\text { REC }\end{array}$ & $\begin{array}{c}\text { C } \\
\text { Handgrip } \\
\text { Math } \\
\text { \& Mirror } \\
\text { Tracing Tasks }\end{array}$ & $\begin{array}{l}\text { Blood } \\
\text { Draw }\end{array}$ & A \\
\hline $\begin{array}{l}\text { Ratnasingam } \\
\text { \& Bishop } \\
\text { (2007) }\end{array}$ & 80 & $19-24$ & Yes & v & 6 & None & Hx of CVD or hypertension & $\begin{array}{l}\text { HR } \\
\text { DBP } \\
\text { SBP }\end{array}$ & REA & $\begin{array}{l}\text { (F) } \\
\text { Neutral } \\
\text { Writing } \\
\text { Task }\end{array}$ & No & A \\
\hline $\begin{array}{l}\text { Richman et } \\
\text { al. (2007) }\end{array}$ & 165 & $\begin{array}{l}33.89 \\
(8.54)\end{array}$ & Yes & v & 5 & 5 & $\begin{array}{l}\text { Diabetes, hypertension, or } \\
\text { prescribed medication for any } \\
\text { other major illness; psychiatric } \\
\text { disorders }\end{array}$ & $\begin{array}{l}\text { HR } \\
\text { DBP } \\
\text { SBP }\end{array}$ & $\begin{array}{l}\text { REA } \\
\text { REC }\end{array}$ & $\begin{array}{l}\text { (F) } \\
\text { Neutral } \\
\text { Reading } \\
\text { Task }\end{array}$ & No & A \\
\hline Ruiz (2003) & 120 & $\begin{array}{l}20.4 \\
(3.4)\end{array}$ & No & v & 3 & 5 & None stated & $\begin{array}{l}\text { HR } \\
\text { DBP } \\
\text { SBP }\end{array}$ & REA & No & $\begin{array}{l}\text { Recall } \\
\text { Recorded } \\
\text { and } \\
\text { Evaluated }\end{array}$ & A \\
\hline $\begin{array}{l}\text { Rutledge et } \\
\text { al. (2001) }\end{array}$ & 126 & $(27.1)$ & Yes & v & 5 & 5 & Dx of CHD or hypertension & $\begin{array}{l}\text { HR } \\
\text { DBP } \\
\text { SBP }\end{array}$ & REA & $\begin{array}{c}\text { (C) } \\
\text { Mental } \\
\text { Arithmetic } \\
\text { Task and } \\
\text { Physical } \\
\text { Hand Grip } \\
\text { Task }\end{array}$ & No & A \\
\hline $\begin{array}{l}\text { Sinha et al. } \\
\text { (1992) }\end{array}$ & 27 & $21-35$ & Yes & 1 & $1+$ & $<1$ & $\begin{array}{l}\text { Hx or current alcohol/drug } \\
\text { abuse/dependence, } \mathrm{CV} \\
\text { abnormalities, hormonal and } \\
\text { endocrine problems, } \\
\text { neurological disease or trauma, } \\
\text { other medical or psychiatric } \\
\text { problems; current prescription } \\
\text { medications }\end{array}$ & $\begin{array}{l}\text { HR } \\
\text { DBP } \\
\text { SBP }\end{array}$ & REA & $\begin{array}{l}\text { (C) } \\
\text { Fear, Anger, } \\
\text { Joy, Sadness, } \\
\text { and Neutral } \\
\text { Imagery }\end{array}$ & No & $A, S, P$ \\
\hline
\end{tabular}




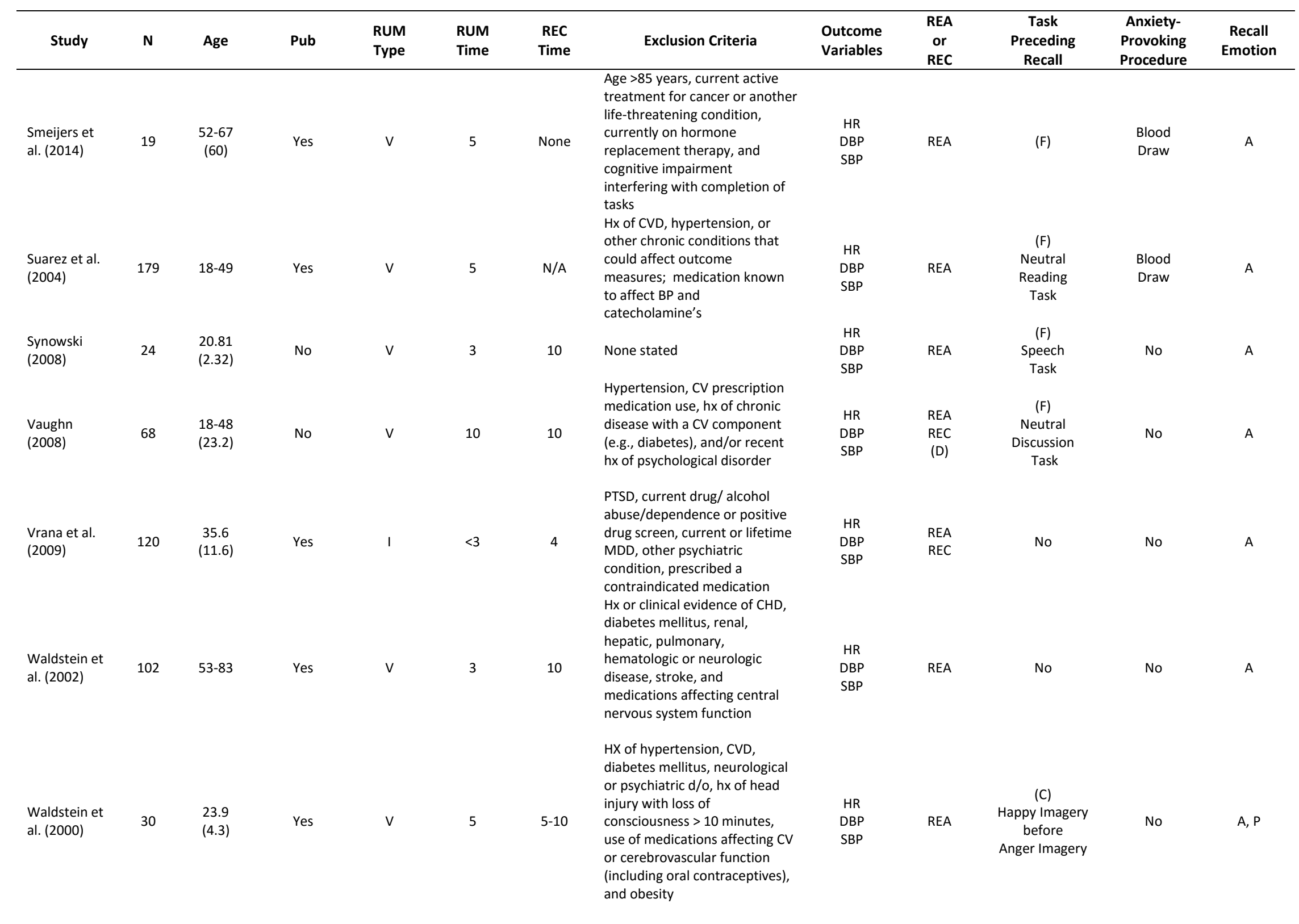




\begin{tabular}{|c|c|c|c|c|c|c|c|c|c|c|c|c|}
\hline Study & $\mathbf{N}$ & Age & Pub & $\begin{array}{l}\text { RUM } \\
\text { Type }\end{array}$ & $\begin{array}{l}\text { RUM } \\
\text { Time }\end{array}$ & $\begin{array}{l}\text { REC } \\
\text { Time }\end{array}$ & Exclusion Criteria & $\begin{array}{l}\text { Outcome } \\
\text { Variables }\end{array}$ & $\begin{array}{l}\text { REA } \\
\text { or } \\
\text { REC }\end{array}$ & $\begin{array}{c}\text { Task } \\
\text { Preceding } \\
\text { Recall }\end{array}$ & $\begin{array}{l}\text { Anxiety- } \\
\text { Provoking } \\
\text { Procedure }\end{array}$ & $\begin{array}{l}\text { Recall } \\
\text { Emotion }\end{array}$ \\
\hline $\begin{array}{l}\text { Why et al. } \\
(2003)\end{array}$ & 114 & $\begin{array}{l}27.3 \\
(6.1)\end{array}$ & Yes & v & 6 & None & $\begin{array}{l}\text { Heart problems, hypertension, } \\
\text { or having undergone any type } \\
\text { of heart surgery }\end{array}$ & $\begin{array}{l}\text { HR } \\
\text { DBP } \\
\text { SBP }\end{array}$ & REA & $\begin{array}{c}\text { (F) } \\
\text { Number } \\
\text { Recall } \\
\text { (C) } \\
\text { Mental } \\
\text { Arithmetic } \\
\text { Task }\end{array}$ & No & A \\
\hline $\begin{array}{l}\text { Why \& } \\
\text { Johnston } \\
\text { (2008) }\end{array}$ & 58 & $\begin{array}{l}21.26 \\
(3.04)\end{array}$ & Yes & v & 5 & 3 & $\begin{array}{l}\text { Medical conditions or taking } \\
\text { medications }\end{array}$ & $\begin{array}{l}\mathrm{HR} \\
\mathrm{DBP} \\
\mathrm{SBP}\end{array}$ & REA & $\begin{array}{c}\text { (C) } \\
\text { Computer } \\
\text { Task }\end{array}$ & No & A \\
\hline
\end{tabular}

Note: Age is represented as mean (standard deviation) or range; Times are provided in minutes; $\mathrm{CV}=$ Cardiovascular; $\mathrm{CVD}=\mathrm{Cardiovascular}$ Disease; NG = Not Given; Pub = Published Study; I = Imagery Recall; V = Verbal Recall; Dx = Diagnosis; Hx = History; HR= Heart Rate; DBP=Diastolic Blood Pressure; SBP= Systolic Blood Pressure; HRV = Heart Rate Variability; RUM = Rumination; REA = Reactivity; REC = Recovery; $\mathrm{BP}=$ Blood Pressure; D/O = Disorder; $\mathrm{MDD}=$ Major Depressive Disorder; $\mathrm{BMI}=$ Body Mass Index; $\mathrm{D}=$ Distraction condition included in study; $\mathrm{A}=$ Anger; $\mathrm{S}=$ Sadness; $\mathrm{P}=$ Positive Affect $\mathrm{C}=$ Counterbalanced; $\mathrm{F}=$ Fixed 
Table 2

Studies for which Participants are Assigned to a Rumination or Distraction Condition following an Angering Task

\begin{tabular}{|c|c|c|c|c|c|c|c|c|c|c|}
\hline Study & $\mathbf{N}$ & Age & Pub & $\begin{array}{l}\text { Rumination } \\
\text { Condition }\end{array}$ & $\begin{array}{l}\text { Baseline } \\
\text { Duration }\end{array}$ & $\begin{array}{l}\text { Rumination } \\
\text { Duration }\end{array}$ & $\begin{array}{l}\text { Distraction } \\
\text { Condition }\end{array}$ & Exclusion Criteria & $\begin{array}{l}\text { Outcome } \\
\text { Variables }\end{array}$ & Study Design \\
\hline $\begin{array}{l}\text { Cohen } \\
(2010)\end{array}$ & 100 & $18-30$ & No & $\begin{array}{l}\text { Absence of } \\
\text { Distraction }\end{array}$ & 10 & 4 & $\begin{array}{l}\text { Read a story and } \\
\text { answer } \\
\text { questions }\end{array}$ & $\begin{array}{l}\text { Any medical condition that could interfere with } \\
\text { CV functioning or that requires continuous } \\
\text { medical attention; pregnancy }\end{array}$ & $\begin{array}{l}\text { HR } \\
\text { DBP } \\
\text { SBP }\end{array}$ & B \\
\hline $\begin{array}{l}\text { Gerin et al. } \\
\text { (2006) }\end{array}$ & 60 & 24. -51 & Yes & $\begin{array}{l}\text { Absence of } \\
\text { Distraction }\end{array}$ & 10 & 5 & $\begin{array}{l}\text { Presence of } \\
\text { visually } \\
\text { interesting } \\
\text { screen, } \\
\text { magazines, and } \\
\text { toys }\end{array}$ & $\mathrm{Hx}$ of hypertension or $\mathrm{CHD}$ & $\begin{array}{l}\text { HR } \\
\text { DBP } \\
\text { SBP }\end{array}$ & W \\
\hline $\begin{array}{l}\text { Glynn et al. } \\
\text { (2002) }\end{array}$ & 20 & $\begin{array}{l}20.1 \\
(3.9)\end{array}$ & Yes & $\begin{array}{l}\text { Absence of } \\
\text { Distraction }\end{array}$ & 10 & 10 & $\begin{array}{l}\text { Lengthy } \\
\text { questionnaire }\end{array}$ & $\begin{array}{l}\text { Reports of poor health or medication that might } \\
\text { affect CV measurements }\end{array}$ & $\begin{array}{l}\text { HR } \\
\text { DBP } \\
\text { SBP }\end{array}$ & B \\
\hline $\begin{array}{l}\text { Larsen et al. } \\
\text { (2012) }\end{array}$ & 133 & $18-29$ & Yes & $\begin{array}{c}\text { Prompted } \\
\text { Recall Imagery }\end{array}$ & 5 & 2 & $\begin{array}{l}\text { Think about prior } \\
\text { weekend in a } \\
\text { non-emotional } \\
\text { way }\end{array}$ & None stated & $\begin{array}{l}\text { HR } \\
\text { DBP } \\
\text { SBP }\end{array}$ & B \\
\hline $\begin{array}{l}\text { McClelland } \\
\text { (2009) }\end{array}$ & 92 & $17-50$ & Yes & $\begin{array}{c}\text { Prompted } \\
\text { Recall Imagery }\end{array}$ & 5 & $>1$ & $\begin{array}{l}\text { Distraction task } \\
\text { (forehead } \\
\text { tracking and } \\
\text { visio-spacial) }\end{array}$ & $\begin{array}{l}\text { Hx of CVD or hypertension; baseline resting } \\
\text { hypertension levels at } 140 / 90 \text { or higher; BMI>30 }\end{array}$ & $\begin{array}{l}\text { HR } \\
\text { DBP } \\
\text { SBP }\end{array}$ & W \\
\hline $\begin{array}{l}\text { McLain } \\
(2010)\end{array}$ & 80 & $18-30$ & No & $\begin{array}{l}\text { Absence of } \\
\text { Distraction }\end{array}$ & 15 & 10 & $\begin{array}{l}\text { Read a neutral } \\
\quad \text { article }\end{array}$ & $\begin{array}{l}\text { HX of CVD, diabetes, or psychiatric disorders. } \\
\text { Prescribed medications (including oral } \\
\text { contraceptives) or over-the-counter medication } \\
\text { that may impact CV function within prior two } \\
\text { months }\end{array}$ & $\begin{array}{l}\text { HR } \\
\text { DBP } \\
\text { SBP }\end{array}$ & B \\
\hline $\begin{array}{l}\text { Neumann et } \\
\text { al. (2004) }\end{array}$ & 80 & $18-30$ & Yes & $\begin{array}{l}\text { Absence of } \\
\text { Distraction }\end{array}$ & 15 & 10 & $\begin{array}{l}\text { Read a neutral } \\
\text { article }\end{array}$ & $\begin{array}{l}\text { Smoking, hx of hypertension, CV or pulmonary } \\
\text { disease, psychiatric disorder, or use of } \\
\text { medications affecting cardiovascular function } \\
\text { (including oral contraceptives) }\end{array}$ & $\begin{array}{l}\text { HR } \\
\text { DBP } \\
\text { SBP }\end{array}$ & B \\
\hline
\end{tabular}




\begin{tabular}{|c|c|c|c|c|c|c|c|c|c|c|}
\hline Study & $\mathbf{N}$ & Age & Pub & $\begin{array}{l}\text { Rumination } \\
\text { Condition }\end{array}$ & $\begin{array}{l}\text { Baseline } \\
\text { Duration }\end{array}$ & $\begin{array}{l}\text { Rumination } \\
\text { Duration }\end{array}$ & $\begin{array}{l}\text { Distraction } \\
\text { Condition }\end{array}$ & Exclusion Criteria & $\begin{array}{l}\text { Outcome } \\
\text { Variables }\end{array}$ & Study Design \\
\hline $\begin{array}{l}\text { Ottaviani et } \\
\text { al. (2011) }\end{array}$ & 60 & $20-54$ & Yes & $\begin{array}{l}\text { Absence of } \\
\text { Distraction }\end{array}$ & 10 & 10 & $\begin{array}{c}\text { Overhear phone } \\
\text { ring/ } \\
\text { conversation }\end{array}$ & $\begin{array}{l}\text { Psychiatric disorders, diagnosis of hypertension } \\
\text { or CHD, hx of cancer, pulmonary problems, active } \\
\text { chronic infections, autoimmune diseases, } \\
\text { diabetes, endocrine disorders, } \\
\text { immunosuppression from a disease, use of drugs } \\
\text { or medications that might affect CV function } \\
\text { and/or catecholamines, obesity, menopause, } \\
\text { oral contraceptives, pregnancy or recent } \\
\text { childbirth }\end{array}$ & $\begin{array}{l}\text { HR } \\
\text { DBP } \\
\text { SBP }\end{array}$ & w \\
\hline $\begin{array}{l}\text { Radstaak et } \\
\text { al (2014) }\end{array}$ & 54 & $\begin{array}{l}21.1 \\
(3.1)\end{array}$ & Yes & $\begin{array}{l}\text { Absence of } \\
\text { Distraction }\end{array}$ & 5 & 5 & $\begin{array}{l}\text { Listen to audio } \\
\text { book }\end{array}$ & Hypertension & $\begin{array}{l}\text { HR } \\
\text { DBP } \\
\text { SBP }\end{array}$ & B \\
\hline $\begin{array}{l}\text { Vaughn } \\
\text { (2008) }\end{array}$ & 137 & $18-48$ & No & $\begin{array}{l}\text { Absence of } \\
\text { Distraction }\end{array}$ & 10 & 10 & $\begin{array}{l}\text { Non-evaluative } \\
\text { distraction task }\end{array}$ & $\begin{array}{l}\text { Hypertension, CV prescription medication use, hx } \\
\text { of chronic disease with a CV component (e.g., } \\
\text { diabetes), and/or recent history of psychological } \\
\text { d/o }\end{array}$ & $\begin{array}{l}\text { HR } \\
\text { DBP } \\
\text { SBP }\end{array}$ & B \\
\hline
\end{tabular}

Note: Age is represented as mean (standard deviation) or range; Times are provided in minutes; Pub = Published; HR= Heart Rate; DBP=Diastolic Blood Pressure; SBP= Systolic Blood Pressure; BMI= Body Mass Index; B = Between; W = Within 


\section{Sadness Rumination}

Sadness Rumination Reactivity and Recovery. Meta-analyses of cardiovascular reactivity to sadness rumination revealed statistically significant and large effects sizes for HR, DBP, and SBP (see Table 3) that were not moderated by any variables (see Table 4). Meta-regression to determine the variability in effect sizes accounted for by biological sex and race/ethnicity was not possible due to the small number of studies in these analyses. Only two studies examined cardiovascular recovery following a sadness rumination task, which revealed a small, yet significant effect size for SBP (see Table 3).

Table 3

Sadness Rumination Reactivity and Recovery Effect Sizes

\begin{tabular}{|c|c|c|c|}
\hline \multicolumn{4}{|c|}{ REACTIVITY } \\
\hline Variable & Effect Size & $\underline{\mathrm{CI}}$ & $Q$ Statistic \\
\hline HR & $.843 * *$ & $.580-1.105$ & $Q(6)=14.048^{*}$ \\
\hline DBP & $1.213^{* *}$ & $.924-1.502$ & $Q(5)=12.385^{*}$ \\
\hline SBP & $1.057 * *$ & $.816-1.299$ & $Q(5)=9.300$ \\
\hline \multicolumn{4}{|c|}{ RECOVERY } \\
\hline Variable & Effect Size & $\underline{\mathrm{CI}}$ & $Q$ Statistic \\
\hline HR & -.026 & -.116 to .114 & $Q(1)=.028^{*}$ \\
\hline DBP & -.110 & -.250 to .030 & $Q(1)=.703$ \\
\hline SBP & $.168 * *$ & .028 to .308 & $Q(1)=.003$ \\
\hline
\end{tabular}


Table 4

Sadness Rumination Reactivity Moderator Analyses

\begin{tabular}{llll}
\hline Variable & HR & DBP & SBP \\
\hline Published & N/A & N/A & N/A \\
Age over 60 & N/A & N/A & N/A \\
Recall Condition & $Q(1)=.345$ & $Q(1)=.369$ & $Q(1)=.206$ \\
Recall Time & $Q(1)=.345$ & $Q(1)=.369$ & $Q(1)=.206$ \\
Within vs Between & $Q(1)=3.68$ & $Q(1)=1.835$ & $Q(1)=.747$ \\
Stressful Condition & $Q(1)=.742$ & $Q(1)=.066$ & $Q(1)=5.297$
\end{tabular}

Note. ${ }^{*} p<.05 ; * * p<.01 ; * * * p<.001$

Sadness rumination reactivity effect sizes did not differ significantly between HR and DBP: $Q(1)=3.492, p=.062$; HR and SBP: $Q(1)=1.302, p=.254$; or DBP and SBP: $Q(1)=.769, p=.380$. Forest plots of weighted effect sizes for individual reactivity studies are shown in Figures 2, 3, and 4.

\begin{tabular}{|c|c|c|c|}
\hline \multicolumn{4}{|c|}{ HR Reactivity Sadness Rumination } \\
\hline Study name & $\begin{array}{l}\text { Std diff } \\
\text { in means }\end{array}$ & $\begin{array}{l}\text { Standard } \\
\text { error }\end{array}$ & $\begin{array}{l}\text { Std diff in means } \\
\text { and } 95 \% \mathrm{Cl}\end{array}$ \\
\hline Brummett et al. (2009) & 0.850 & 0.080 & 0 \\
\hline Burns (2006) & 0.940 & 0.170 & \\
\hline Burns et al. (2003) & 0.290 & 0.300 & - \\
\hline Foster et al. (1997) & 0.000 & 0.350 & - \\
\hline Neumann \& Waldstein a & 1.300 & 0.350 & م- \\
\hline Neumann \& Waldstein b & 1.320 & 0.330 & D- \\
\hline \multirow[t]{4}{*}{ Sinha et al. (1992) } & 1.100 & 0.290 & $p-$ \\
\hline & 0.843 & 0.134 & \\
\hline & & & $\begin{array}{lllll}-2.00 & -1.00 & 0.00 & 1.00 & 2.00\end{array}$ \\
\hline & & & Below Baseline Above Baseline \\
\hline
\end{tabular}

Figure 2. Forest plot of seven weighted effect sizes for HR reactivity during sadness rumination. 
Study name

Burns (2006)

Burns et al. (2003)

Neumann \& Waldstein (2001)

Neumann \& Waldstein (2001) b

Sinha et al. (1992)

$$
\begin{aligned}
& \text { Std diff Standard } \\
& \text { in means error }
\end{aligned}
$$

$\begin{array}{ll}0.870 & 0.080 \\ 1.300 & 0.180 \\ 1.670 & 0.350 \\ 1.400 & 0.350 \\ 1.480 & 0.340 \\ 1.050 & 0.290 \\ 1.213 & 0.147\end{array}$

Std diff in means and $95 \% \mathrm{Cl}$

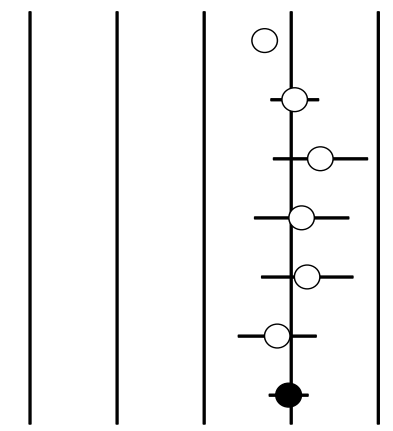

$-2.50-1.250 .001 .252 .50$

Below Baseline Above Baseline

\begin{tabular}{|c|c|c|c|}
\hline \multicolumn{4}{|c|}{ SBP Reactivity Sadness Rumination } \\
\hline \multicolumn{4}{|c|}{$\begin{array}{l}\text { Std diff Standard } \\
\text { in means error }\end{array}$} \\
\hline Brummett et al. (2009) & 0.810 & 0.080 & 0 \\
\hline Burns (2006) & 1.060 & 0.170 & -0 \\
\hline Burns et al. (2003) & 1.330 & 0.330 & \\
\hline Neumann \& Waldstein (2001) a & 1.180 & 0.340 & \\
\hline Neumann \& Waldstein (2001) b & 1.670 & 0.350 & $-\infty$ \\
\hline Sinha et al. (1992) & 0.950 & 0.290 & $-\mathrm{Ot}$ \\
\hline & 1.057 & 0.123 & \\
\hline \multicolumn{4}{|r|}{ 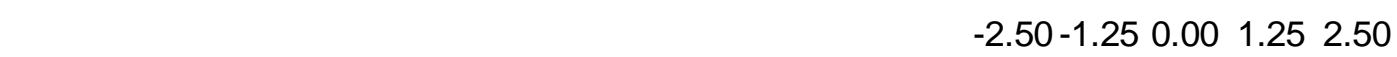 } \\
\hline & & & Below Baseline Above Baseline \\
\hline
\end{tabular}

Figure 3. Forest plot of six weighted effect sizes for DBP reactivity during sadness rumination.

Figure 4. Forest plot of six weighted effect sizes for SBP reactivity during sadness rumination. 
Sadness Rumination Publication Bias. Although the trim and fill procedure did not indicate the presence of publication bias for the analyses of sadness rumination reactivity, the limited number of studies is not ideal for this procedure. Funnel plots with the Duval and Tweedie trim and fill procedure are shown in Figures 5, 6, and 7.

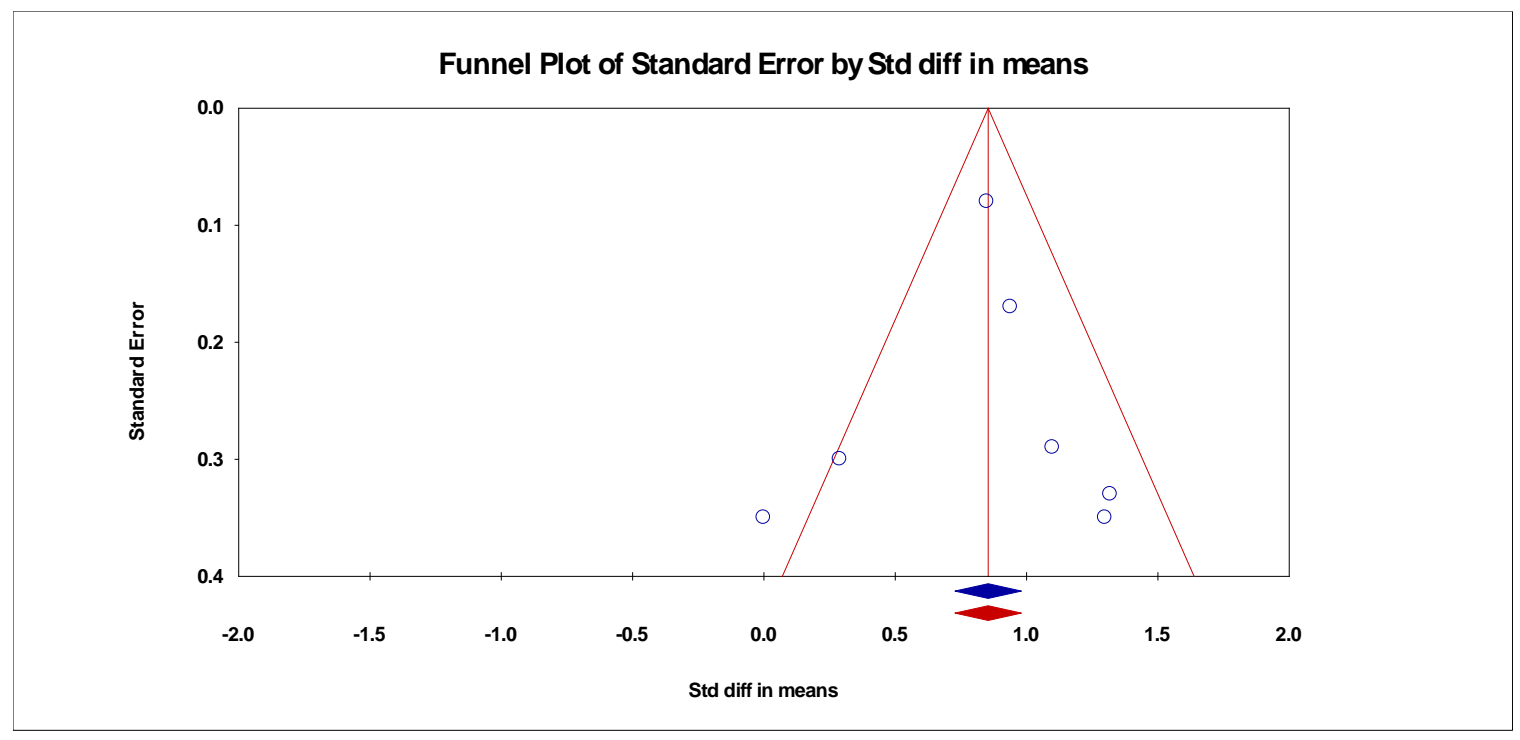

Figure 5. Funnel plot and Duval and Tweedie's trim and fill for HR sadness rumination reactivity. No studies were trimmed.

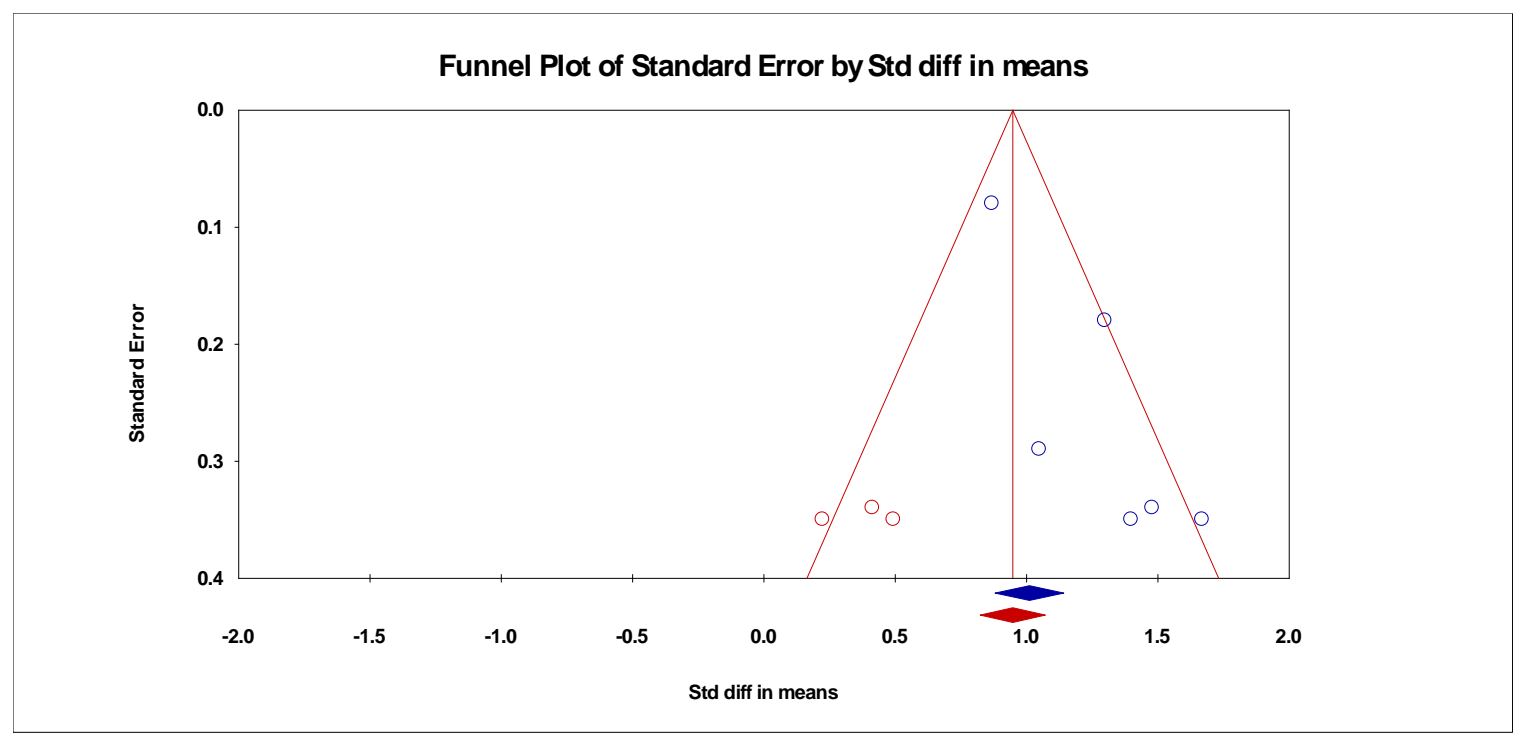

Figure 6. Funnel plot and Duval and Tweedie's trim and fill for DBP sadness rumination reactivity. Three studies were trimmed with an adjusted effect size of $d=.982$ (95\% CI: .856 to $1.109)$. 


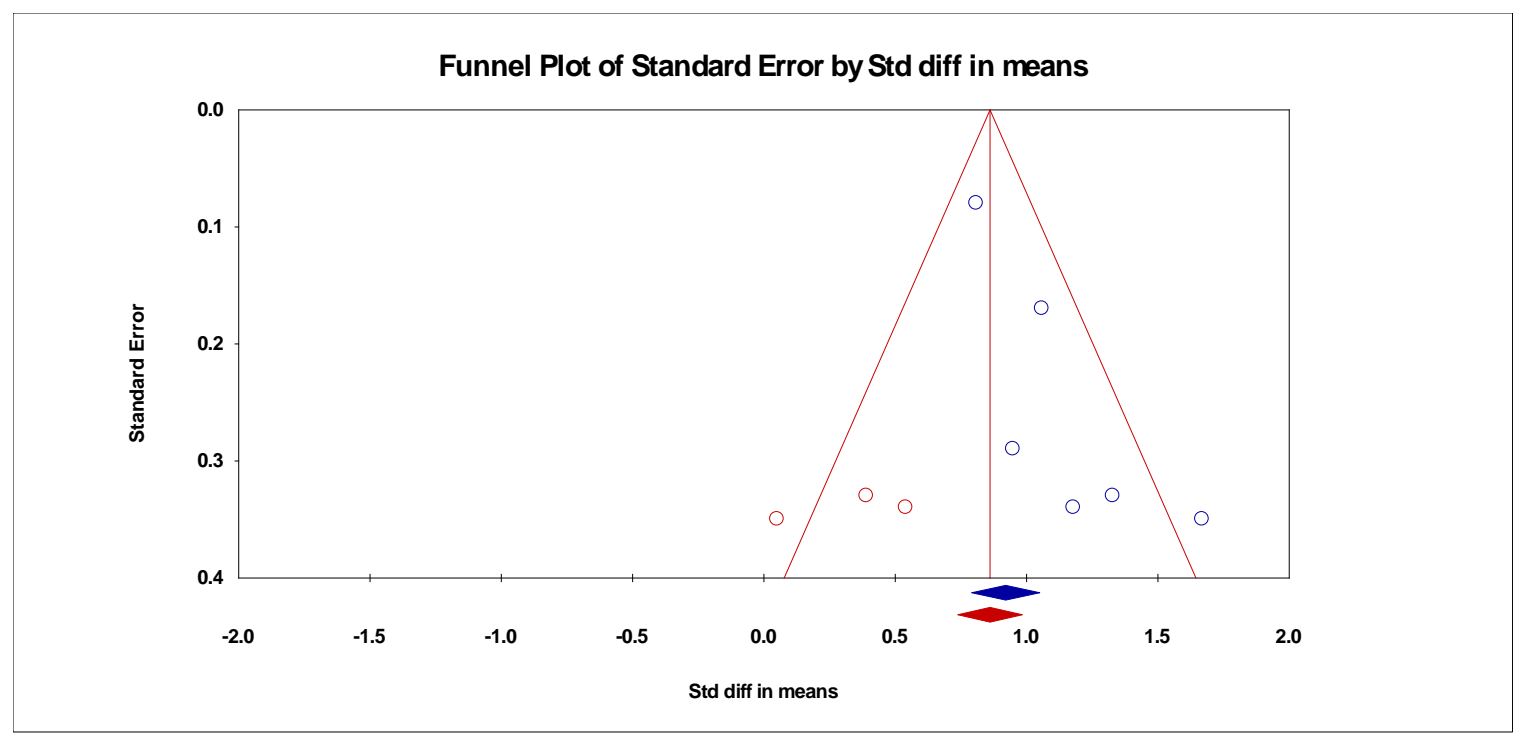

Figure 7. Funnel plot and Duval and Tweedie's trim and fill for SBP sadness rumination reactivity. Three studies trimmed with an adjusted effect size of $d=.861$ (95\% CI: .738 to .983).

\section{Rumination on Positive Emotion}

Rumination on Positive Emotion Reactivity. Meta-analyses of cardiovascular reactivity to rumination on positive emotion revealed significant and large effect sizes for HR, DBP, and SBP (see Table 5). DBP reactivity was moderated by type and duration of recall (see Tables 5 and 6). No studies examined recovery to rumination on positive emotion.

Table 5

Rumination on Positive Emotion Reactivity Effect Sizes

\section{REACTIVITY}

\begin{tabular}{cccc}
\hline Variable & $\underline{\text { Effect Size }}$ & $\underline{\text { CI }}$ & $Q$ Statistic \\
HR & $.903 * * *$ & .400 to 1.394 & $Q(5)=21.840^{* * *}$ \\
DBP & $1.147 * * *$ & .271 to 2.023 & $Q(4)=50.554 * * *$ \\
SBP & $1.249 * * *$ & .971 to 1.527 & $Q(4)=3.627$
\end{tabular}

Note. ${ }^{*} p<.05 ; * * p<.01 ; * * * p<.001$ 
Table 6

Rumination on Positive Emotion Reactivity Effect Size Moderator Analyses

\begin{tabular}{cccc}
\hline Variable & HR & DBP & SBP \\
\hline Published & N/A & N/A & N/A \\
Age over 60 & N/A & N/A & N/A \\
Recall Cond & $Q(1)=.256$ & $Q(1)=43.733^{* * *}$ & $\mathrm{Q}(1)=.206$ \\
Recall Time & $Q(1)=.256$ & $Q(1)=43.733 * * *$ & $Q(1)=.025$ \\
With vs Btwn & $Q(1)=3.68$ & $Q(1)=1.835$ & $Q(1)=.747$ \\
Stressful Cond & $Q(1)=.742$ & $Q(1)=.890$ & $Q(1)=5.297$
\end{tabular}

Note . Cond $=$ Condition; With $=$ Within; Btwn = Between $; *^{*} p .05 ; * * p<.01 ; * * * p<.001$

Table 7

Moderators of Rumination on Positive Emotion Reactivity Effect Sizes

\begin{tabular}{|c|c|c|c|c|}
\hline & \multicolumn{2}{|c|}{ Vocal Recall } & \multicolumn{2}{|c|}{ Imagery Recall } \\
\hline & Effect Size & $\underline{\mathrm{CI}}$ & Effect Size & $\underline{\mathrm{CI}}$ \\
\hline \multirow[t]{3}{*}{ DBP } & $1.545^{* * *}$ & 1.242 to 1.847 & $-.570^{*}$ & -1.119 to -.021 \\
\hline & \multicolumn{2}{|c|}{ Recall 3-6 Minutes } & \multicolumn{2}{|c|}{ Recall $<3$ Minutes } \\
\hline & Effect Size & $\underline{\mathrm{CI}}$ & Effect Size & $\underline{\mathrm{CI}}$ \\
\hline DBP & $1.545^{* * *} *$ & 1.242 to 1.847 & $-.570 *$ & -1.119 to -.021 \\
\hline
\end{tabular}

Overall effect sizes for each the cardiovascular outcome variables did not differ significantly for HR and DBP: $Q(1)=.173, p=.677$; HR and SBP: $Q(1)=1.178, p=$ .278 ; or DBP and SBP: $Q(1)=.041, p=.840$. Forest plots for the analyses of each cardiovascular variable are displayed in Figures 8, 9, and 10. 
Study name

Foster et al. (1997)

Neumann \& Waldstein (2001) a $1.190 \quad 0.340$

Neumann \& Waldstein (2001) b $1.200 \quad 0.330$

Sinha et al. (1992)

Waldstein et al. (2000)
Std diff Standard in means error

$\begin{array}{ll}0.239 & 0.310 \\ 0.100 & 0.250 \\ 1.190 & 0.340 \\ 1.200 & 0.330 \\ 1.270 & 0.300 \\ 1.490 & 0.290 \\ 0.903 & 0.257\end{array}$

Std diff in means and $95 \% \mathrm{Cl}$

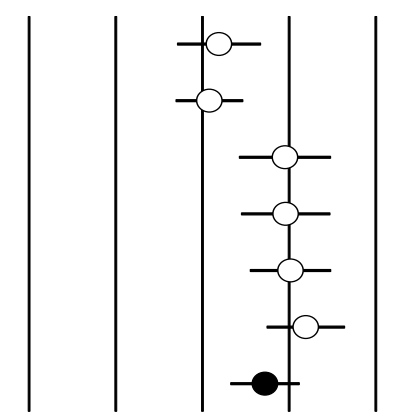

$-2.50-1.250 .001 .252 .50$

Below Baseline Above Baseline

Figure 8. Forest plot of six weighted effect sizes for HR reactivity during positive rumination.

DBP Reactivity Rumination on Positive Emotion

Study name

Std diff Standard in means error

Burns et al. (2003)

Neumann \& Waldstein (2001) a $\quad 1.230 \quad 0.240$

Neumann \& Waldstein (2001) b $1.910 \quad 0.260$

Sinha et al. (1992)

Waldstein et al. (2000)
$-0.580 \quad 0.280$

$1.540 \quad 0.290$

$1.147 \quad 0.447$
Std diff in means and $95 \% \mathrm{Cl}$

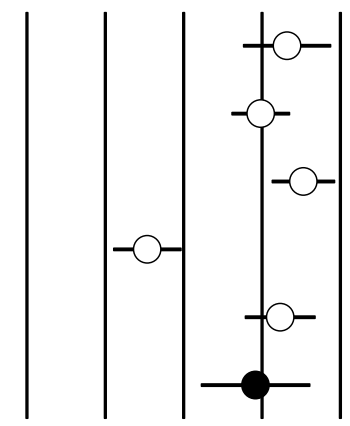

$-2.50-1.250 .001 .252 .50$

Below Baseline Above Baseline

Figure 9. Forest plot of five weighted effect sizes for DBP reactivity during positive rumination. 
Study name

Std diff Standard

in means error

Burns et al. (2003) $\quad 0.900 \quad 0.320$

Neumann \& Waldstein (2001) a $1.710 \quad 0.370$

Neumann \& Waldstein (2001) b $1.010 \quad 0.320$

Sinha et al. (1992) $\quad 1.290 \quad 0.300$

Waldstein et al. (2000) $\quad 1.410 \quad 0.290$

$1.249 \quad 0.142$
Std diff in means and $95 \% \mathrm{Cl}$

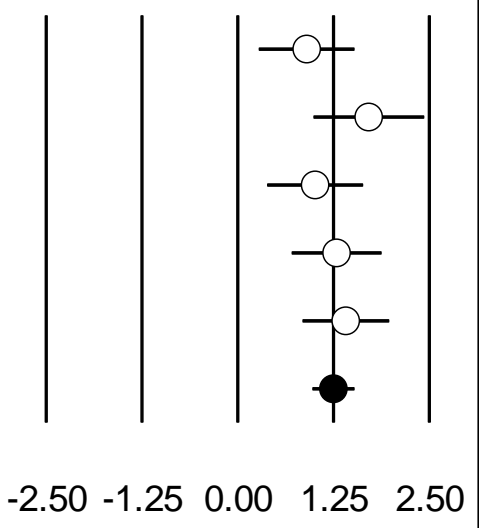

Below Baseline Above Baseline

Figure 10. Forest plot of five weighted effect sizes for SBP reactivity during positive rumination.

Rumination on Positive Emotion Publication Bias. Although the trim and fill procedure did not indicate the presence of publication bias for these analyses, the limited number of studies is not ideal for this procedure; thus, it is still possible that publication bias may exist. Funnel plots with the Duval and Tweedie trim and fill procedure are shown in Figures 11, 12, and 13. 


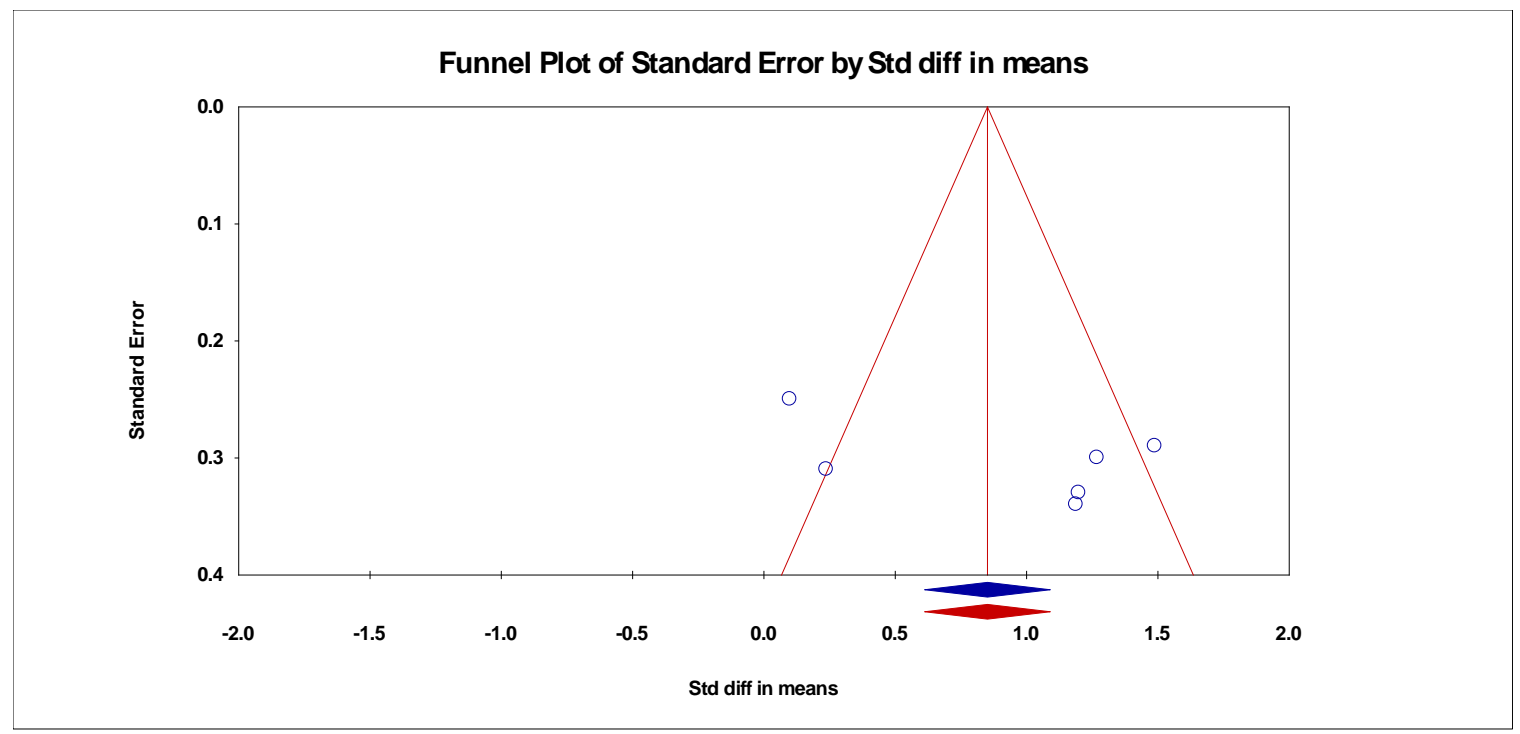

Figure 11. Funnel plot and Duval and Tweedie's trim and fill for HR rumination on positive emotion reactivity. No studies were trimmed.

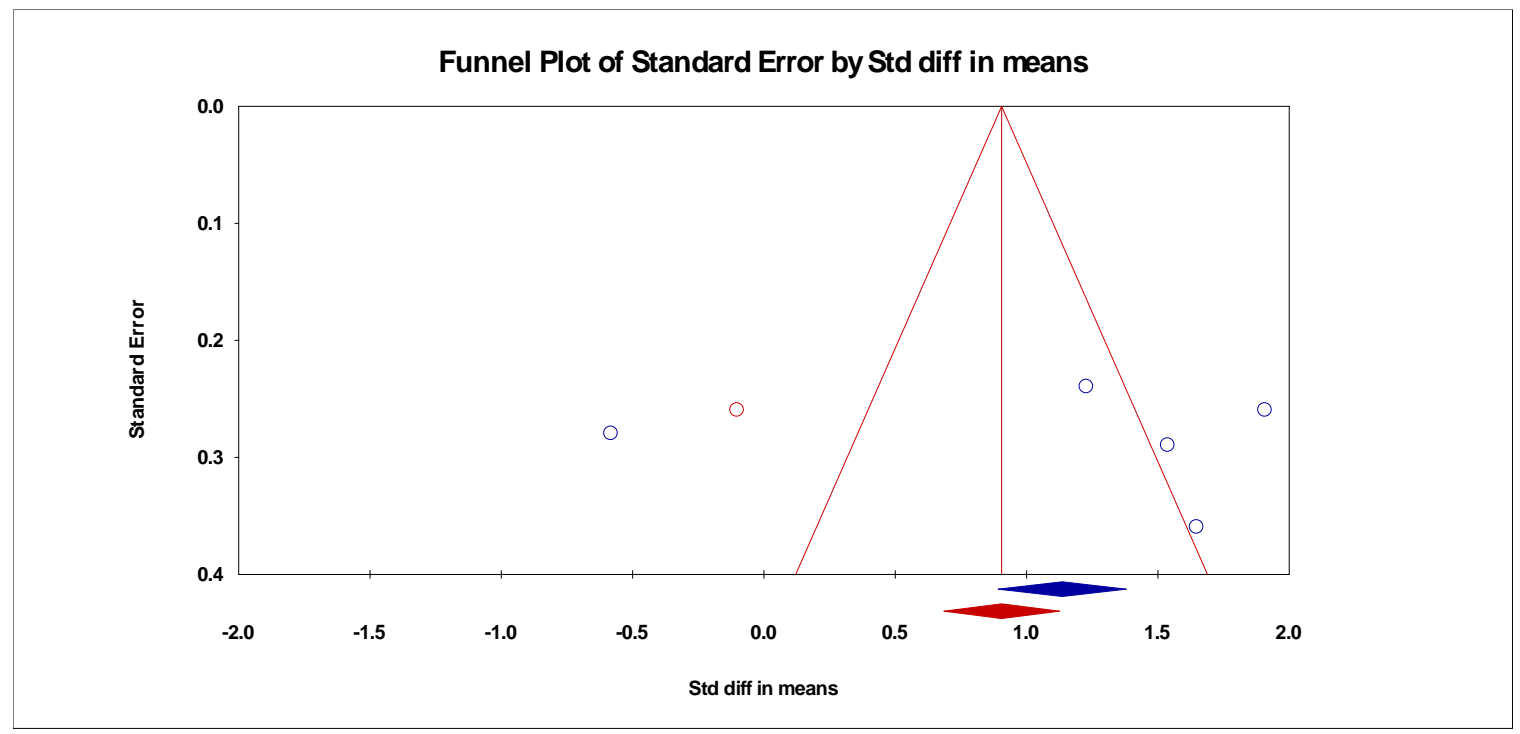

Figure 12. Funnel plot and Duval and Tweedie's trim and fill for DBP rumination on positive emotion reactivity. One study was trimmed with an adjusted effect size of $d=.923$ (95\% CI: .703 to 1.142 ). 


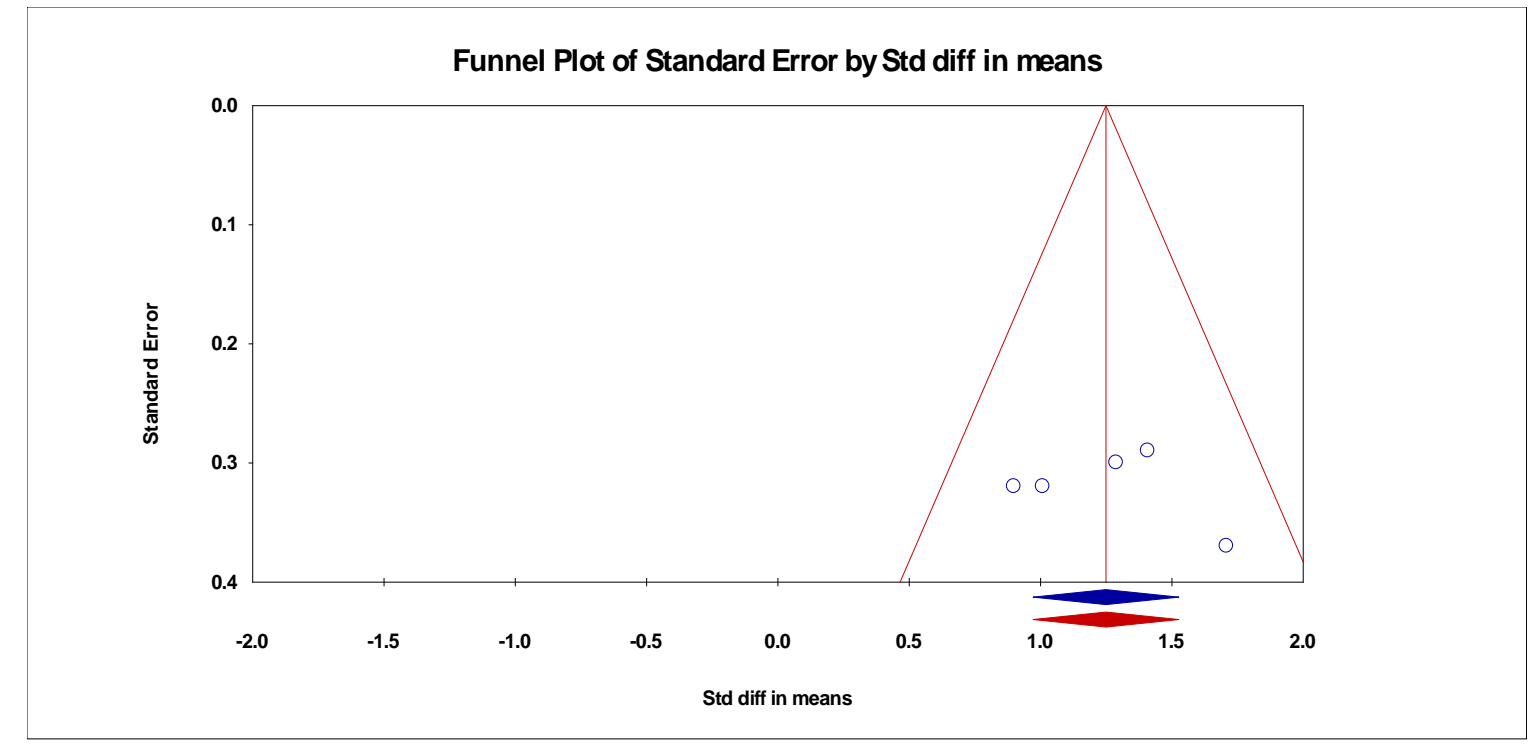

Figure 13. Funnel plot and Duval and Tweedie's trim and fill for SBP rumination on positive emotion reactivity. No studies were trimmed.

\section{Angry Rumination}

Angry Rumination Reactivity and Recovery. Meta-analyses of cardiovascular reactivity to angry rumination revealed significant overall effect sizes for all cardiovascular variables; while angry rumination recovery effect sizes were only significant for SBP (See Table 8). Some reactivity effect sizes were moderated by recall condition, recall time, and an anxiety evoking task in the study design; whereas some recovery effect sizes were moderated by publication status and age of sample (See Tables 9, 10, and 11).

Table 8

Angry Rumination Reactivity and Recovery Effect Sizes

\begin{tabular}{cccc}
\hline \multicolumn{3}{c}{ REACTIVITY } \\
\hline$\underline{\text { Variable }}$ & $\underline{\text { Effect Size }}$ & $\underline{\text { CI }}$ & $Q$ Statistic \\
HR & $.893^{* * *}$ & .737 to 1.050 & $Q(40)=303.033 * * *$ \\
DBP & $1.420 * * *$ & 1.213 to 1.628 & $Q(39)=483.213 * * *$
\end{tabular}




\begin{tabular}{|c|c|c|c|}
\hline \multicolumn{4}{|c|}{ REACTIVITY } \\
\hline$\underline{\text { Variable }}$ & Effect Size & $\underline{\mathrm{CI}}$ & $Q$ Statistic \\
\hline SBP & $1.371 * * *$ & 1.185 to 1.558 & $Q(40)=417.690 * * *$ \\
\hline HRV & $-1.181 * *$ & -2.044 to -.318 & $Q(3)=79.608 * * *$ \\
\hline \multicolumn{4}{|c|}{ RECOVERY } \\
\hline Variable & Effect Size & $\underline{\mathrm{CI}}$ & $Q$ Statistic \\
\hline HR & .220 & -.009 to .449 & $Q(14)=115.882 * * *$ \\
\hline DBP & .200 & -.077 to .477 & $Q(16)=216.314 * * *$ \\
\hline SBP & $.639 * * *$ & .347 to .931 & $Q(17)=264.964 * * *$ \\
\hline HRV & -.562 & -1.425 to .300 & $Q(1)=13.215^{* * *}$ \\
\hline
\end{tabular}

Note. ${ }^{*} p<.05 ; * * p<.01 ; * * * p<.001$

Table 9

Angry Rumination Reactivity and Recovery Moderator Analyses

\begin{tabular}{|c|c|c|c|}
\hline \multicolumn{4}{|c|}{ REACTIVITY } \\
\hline Moderator Variable & $\underline{\mathrm{HR}}$ & $\underline{\mathrm{DBP}}$ & $\underline{\text { SBP }}$ \\
\hline Published & $Q(1)=.002$ & $Q(1)=.001$ & $Q(1)=1.284$ \\
\hline Age over 60 & $Q(1)=.008$ & $Q(1)=1.344$ & $Q(1)=.998$ \\
\hline Recall Condition & $Q(1)=13.84^{* * *}$ & $Q(1)=46.399 * * *$ & $Q(1)=10.166^{* * *}$ \\
\hline Recall Time & $Q(1)=9.395^{* * *}$ & $Q(1)=42.533 * * *$ & $Q(1)=7.773^{* *}$ \\
\hline Within vs Between & $Q(1)=.362$ & $Q(1)=3.011$ & $Q(1)=1.151$ \\
\hline Stressful Condition & $Q(1)=9.519^{*}$ & $Q(1)=3.589$ & $Q(1)=2.709$ \\
\hline \multicolumn{4}{|c|}{ RECOVERY } \\
\hline Moderator Variable & $\underline{\mathrm{HR}}$ & $\underline{\mathrm{DBP}}$ & $\underline{\text { SBP }}$ \\
\hline Published & $Q(1)=.901$ & $Q(1)=.455$ & $Q(1)=4.657^{*}$ \\
\hline Age over 60 & $Q(1)=2.051$ & $Q(1)=11.522 * * *$ & $Q(1)=7.780^{* *}$ \\
\hline Recall Condition & $Q(1)=3.260$ & $Q(1)=.001$ & $Q(1)=.162$ \\
\hline Recall Time & $Q(1)=2.727$ & $Q(1)=.338$ & $Q(1)=1.233$ \\
\hline Within vs Between & $Q(1)=2.188$ & $Q(1)=2.570$ & $Q(1)=.178$ \\
\hline
\end{tabular}




\begin{tabular}{lccc}
\hline \multicolumn{3}{c}{ RECOVERY } \\
\hline Moderator Variable & $\underline{\mathrm{HR}}$ & $\underline{\mathrm{DBP}}$ & $\underline{\text { SBP }}$ \\
Stressful Condition & $Q(1)=.823$ & $Q(1)=.570$ & $Q(1)=2.064$ \\
\hline
\end{tabular}

Note. ${ }^{*} p<.05 ; * * p<.01 ; * * * p<.001$

Table 10

Moderators for angry rumination reactivity effect sizes

\begin{tabular}{|c|c|c|c|c|}
\hline & \multicolumn{2}{|c|}{ Vocal Recall } & \multicolumn{2}{|c|}{ Imagery Recall } \\
\hline & $\underline{\text { Effect Size }}$ & $\underline{\mathrm{CI}}$ & Effect Size & $\underline{\mathrm{CI}}$ \\
\hline HR & $1.057 * * *$ & .918 to 1.196 & $.399 *$ & .082 to .717 \\
\hline DBP & $1.653 * * *$ & 1.495 to 1.811 & $.504 * * *$ & .214 to .795 \\
\hline \multirow[t]{3}{*}{ SBP } & $1.525 * * *$ & 1.347 to 1.743 & $.740 * * *$ & .290 to 1.189 \\
\hline & \multicolumn{2}{|c|}{ Recall < 3 Minutes } & \multicolumn{2}{|c|}{ Recall 3-6 Minutes } \\
\hline & Effect Size & $\underline{\mathrm{CI}}$ & $\underline{\text { Effect Size }}$ & $\underline{\mathrm{CI}}$ \\
\hline $\mathrm{HR}$ & $.489 * *$ & .185 to .793 & $1.018 * * *$ & .870 to 1.166 \\
\hline DBP & $.482 * * *$ & .175 to .790 & $1.632 * * *$ & 1.475 to 1.790 \\
\hline \multirow[t]{3}{*}{ SBP } & $.802 * * *$ & .336 to 1.268 & $1.531 * * *$ & 1.333 to 1.693 \\
\hline & \multicolumn{2}{|c|}{ Stressful Lab Procedure } & \multicolumn{2}{|c|}{ No Stressful Lab Procedure } \\
\hline & Effect Size & $\underline{\mathrm{CI}}$ & Effect Size & $\underline{\mathrm{CI}}$ \\
\hline HR & $1.275^{* * *}$ & 1.039 to 1.512 & $.818 * * *$ & .650 to .986 \\
\hline
\end{tabular}

Table 11

Moderators of angry rumination recovery effect sizes

\begin{tabular}{ccccc}
\hline & \multicolumn{2}{c}{ Participants $>$ age 60 } & \multicolumn{2}{c}{ Participants 60 and younger } \\
\hline$\underline{\text { Variable }}$ & $\underline{\text { Effect Size }}$ & $\underline{\text { CI }}$ & $\underline{\text { Effect Size }}$ & $\underline{\text { CI }}$ \\
DBP & $-.430^{* *}$ & -.704 to -.156 & .244 & -.032 to .519 \\
SBP & .070 & -.204 to .344 & $.649 * * *$ & .349 to .949 \\
\hline
\end{tabular}




\begin{tabular}{ccccc}
\hline & \multicolumn{2}{c}{ Published } & \multicolumn{2}{c}{ Not Published } \\
\hline$\underline{\text { Variable }}$ & $\underline{\text { Effect Size }}$ & $\underline{\text { CI }}$ & $\underline{\text { Effect Size }}$ & $\underline{\text { CI }}$ \\
SBP & $.732 * * *$ & .378 to 1.086 & .226 & -.067 to .519 \\
\hline Note. ${ }^{*} p<.05 ; * * p<.01 ; * * * p<.001$ & & &
\end{tabular}

Meta-regression revealed that biological sex and race/ethnicity did not explain a significant amount of variability in effect sizes to angry rumination for reactivity: HR: $Q(1)=.900, p=.6088$; DBP: $Q(1)=.140, p=.931 ;$ or SBP: $Q(1)=.45, p=.798$; or recovery: HR: $Q(1)=.69, p=.708$; DBP: $Q(1)=3.11, p=.211$, or SBP: $Q(1)=.45$, $p=.798$. Beta values for the regression models are displayed in Tables 12 and 13 .

Table 12

Angry Rumination Cardiovascular Reactivity Beta Weights

\begin{tabular}{|c|c|}
\hline \multicolumn{2}{|c|}{ HR Reactivity Angry Rumination } \\
\hline$\underline{\text { Covariate }}$ & $\underline{\beta}$ \\
\hline Biological Sex & .305 \\
\hline Race/Ethnicity & -.004 \\
\hline \multicolumn{2}{|c|}{ DBP Reactivity Angry Rumination } \\
\hline$\underline{\text { Covariate }}$ & $\underline{\beta}$ \\
\hline Biological Sex & .372 \\
\hline Race/Ethnicity & .004 \\
\hline \multicolumn{2}{|c|}{ DBP Reactivity Angry Rumination } \\
\hline Covariate & $\underline{\beta}$ \\
\hline Biological Sex & .228 \\
\hline Race/Ethnicity & .530 \\
\hline
\end{tabular}

Note. $* p<.05 ; * * p<.01 ; * * * p<.001$ 
Table 13

Angry Rumination Cardiovascular Recovery Beta Weights

\begin{tabular}{cc}
\hline HR Recovery Angry Rumination & \multicolumn{1}{c}{ Covariate } \\
\hline Biological Sex & -.357 \\
Race/Ethnicity & -.201 \\
\hline DBP Recovery Angry Rumination & \\
\hline Covariate & -.979 \\
Biological Sex & -1.356 \\
Race/Ethnicity & $\underline{\beta}$ \\
\hline SBP Recovery Angry Rumination & -.950 \\
\hline Covariate & -.203 \\
Biological Sex &
\end{tabular}

Forest plots illustrating each study's weighted effect size and precision are shown in Figures 11, 12, 13, 14, 15, 16, 17, and 18. 
HR Reactivity Angry Rumination

Sudyname

Siddff inmeans and $95 \% \mathrm{Cl}$

Siddff Stancerd

inmeans error

Bechthemeta. (2002)

Berighted. (1997)

Brown(1999)

Brummet eta. (2009)

Burns (2006)

Burnsetal. (2003)

Crels etal. (1998)

Cohen (2010)

Copper etal. (2014)

Ditto, Miller, \&Marice(1987) a

Ditto, Miller, \& Marice(1987) b

Foster etal. (1999)

Foster etal. (1997)

Fredidsonetal. (2000)

Friedberg etal. (2007)

Gerinetal. (2006)

Gymetal. (2002)

Henninger (2001)

Ironsonetal. (1992)

Jonassairt eta. (2009)

Karioetd. (2002)

Laver etal. (1995)

Leoneta. (2007)

Linegerge, M.D. (2005)

McLan(2010)

McClellandet d. (2008)

Namem\& Whaldsten (2001)

Namemetal. (2004)

Ratrasingam\&Bishop(2007)

Richmental. (2007)

Ruzz(2003)

Ritledgeeta. (2001)

Simaeta. (1992)

Smejers etal. (2014)

Sterezetal. (2004)

Snouski (2008)

Vaugh (2008)

Vranaetal. (2009)

Waldsteinetal. (2002)

Waldsteinetal. (2000)

Why\&Jdonston (2008)

$0.080 \quad 0.190$

$1.220 \quad 0.510$

$1.300 \quad 0.170$

$\begin{array}{lll}1.030 & 0.080\end{array}$

$0.940 \quad 0.170$

$0.410 \quad 0.310$

$\begin{array}{lll}1.500 & 0.230\end{array}$

$0.810 \quad 0.150$
0.000

$1.600 \quad 0.180$

$1.090 \quad 0.340$

$0.130 \quad 0.300$

$1.930 \quad 0.490$

$0.160 \quad 0.350$

$0.170 \quad 0.170$

$0.720 \quad 0.150$

$1.280 \quad 0.200$

$\begin{array}{lll}-0.690 & 0.340\end{array}$

$1.200 \quad 0.150$

$0.920 \quad 0.490$

$0.410 \quad 1.420$

$\begin{array}{lll}1.310 \quad 1.420 & 0.140\end{array}$

$0.880 \quad 0.140$

$\begin{array}{lll}1.820 & 0.220\end{array}$

$0.130 \quad 0.200$

$0.720 \quad 0.160$

$0.010 \quad 0.150$

$\begin{array}{lll}1.000 & 0.230\end{array}$

$1.270 \quad 0.170$

$\begin{array}{lll}1.350 & 0.170\end{array}$

$0.900 \quad 0.120$

$1.300 \quad 0.140$

$0.760 \quad 0.130$

$\begin{array}{lll}1.370 \quad 0.300 & 0\end{array}$

$\begin{array}{lll}1.860 & 0.390\end{array}$

$\begin{array}{lll}1.440 & 0.120\end{array}$

$\begin{array}{lll}1.590 & 0.330\end{array}$

$0.310 \quad 0.170$

$0.400 \quad 0.130$

$1.350 \quad 0.160$

$\begin{array}{lll}0.830 & 0.270\end{array}$

$0.640 \quad 0.190$
0.30

$\begin{array}{lll}0.340 & 0.130\end{array}$

Whyetal. (2003)

$0.893 \quad 0.080$

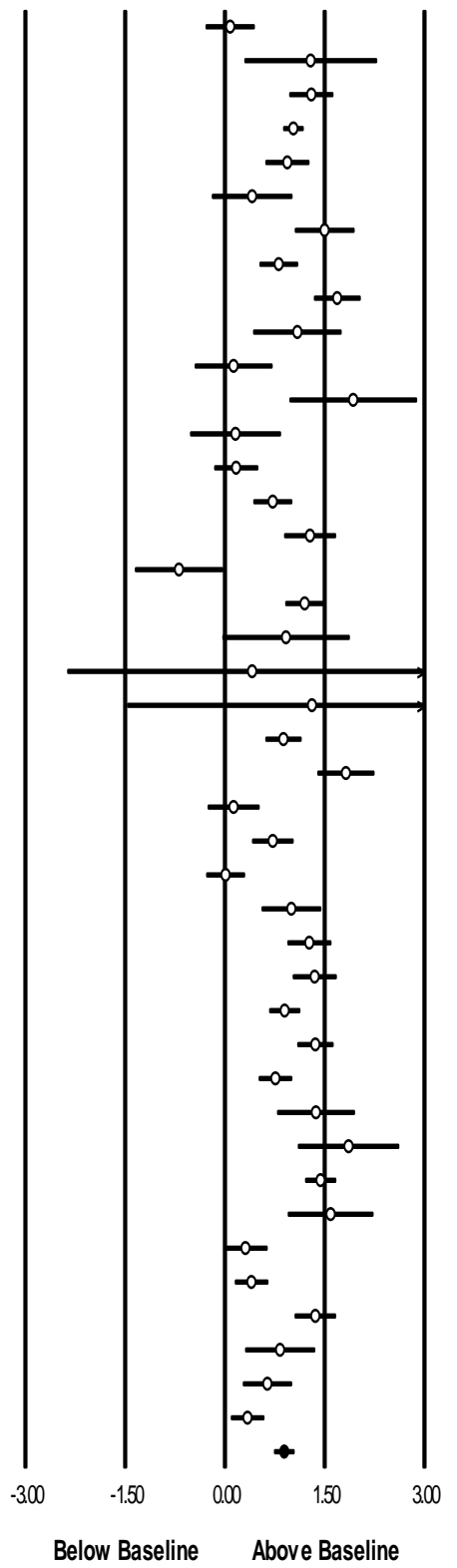

Figure 14. Forest plot of 41 weighted effect sizes for HR reactivity during angry rumination. 


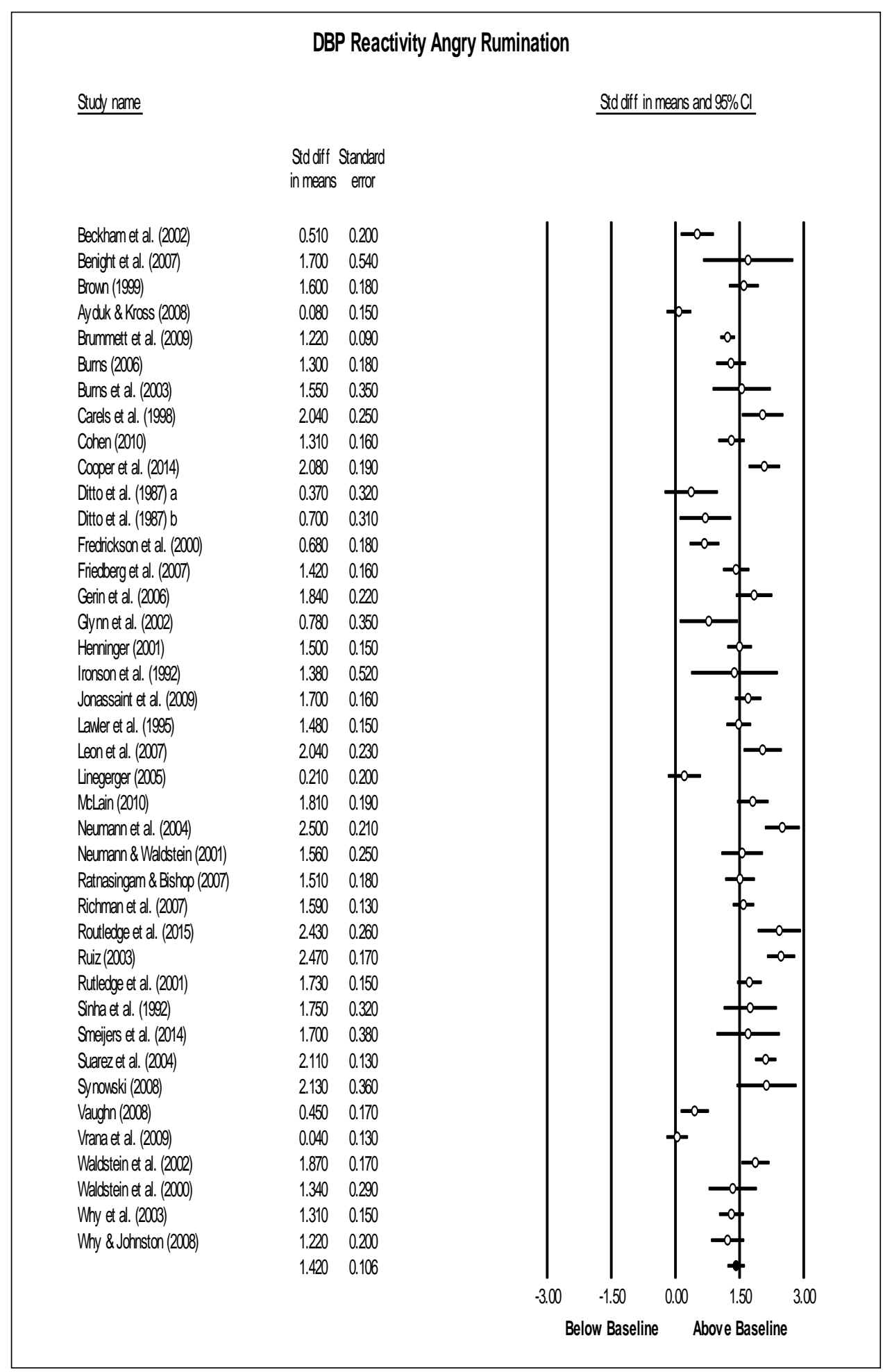

Figure 15. Forest plot of 40 weighted effect Sizes for DBP reactivity during angry rumination. 


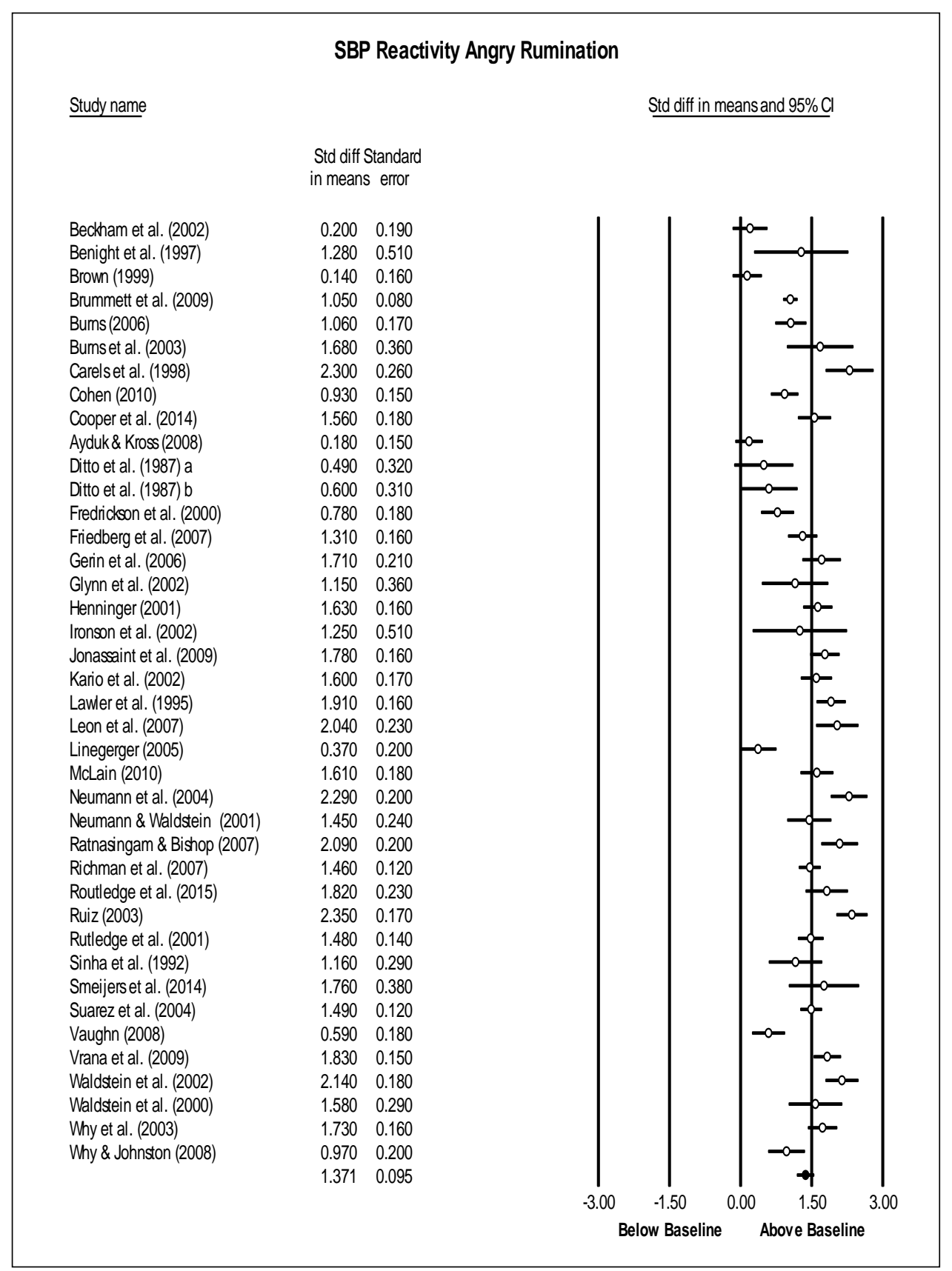

Figure 16. Forest plot of 41 weighted effect sizes for SBP reactivity during angry rumination. 
HRV Reactivity Angry Rumination

Study name

Std diff Standard

Std diff in means in means error

Marci et al. (2007)

Neuman et al. (2004)

$\begin{array}{ll}-1.130 & 0.340\end{array}$

Ottaviani \& Shapiro (2011)

$-1.470 \quad 0.130$

$\begin{array}{ll}-1.990 & 0.160\end{array}$

Ottaviani et al. (2009)

$\begin{array}{ll}-0.130 & 0.150\end{array}$

$\begin{array}{ll}-1.181 & 0.440\end{array}$ and $95 \% \mathrm{Cl}$

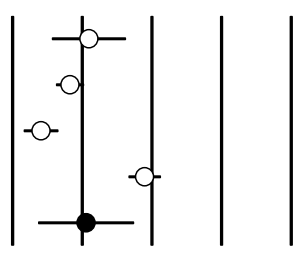

$-2.50-1.250 .001 .252 .50$

Below Baseline Above Baseline

Figure 17. Forest plot of 4 weighted effect sizes for HRV reactivity during angry rumination.

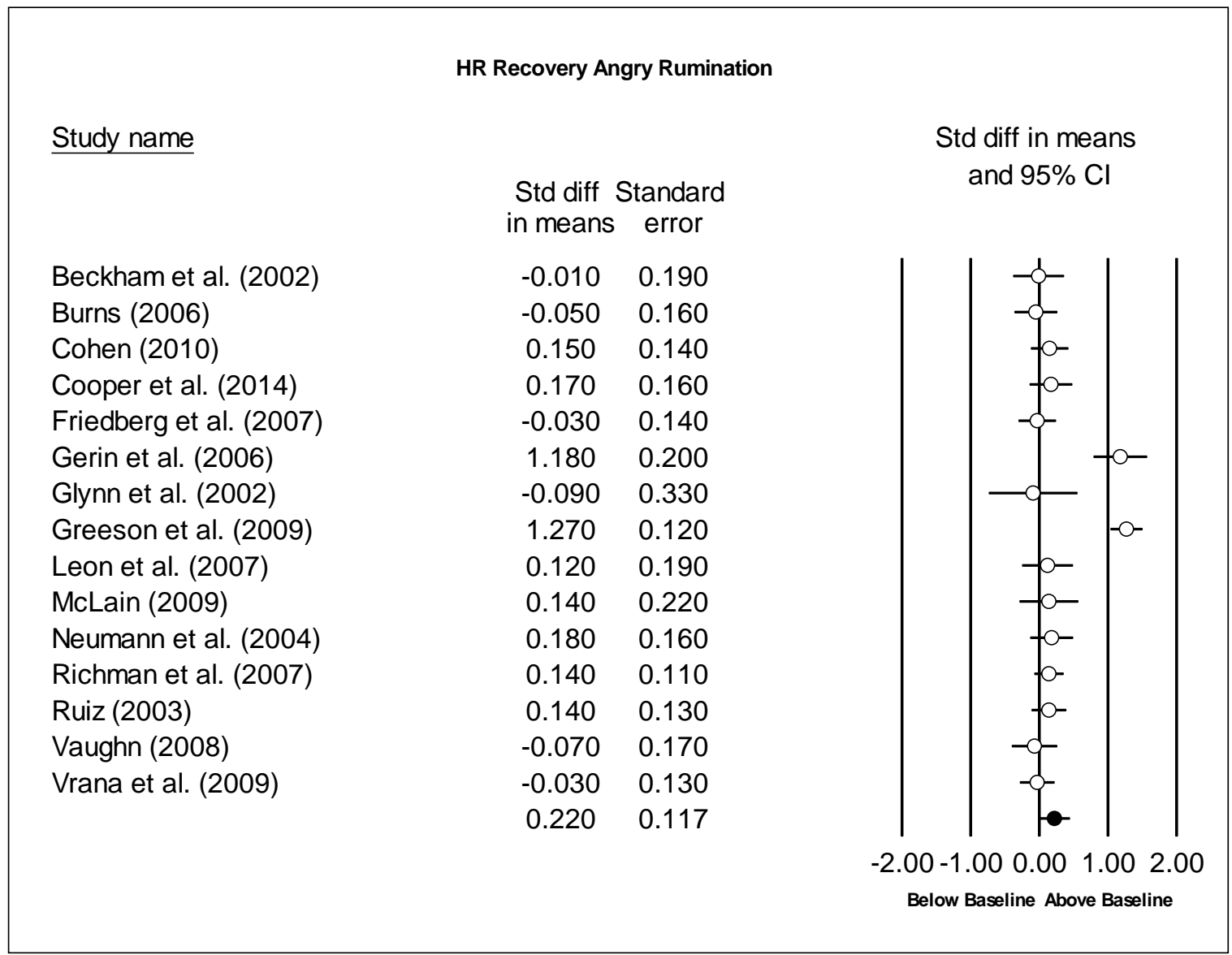

Figure 18. Forest plot of 15 effect sizes for HR recovery following angry rumination. 


\section{DBP Recovery Angry Rumination}

Study name

\begin{tabular}{|c|c|}
\hline $\begin{array}{l}\text { Std diff } \\
\text { in means }\end{array}$ & $\begin{array}{l}\text { Standard } \\
\text { error }\end{array}$ \\
\hline 0.210 & 0.190 \\
\hline 0.010 & 0.160 \\
\hline 0.090 & 0.150 \\
\hline 0.140 & 0.160 \\
\hline 0.360 & 0.140 \\
\hline-0.430 & 0.140 \\
\hline 1.730 & 0.210 \\
\hline 0.860 & 0.350 \\
\hline 1.250 & 0.120 \\
\hline-0.180 & 0.190 \\
\hline-0.570 & 0.230 \\
\hline-0.670 & 0.160 \\
\hline-0.140 & 0.110 \\
\hline 0.510 & 0.200 \\
\hline 0.310 & 0.130 \\
\hline 0.000 & 0.170 \\
\hline 0.080 & 0.130 \\
\hline 0.200 & 0.141 \\
\hline
\end{tabular}

Std diff in means and $95 \% \mathrm{Cl}$

Beckham et al. (2002)

Burns (2006)

Ayduk \& Kross (2008)

Cooper et al. (2014)

Cohen (2010)

Friedberg et al. (2007)

Gerin et al. (2006)

Glynn et al. (2002)

Greeson (2009)

Leon et al. (2007)

McLain (2009)

Neumann et al. (2004)

Richman et al. (2007)

Routledge et al. (2015)

Ruiz (2003)

Vaughn (2009)

Vrana et al. (2009)

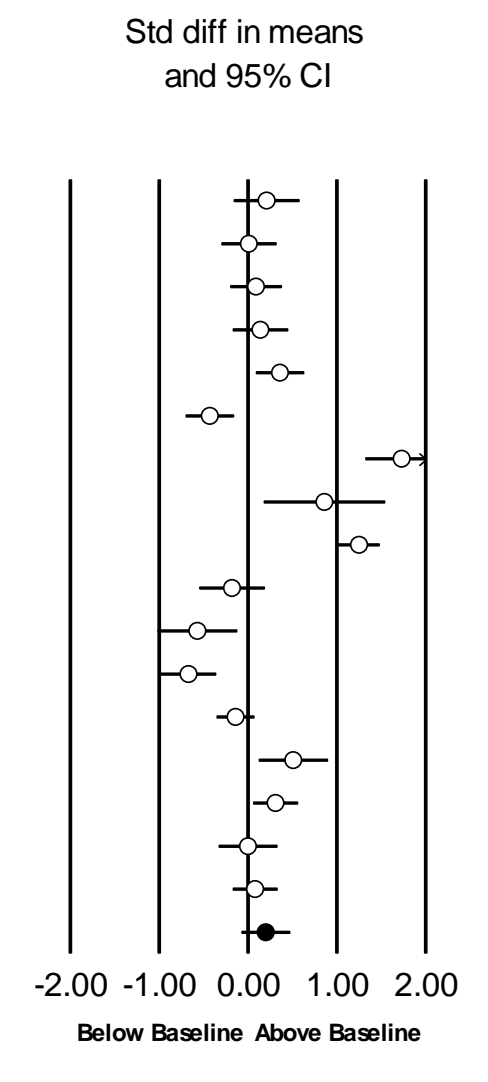

Figure 19. Forest plot of 17 effect sizes for DBP recovery following angry rumination. 


\section{SBP Recovery Angry Rumination}

Study name

Std diff Standard

Std diff in means

in means error

Beckham et al. (2002)

$0.130 \quad 0.190$

Burns (2006)

$0.160 \quad 0.160$

Cohen (2010)

$0.130 \quad 0.140$

Cooper et al. (2014)

$0.690 \quad 0.160$

Ayduk \& Kross (2008)

$0.180 \quad 0.150$

Friedberg et al. (2007)

$0.070 \quad 0.140$

Gerin et al. (2006)

$1.630 \quad 0.210$

Glynn et al. (2002)

$1.280 \quad 0.360$

Greeson et al. (2009)

$1.080 \quad 0.110$

Kario et al. (2002)

$\begin{array}{ll}1.600 & 0.170\end{array}$

Leon et al. (2007)

$\begin{array}{ll}1.170 & 0.200\end{array}$

McLain (2009)

$0.160 \quad 0.220$

Neumann et al. (2004)

$0.140 \quad 0.160$

$0.040 \quad 0.110$

Routledge et al. (2015) $\quad 0.670 \quad 0.200$

Ruiz (2003)

$0.590 \quad 0.130$

Vaughn (2009)

$-0.030 \quad 0.170$

Vrana et al. (2009)

$2.000 \quad 0.160$

$0.639 \quad 0.149$

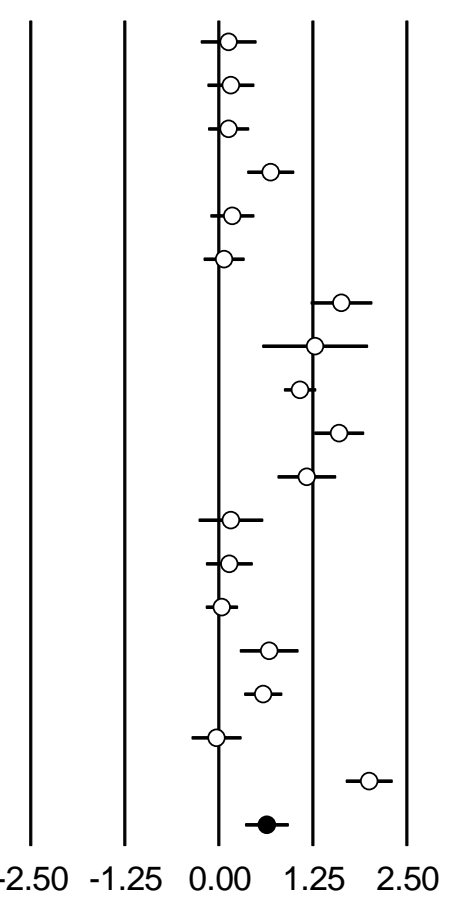

Below Baseline Above Baseline

Figure 20. Forest plot of 18 effect sizes for SBP recovery following angry rumination.

Angry Rumination Reactivity and Recovery Publication Bias. There was no

indication of publication bias for reactivity or recovery analyses. Funnel plots with the Duval and Tweedie trim and fill procedure are shown in Figures 15, 16, 17, 18, 19, \& 20. 


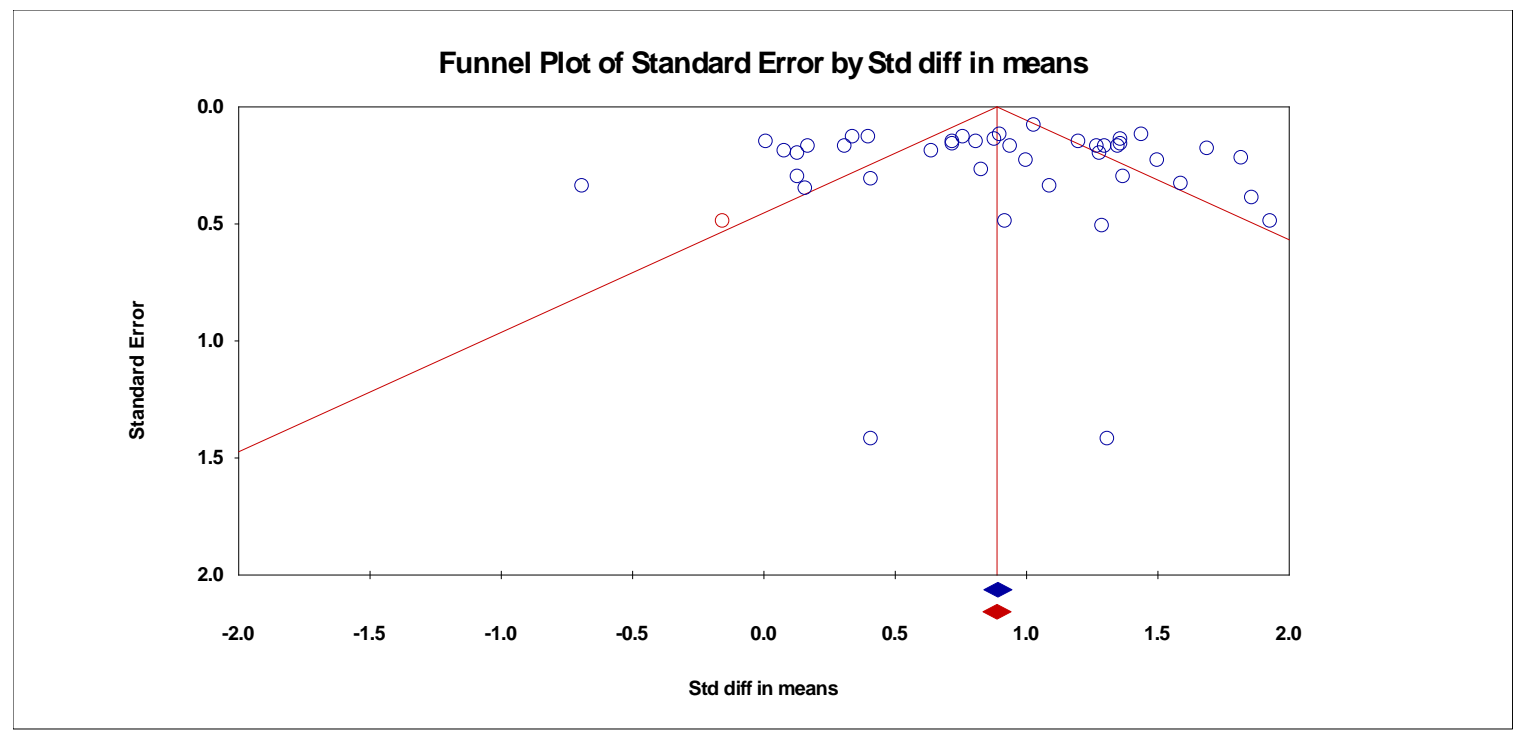

Figure 21. Funnel plot and Duval and Tweedie's trim and fill for HR angry rumination reactivity. Two studies were trimmed with an adjusted effect size of $d=.882$ (95\% CI: .829 to .936).

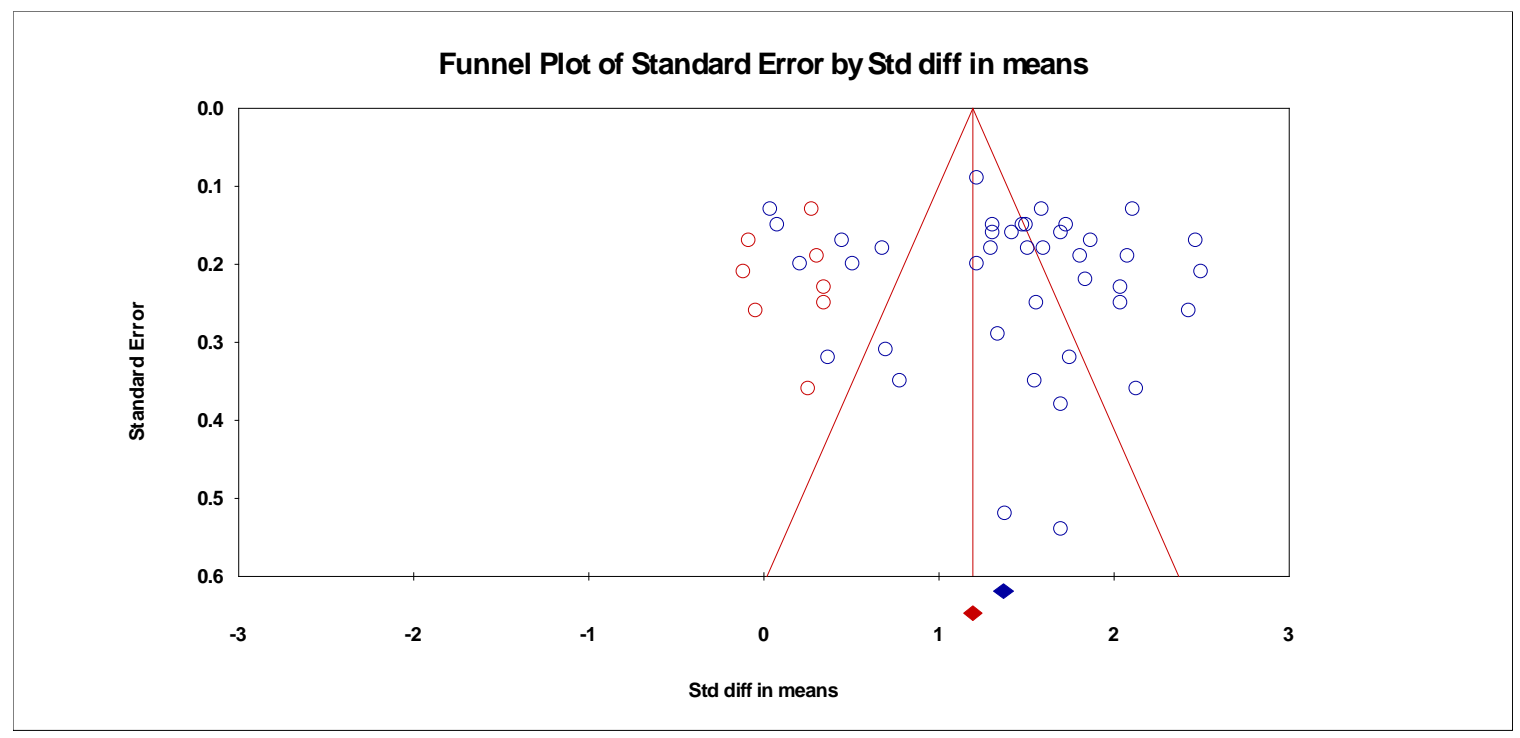

Figure 22. Funnel plot and Duval and Tweedie's trim and fill for DBP angry rumination reactivity. Seven studies were trimmed with an adjusted effect size of $d=1.122$ (95\% CI: 1.165 to 1.271$)$. 


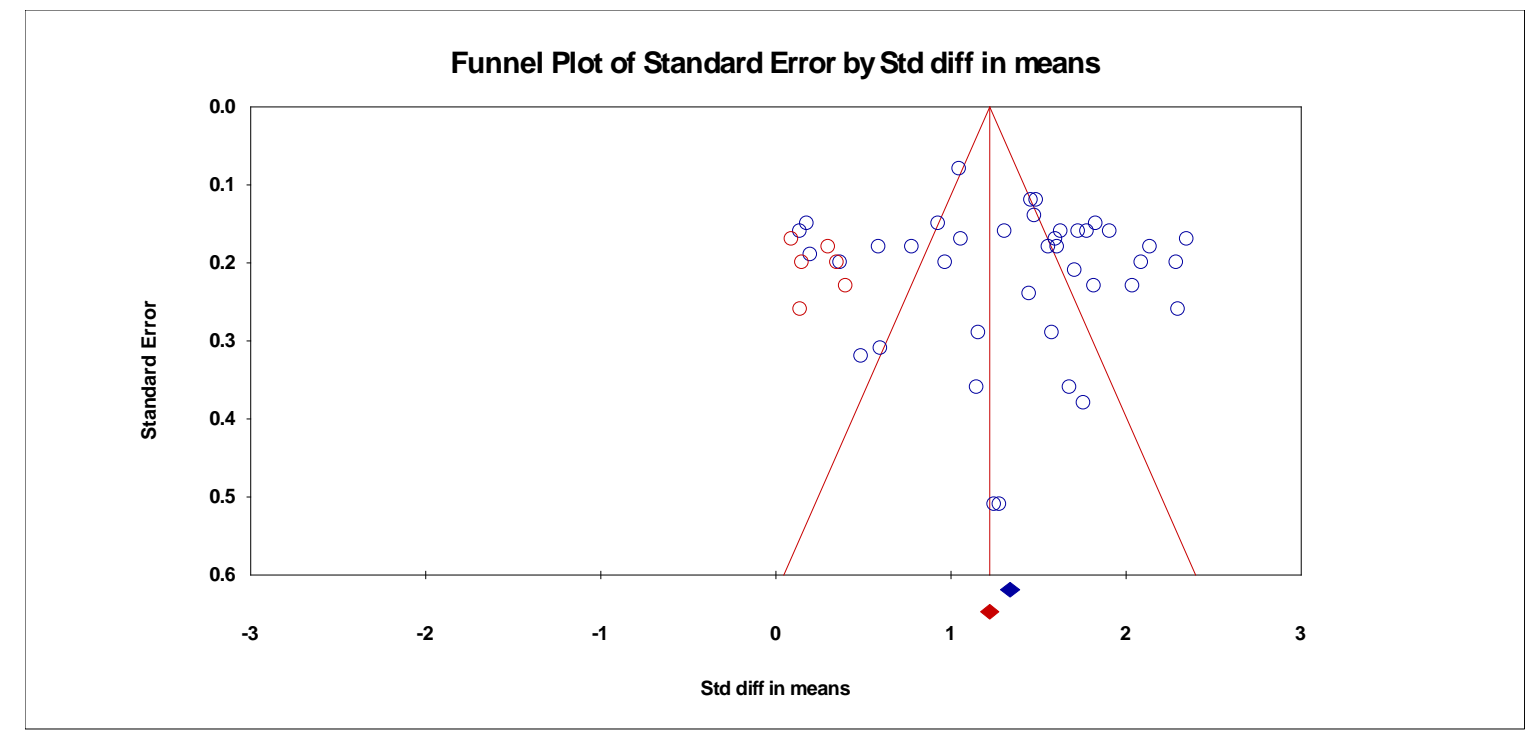

Figure 23. Funnel plot and Duval and Tweedie's trim and fill for SBP angry rumination reactivity. Six studies were trimmed with an adjusted effect size of $d=1.221$ (95\% CI: 1.169 to $1.273)$.

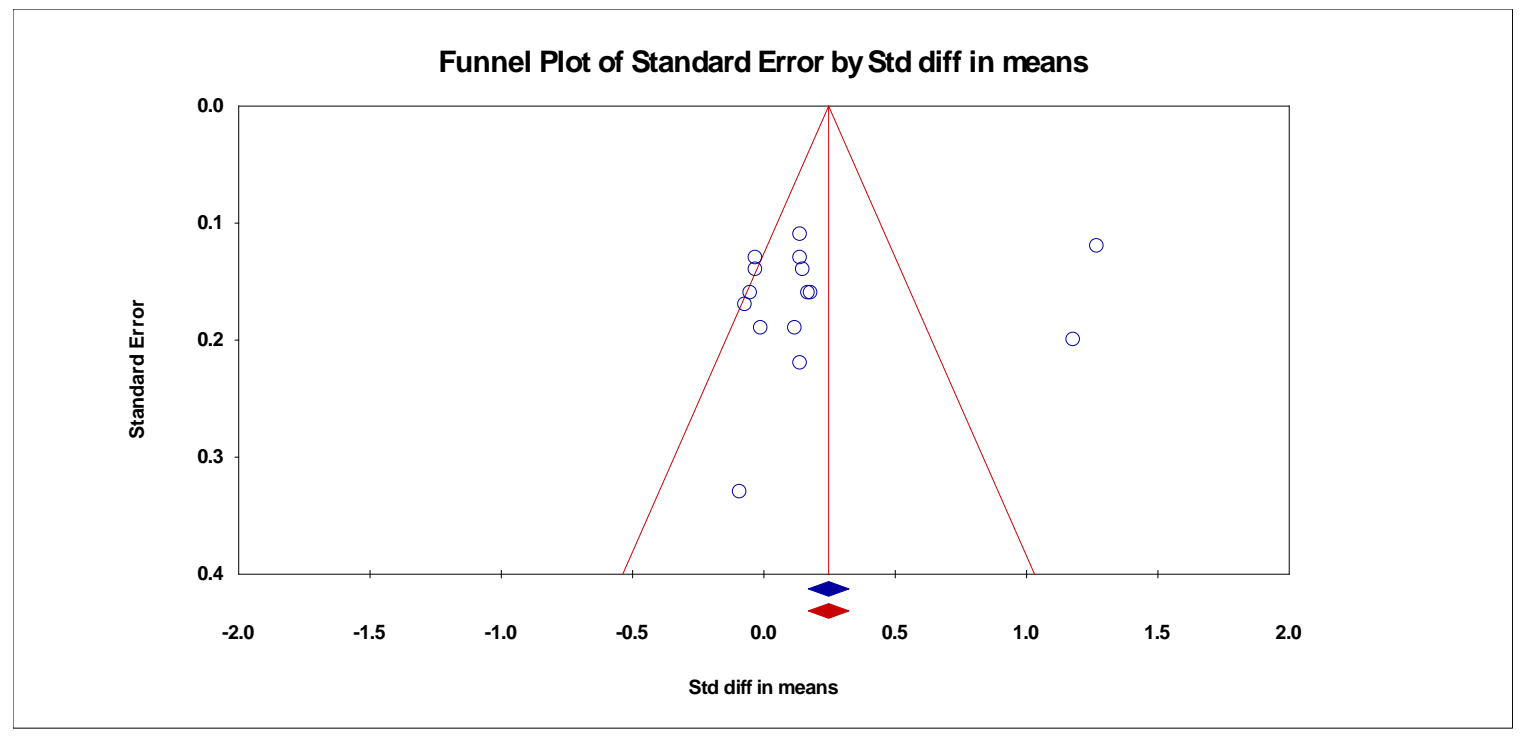

Figure 24. Funnel plot and Duval and Tweedie's trim and fill for HR angry rumination recovery. No studies were trimmed. 


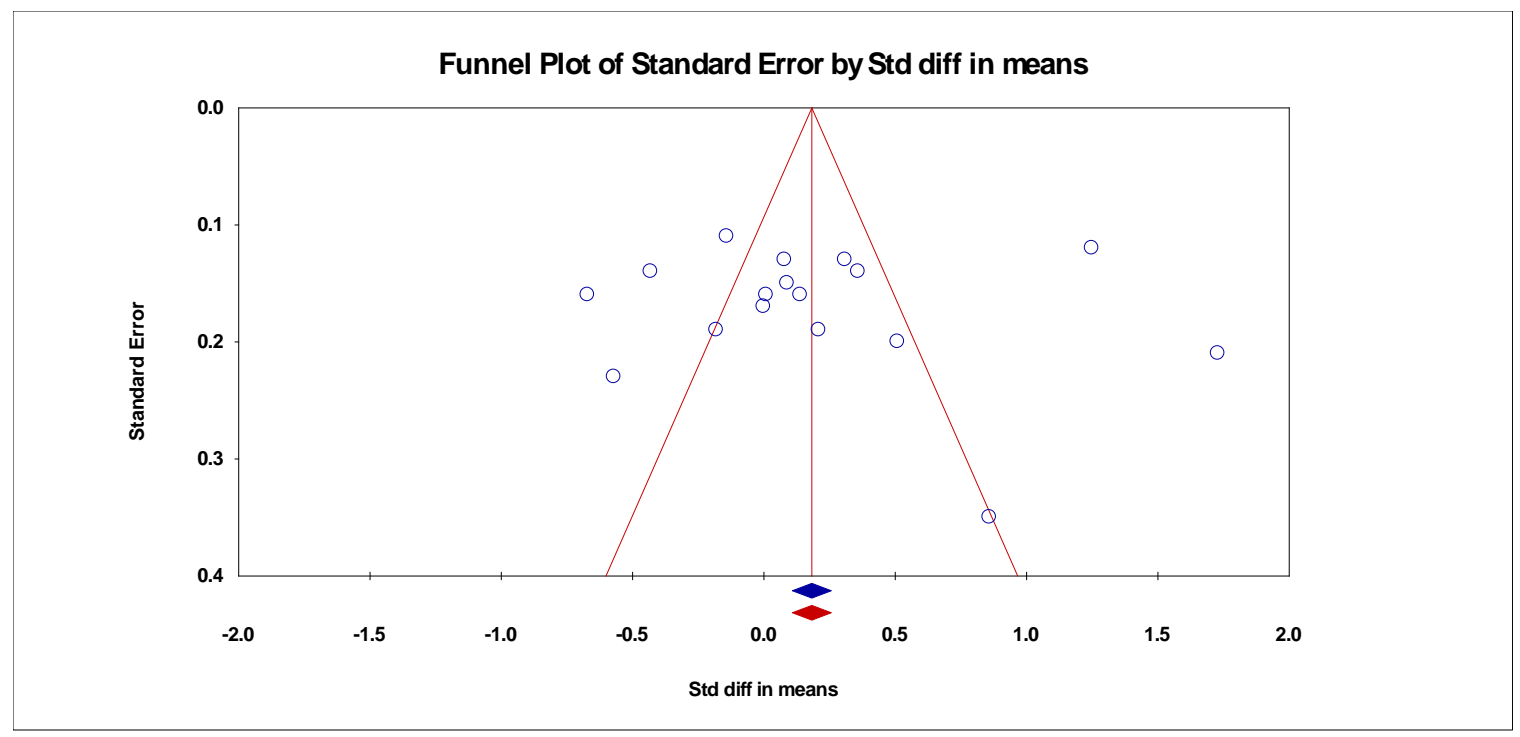

Figure 25. Funnel plot and Duval and Tweedie's trim and fill for DBP angry rumination recovery. No studies were trimmed.

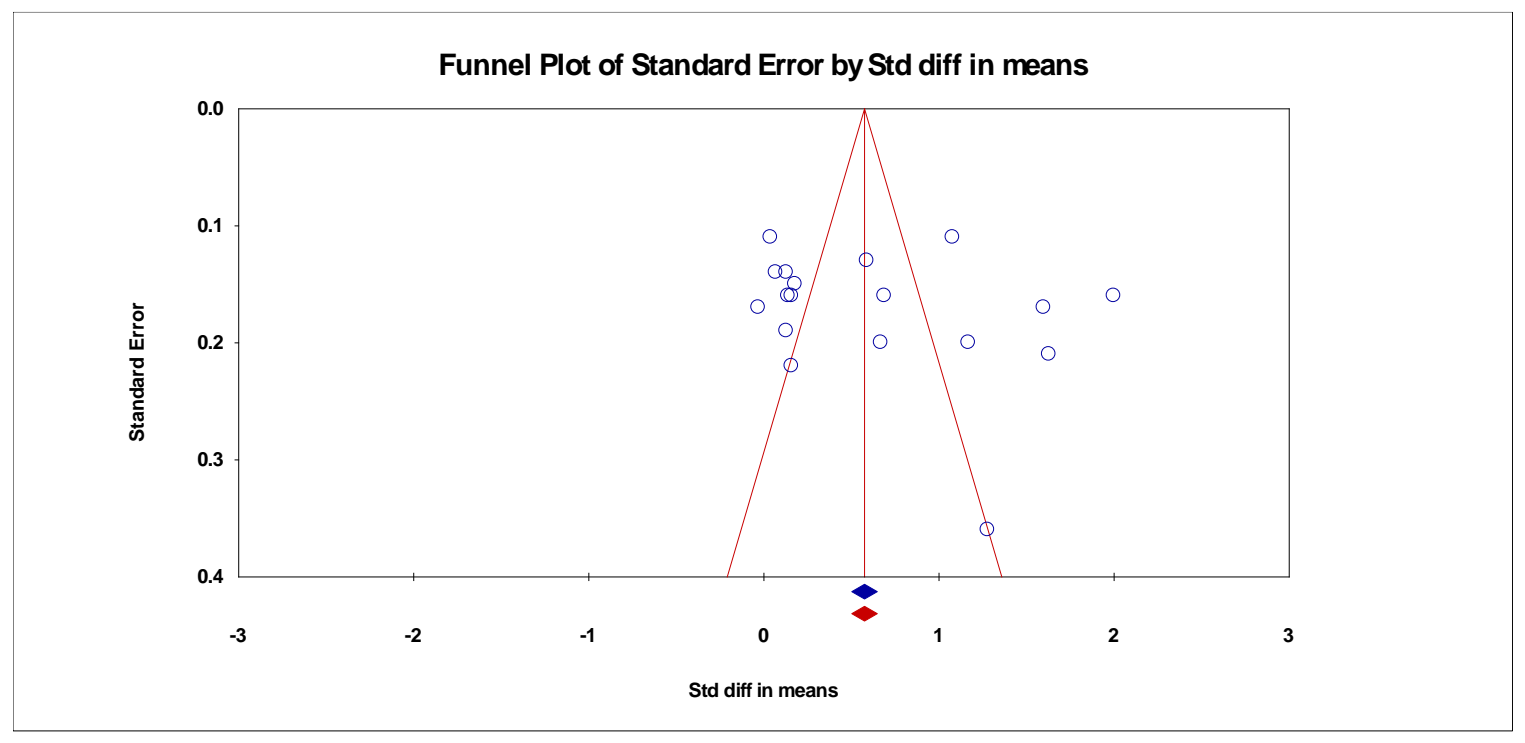

Figure 26. Funnel plot and Duval and Tweedie's trim and fill for SBP angry rumination recovery. No studies were trimmed.

Reactivity and Recovery Effect Sizes within and across Rumination Types.

Comparisons between cardiovascular variables revealed that overall DBP and SBP angry 
reactivity effect sizes were significantly greater than HR reactivity overall effect size, $Q$ $(1)=18.146(p<.001)$ and $Q(1)=16.856(p<.001)$, respectively.

There were no significant differences in cardiovascular reactivity to angry, sadness, and positive rumination for HR: $Q(1)=.137, p=.934$; DBP: $Q(1)=1.584, p=$ .453 ; or SBP: $Q(1)=4.70, p=.095$. There was also no significant difference between cardiovascular recovery to angry and sadness rumination for HR: $Q(1)=3.219, p=.073$; whereas there was a significant difference for DBP: $Q(1)=4.052, p<.05$; and SBP: $Q$ $(1)=7.493, p<.05$. The overall cardiovascular reactivity and recovery effect sizes for each of the emotion-focused rumination subtypes are shown in Table 14.

Table 14 Cardiovascular Reactivity and Recovery Effect Sizes across Types of Rumination

\begin{tabular}{ccc}
\hline & HR Reactivity & \multicolumn{1}{c}{$95 \% \mathrm{CI}$} \\
\hline Rumination Type & $\underline{\text { Effect Size }}$ & .737 to 1.050 \\
Angry & $.893^{* * *}$ & .580 to 1.502 \\
Sadness & $.843^{* * *}$ & .400 to 1.394 \\
Positive & $.963^{* * *}$ & $\underline{95 \% \mathrm{CI}}$ \\
\hline Rumination Type & DBP Reactivity & 1.213 to 1.628 \\
Angry & $\underline{\text { Effect size }}$ & .924 to 1.502 \\
Sadness & $1.420^{* * *}$ & .271 to 2.023 \\
Positive & $1.213 * * *$ & $\underline{95 \% \mathrm{CI}}$ \\
\hline Rumination Type & $1.147 * * *$ & 1.185 to 1.558 \\
Angry & SBP Reactivity & .816 to 1.299 \\
Sadness & $\underline{\text { Effect Size }}$ \\
Positive & $1.371^{* * *}$ & .971 to 1.527 \\
\hline
\end{tabular}




\begin{tabular}{|c|c|c|}
\hline \multicolumn{3}{|c|}{ HR Recovery } \\
\hline Rumination Type & Effect Size & $95 \% \mathrm{CI}$ \\
\hline Angry & .219 & -.009 to .447 \\
\hline Sadness & .026 & -.116 to .114 \\
\hline \multicolumn{3}{|c|}{ DBP Recovery } \\
\hline Rumination Type & Effect Size & $95 \% \mathrm{CI}$ \\
\hline Angry & .203 & -.068 to .473 \\
\hline Sadness & -.110 & -.250 to .030 \\
\hline \multicolumn{3}{|c|}{ SBP Recovery } \\
\hline Rumination Type & Effect Size & $95 \% \mathrm{CI}$ \\
\hline Angry & $.615 * * *$ & .327 to .904 \\
\hline Sadness & $.168 *$ & .028 to .308 \\
\hline
\end{tabular}

Cardiovascular Reactivity for Angry Rumination vs. Distraction. Cardiovascular

effect size differences between angry rumination and distraction conditions were significant for DBP only (see Table 15), which was not moderated when analyzed by subgroup (see Table 16). However, publication status and within vs. between study design moderated HR effect sizes (see Table 17).

Table 15

Rumination vs. Distraction Effect Sizes

\begin{tabular}{cccc}
\hline Variable & Effect Size & CI & $Q$ Statistic \\
\hline HR & .048 & -.135 to .232 & $Q(9)=17.744$ \\
DBP & $.300^{*}$ & .053 to .547 & $Q(9)=12.468$ \\
SBP & .079 & -.060 to .219 & $Q(9)=10.429$ \\
\hline
\end{tabular}

Note. ${ }^{*} p<.05 ; * * p<.01 ; * * * p<.001$ 
Table 16

Rumination vs. Distraction Reactivity Subgroup Moderator Analyses

\begin{tabular}{cccc}
\hline Moderator Variable & HR & DBP & SBP \\
\hline Published & $Q(1)=7.460^{* *}$ & $Q(1)=1.438$ & $Q(1)=.349$ \\
Recall Time & $Q(1)=.387$ & $Q(1)=1.594$ & $Q(1)=0.00$ \\
Within vs Between & $Q(1)=5.292^{*}$ & $Q(1)=.503$ & $Q(1)=0.00$ \\
\hline
\end{tabular}

Note. $* p<.05 ; * * p<.01 ; * * * p<.001$

Table 17

Rumination vs. Distraction HR Subgroup Moderators

\begin{tabular}{|c|c|c|c|c|}
\hline \multirow[b]{2}{*}{ Variable } & \multicolumn{2}{|c|}{ Published } & \multicolumn{2}{|c|}{ Unpublished } \\
\hline & Effect Size & $\underline{\mathrm{CI}}$ & Effect Size & $\underline{\mathrm{CI}}$ \\
\hline \multirow[t]{2}{*}{ HR } & .181 & .028 to .335 & -.221 & -.440 to -.003 \\
\hline & \multicolumn{2}{|c|}{ Within } & \multicolumn{2}{|c|}{ Between } \\
\hline Variable & Effect Size & $\underline{\mathrm{CI}}$ & Effect Size & $\underline{\mathrm{CI}}$ \\
\hline HR & .302 & .076 to .528 & -.046 & -.239 to .147 \\
\hline
\end{tabular}

Cardiovascular reactivity effect sizes for each of the variables were not significantly different from each other (see Table 18). Forest plots with weighted effect sizes are shown in Figures 24, 25, and 26.

Table 18

Angry Rumination vs. Distraction Comparison across Variables

\begin{tabular}{cc}
\hline Variable & $Q$ Statistic \\
\hline HR vs. DBP & $Q(1)=2.495$ \\
DBP vs. SBP & $Q(1)=.920$ \\
DBP vs. SBP & $Q(1)=.920$ \\
\hline
\end{tabular}

Note. $* p<.05 ; * * p<.01 ; * * * p<.001$ 
A regression analysis was performed for each cardiovascular variable with effect size as the dependent variable and biological sex and race as independent variables.

These analyses revealed that biological sex and race did not predict significant variability in cardiovascular effect size for HR: $Q(2)=2.32, p=.312$; DBP: $Q(2)=1.65, p=.438$; or SBP: $Q(2)=2.55, p=.279 . R^{2}$ for each of the HR, DBP, and SBP models was 0.0. Beta weights are provided in Table 19.

Table 19

Angry Rumination vs. Distraction vs. Beta Weights

\begin{tabular}{ccc}
\hline & HR Effect Size & \\
\hline Covariate & & $\beta$ \\
Biological Sex & .891 & .280 \\
Race/Ethnicity & DBP Effect Size & $\underline{\beta}$ \\
\hline Covariate & -.804 \\
Biological Sex & .610 \\
Race/Ethnicity & SBP Effect Size \\
\hline Covariate & $\underline{\beta}$ \\
Biological Sex & .305 \\
\hline Race/Ethnicity & \\
\hline
\end{tabular}

Note. ${ }^{*} p<.05 ; * * p<.01 ; * * * p<.001$ 
HR Angry Rumination vs. Distraction

Study name

Hedges's g and 95\% Cl

Hedges's

g p-Value

Cohen (2010)

Gerin et al. (2006)

$\begin{array}{lll}-0.100 & 0.617\end{array}$

0.3200 .075

Glynn et al. (2002)

0.1100 .807

Larsen et al. (2012)

0.0100 .953

McClelland et al. (2008)

$0.290 \quad 0.053$

McLain (2009)

$-0.1700 .440$

Neumann et al. (2004)

$-0.1200 .585$

Ottaviani et al. (2011)

0.6700 .013

Raadstak et al. (2014)

$-0.060 \quad 0.824$

Vaughn (2008)

$-0.3400 .046$

0.0480 .605

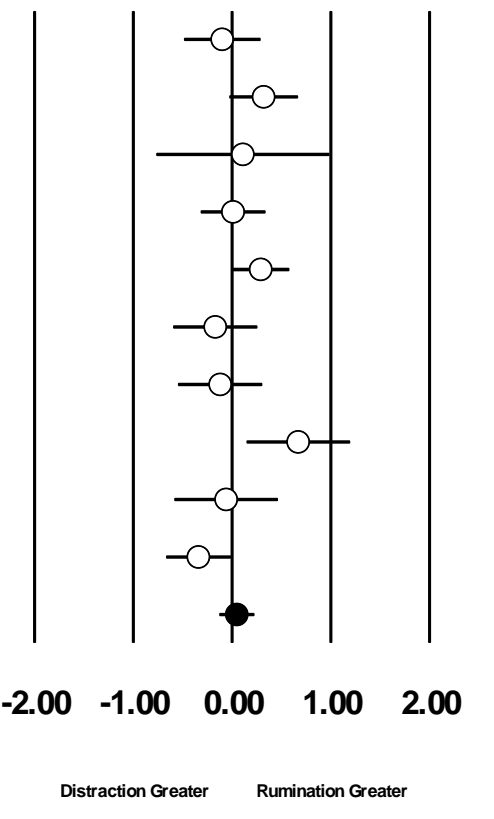

Figure 27. Forest plot of 10 effect sizes for difference in HR reactivity of angry rumination and distraction conditions. 


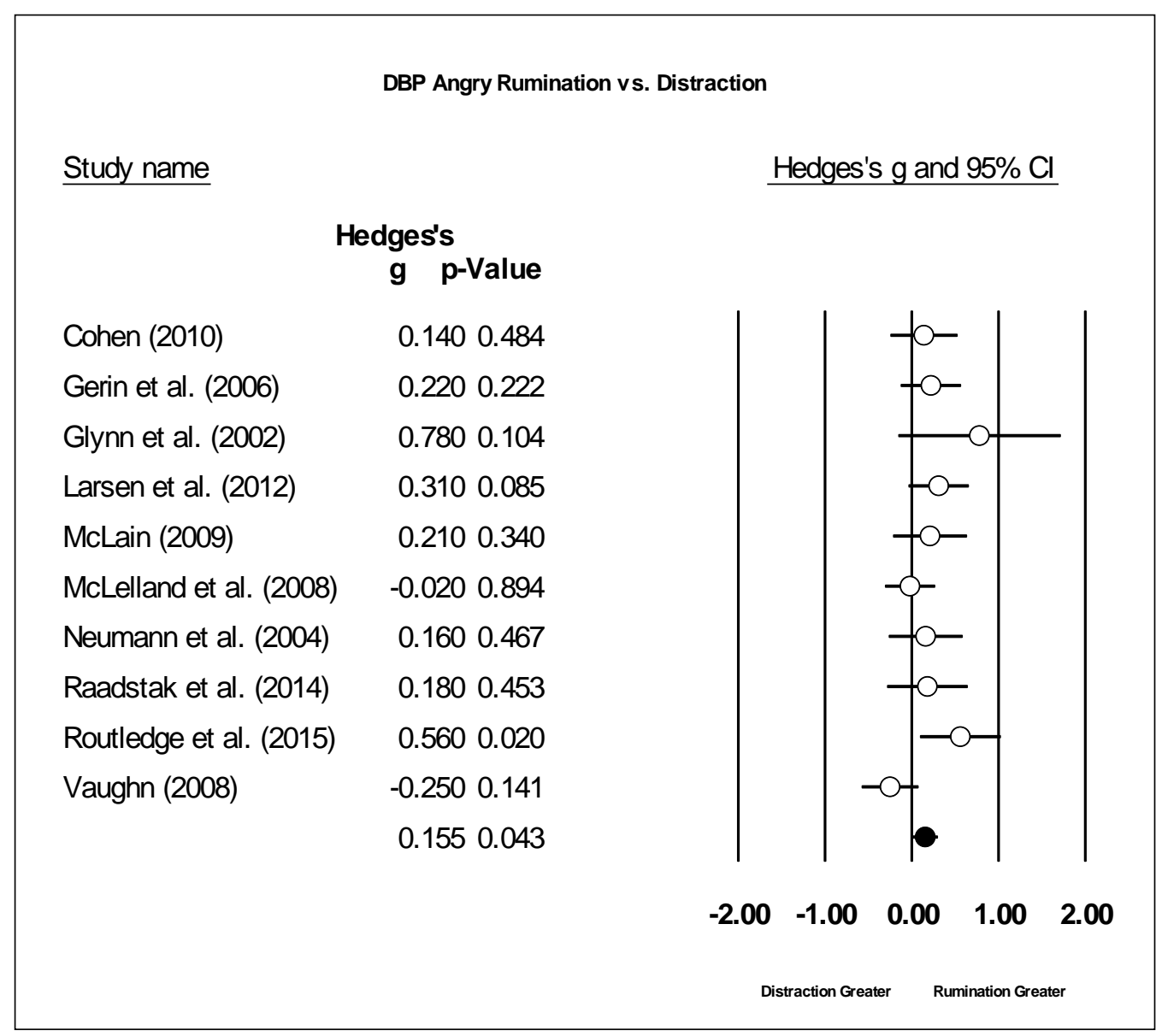

Figure 28. Forest plot of 10 effect sizes for difference in DBP reactivity between angry rumination and distraction conditions. 


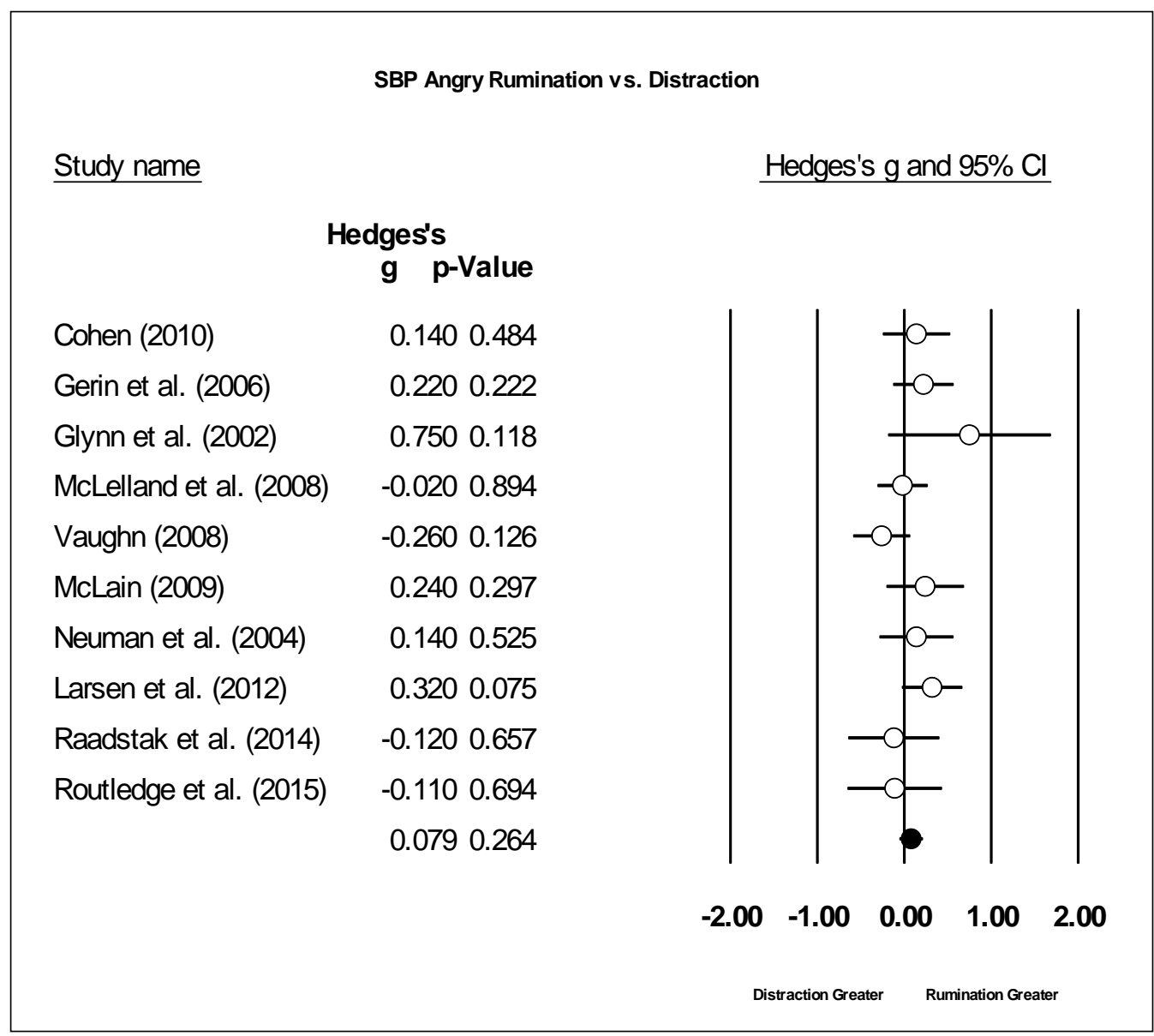

Figure 29. Forest plot of 10 effect sizes for difference in SBP reactivity between angry rumination and distraction conditions.

Angry Rumination vs. Distraction Publication Bias. Funnel plots with the Duval and Tweedie trim and fill procedure were performed for each analysis (see Figures 27, 28, and 29), and resulted in an adjusted effect size for DBP reactivity that went from significant to insignificant, indicating that the file drawer effect may exist for this analysis. 


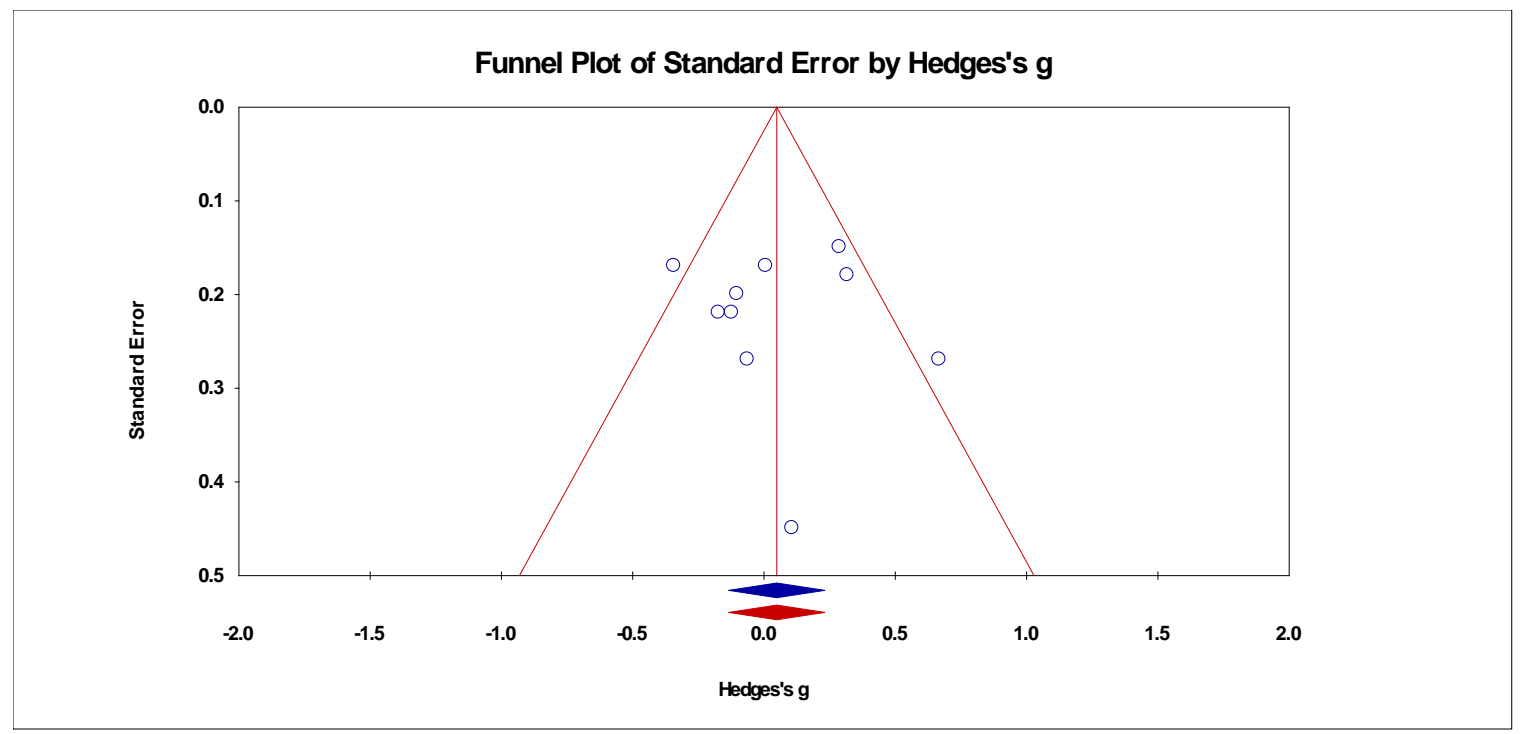

Figure 30. Funnel plot and Duval and Tweedie's trim and fill for HR angry rumination vs. distraction. No studies were trimmed.

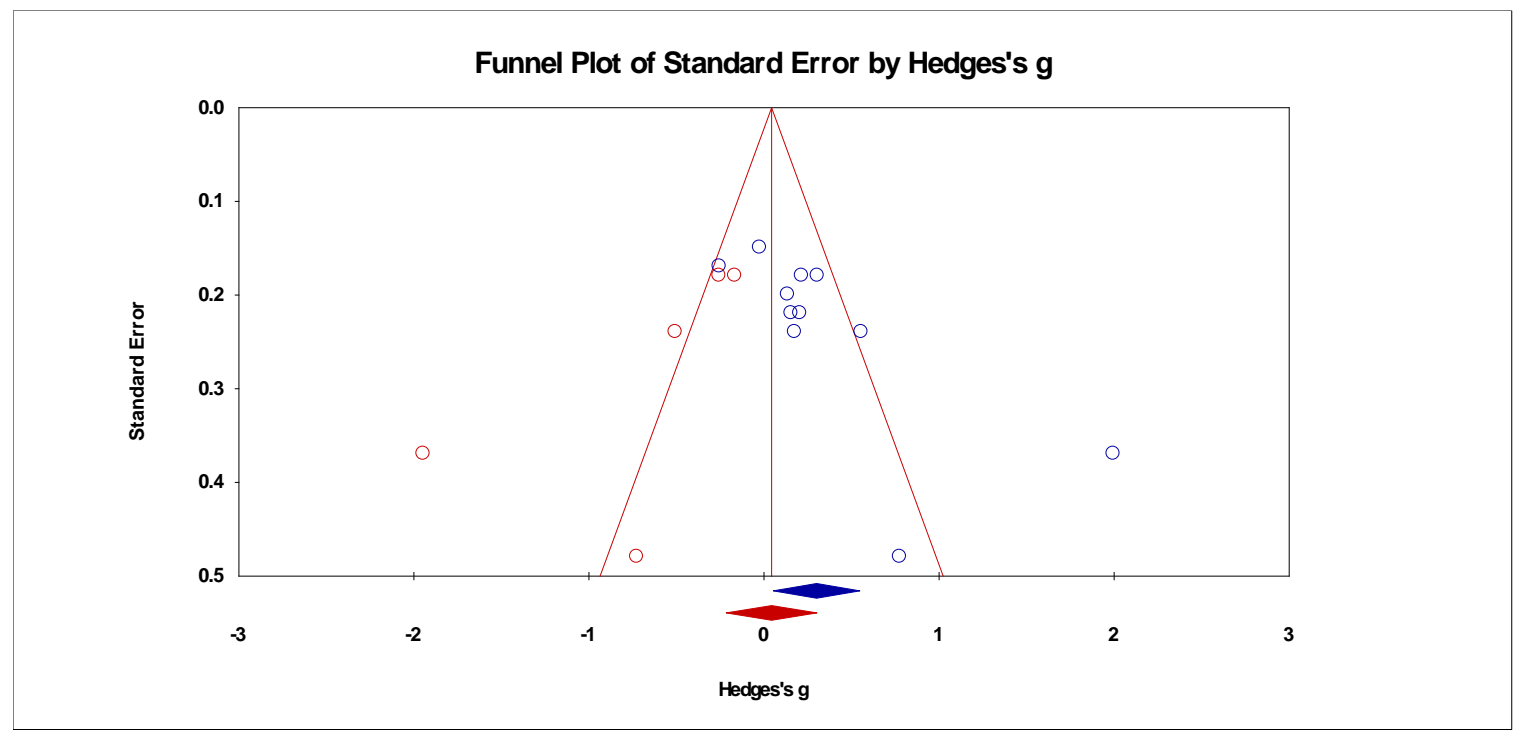

Figure 31. Funnel plot and Duval and Tweedie's trim and fill for DBP angry rumination vs distraction. Five studies were trimmed with an adjusted effect size of Hedges $g=.034$ (95\% CI: .215 to .302$)$. 


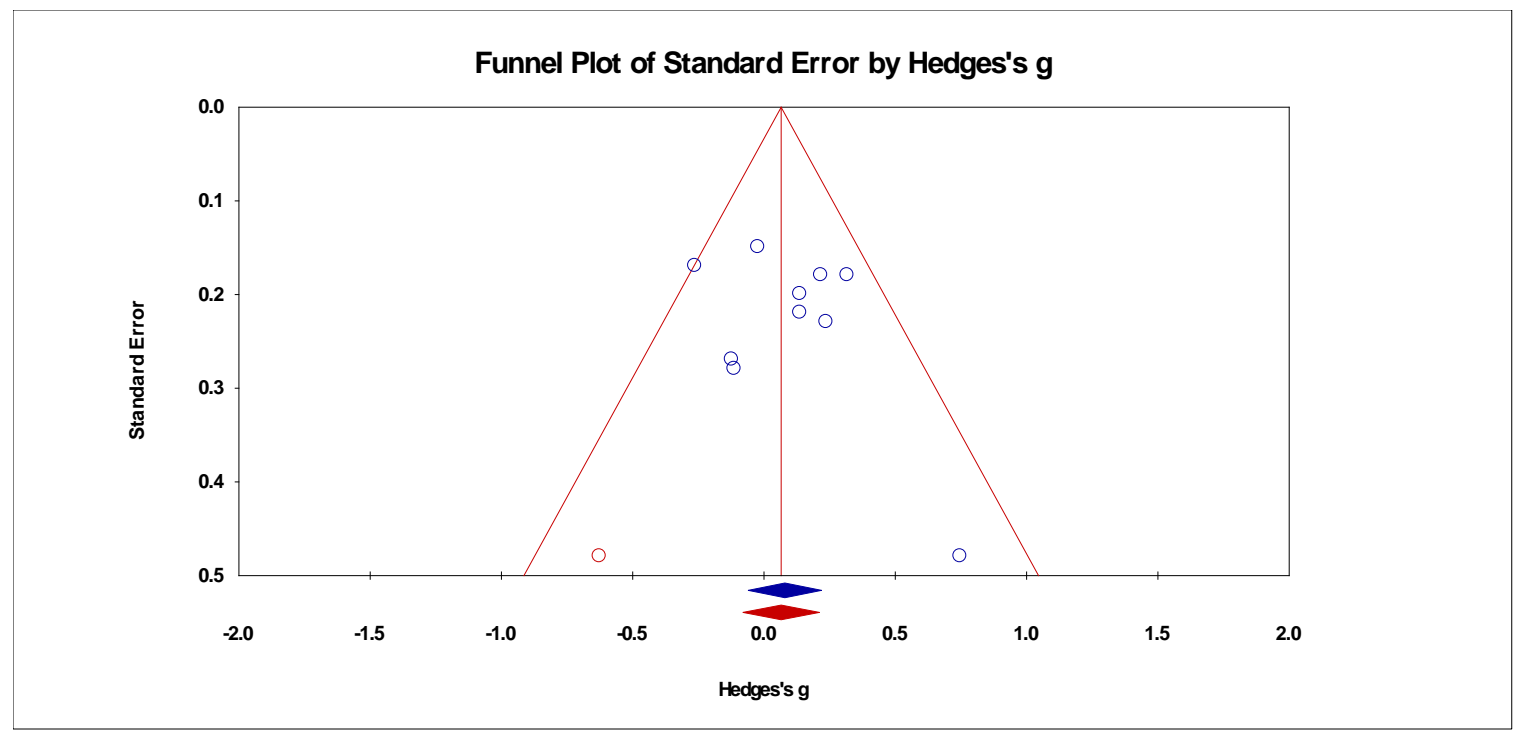

Figure 32. Funnel plot and Duval and Tweedie's trim and fill for SBP angry rumination vs. distraction. One study was trimmed with an adjusted effect size of Hedges $g=.065$ (95\% CI: .080 to .211$)$. 


\section{DISCUSSION}

This study attempted to advance the understanding of rumination as a possible link between depressive and hostile dispositions and CVD by examining the magnitude of cardiovascular responses to corresponding rumination types, and comparing them to rumination on positive emotion. Another goal of this study was to investigate the effectiveness of distraction in reducing cardiovascular responses to rumination by calculating effect size differences between rumination and distraction conditions.

\section{Cardiovascular Responses within Rumination Types}

Sadness Rumination. Results revealed large and significant overall HR, DBP, and SBP effect sizes during induced sadness rumination; suggesting that this emotion regulation strategy common to depressed individuals (Balsamo, 2010) is associated with heightened cardiovascular arousal. The two studies examining cardiovascular recovery following sadness rumination revealed that only SBP was significantly elevated (albeit a small effect size) during recovery. These results indicate that the tendency to engage in sadness rumination could generate repeated acute and prolonged stress responses that may contribute to CVD susceptibility over time, and raise the question of whether extended elevated SBP plays a particularly salient role.

Rumination on Positive Emotion. Results revealed large and significant overall cardiovascular effect sizes during induced rumination on positive emotion, indicating that cognitively reconstructing positive events elicit substantial physiological arousal. While these reactivity results are similar to sadness and angry rumination, such acute 
cardiovascular responses from recalled joyful events may not take on the same trajectory as those associated with negatively-valenced memories and thus, have different health implications. For example, physiological arousal may be of shorter duration for the mental recreation of happy vs. negative events; a pattern that has been supported in the research (e.g., Brosschot \& Thayer, 2003). However, the distinction between mental processes that promote acute vs. prolonged activation is important given that the latter may be a better predictor of poor health outcomes (Brosschot, Gerin, \& Thayer, 2006). Physiological arousal associated with rumination on positive emotion may also differ from other types of rumination through distinct emotion-specific activation of various biological systems. For example, stress (usually associated with negative emotions) is known to elicit an endocrine reaction that increases levels of circulating cortisol; which in turn impacts various biological processes (e.g., making glucose readily available) and behaviors. While this cortisol response is not triggered by positive emotion, joy can prompt the release of oxytocin that promotes social-seeking behaviors and may contribute to lowering of inflammatory markers (Ahmed \& Elosaily, 2011). Thus, while both negative and positive emotions are associated with cardiovascular arousal, interconnected bodily systems likely react to these emotions in specified manners that should be examined in concert with cardiovascular variables in order to fully understand the health implications associated with the different types of rumination.

Angry Rumination. Results revealed large and significant overall HR, DBP, and SBP reactivity effect sizes during angry rumination. Unlike the other rumination types, the magnitude of angry rumination reactivity was significantly larger for both DBP and SBP compared to HR. There was also a significant and moderate SBP recovery effect 
size. Thus, it appears that blood pressure could play a particularly salient role in cardiovascular implications for this emotion coping strategy; with SBP remaining elevated for a sustained period of time. Given that hypertension (high blood pressure) is consistently identified as a prominent risk factor for CVD (e.g., Dawber, Moore, \& Mann, 1957; Yusuf et al., 2004), and that a recent meta-analysis revealed the significant role of elevated SBP in the development of CVD (Peters, Huxley, \& Woodward, 2013); it is important to consider psychological factors contributing to high blood pressure. The current results suggest a possible role for angry rumination in this process via repeated acute and prolonged cardiovascular stress responses.

\section{Cardiovascular Response Comparisons across Rumination Types}

Reactivity effect sizes did not differ significantly across rumination types for each of the cardiovascular variables. However, DBP and SBP recovery effect sizes were significantly greater for angry than sadness rumination; indicating that it may take longer to return to baseline blood pressure levels following angry, rather than sadness, rumination. One explanation for these findings is the possibility of distinct physiological responses for different negative emotions, which has been suggested by some researchers (e.g., Montoya, Campos, \& Schandry, 2005). Nonetheless, the results raise the question of whether a tendency to engage in angry rumination may have greater cardiovascular health ramifications than a tendency to engage in sadness rumination; a question that could be addressed be examining the relationship between trait rumination (the propensity to engage in this emotion coping style) for each of these rumination types and long-term cardiovascular implications. However, much of the initial research on trait 
rumination conceptualizes this concept as a unified construct and limited studies explore a trait rumination-cardiovascular health link.

\section{Rumination vs. Distraction}

Analyses of the effectiveness of distraction in reducing cardiovascular arousal associated with rumination was performed in the context of angry rumination due to lack of such studies incorporating other types of rumination. There was a small significant effect size for DBP only, in which those in angry rumination conditions had higher DBP reactivity than those in distraction conditions. However, the likelihood of publication bias was revealed in this particular analysis, with a trim and fill procedure providing an adjusted effect size that was not significant. This finding, and the lack of significant differences in SBP and HR between angry rumination and distraction conditions, reveals the importance of considering alternate methods for counteracting cardiovascular reactivity and recovery to angry rumination.

Potential alternatives to distraction continue to be identified and show promise in their potential to counteract physiological stress-responses. For example, Ayduk and Kross (2008) demonstrated that forgiving and self-distancing serve as effective alternates to distraction in reducing physiological arousal to anger. Ray, Wilhelm, \& Gross (2008) found that reappraisal of an event from an impartial observer's perspective was effective at decreasing anger and sympathetic arousal compared to ruminating about the event.

Other researchers have demonstrated that social connectedness can diminish blood pressure reactivity and enhance recovery from negative emotional states (Ong \& Allaire, 2005); and therefore, adopting a pro-social stance (e.g., acceptance and compassion) to negative events could potentially offset intense prolonged physiological reactions to 
actual, as well as mentally recreated, stressors. These emotion regulation strategies may not only serve as viable options to distraction; but also provide greater benefits given that seeking social-support and perspective-taking are considered adaptive stress responses. Both distraction and rumination have been thought of as forms of resistance (keeping unpleasant thoughts out of awareness and not letting go of the past, respectively; Key, 2011). Thus, some researchers are investigating the physiological benefits of mindfulness; which seems to be effective at decreasing perseveratory processes, while maintaining awareness of one's internal state (Labelle, Campbell, \& Carlson, 2010). Limited research has directly compared the cardiovascular benefits of mindfulness vs. distraction; with one study revealing no statistical difference between the two (Key, 2011). In sum, the identification and evaluation of alternatives to distraction is a relatively new endeavor, which continues to reveal potential strategies to mitigate the cardiovascular responses of rumination in order to promote optimal psychological and physical health.

\section{Moderating Variables}

Study Design. Moderator analyses revealed that study design factors potentially affect outcomes. Rumination induction method was found to impact the significance of angry rumination for $\mathrm{HR}, \mathrm{DBP}$, and SBP; as well as the significance of rumination on positive emotion for DBP. Rumination induction methods entailing verbalization of thoughts resulted in significantly greater cardiovascular responses for these variables than recall methods prompting imagery without vocalization. These results are consistent with those noted by other researchers, who cite the possibility of physiological arousal from merely speaking (e.g., Girdler et al., 1990). While articulation is one hypothesis to 
account for the differences in effect sizes between verbal and imagery conditions, it is possible that verbalization may prompt increasingly thorough cognitive processing that could elicit greater arousal. Nonetheless, it should be noted that a mechanism associated with oral recall potentially increases physiological arousal beyond that of rumination alone. The lack of moderating effect of rumination condition on sadness rumination may be due to the small sample for this analyses, which contained one study using an imagery recall method.

Another aspect of study design that appears to influence cardiovascular effect size is the duration of rumination, which was found to impact the significance of angry rumination reactivity for $\mathrm{HR}, \mathrm{DBP}$, and $\mathrm{SBP}$. Effect sizes were significantly greater for studies in which participants ruminated between three to six minutes compared to those in which rumination lasted for less than three minutes. Since this distinction was not found for other types of rumination, it may be that angry rumination increases physiological arousal more rapidly than the others (i.e., that a significant increase in reactivity over time is present in other types of rumination if given enough time to ruminate). Further research could investigate the association between rumination length and reactivity to determine if cardiovascular elevations from baseline continue beyond six minutes and at what point they level off. This could provide valuable information as to the implications of cardiovascular risk for people who have difficulty disengaging from rumination once initiated.

Moderator analyses also reveal the importance of considering that study design could influence physiological stress responses in participants. In particular, the significance of angry reactivity for HR was significantly larger for studies in which 
procedures incorporated an anxiety-provoking component; including a blood draw (to obtain plasma biological markers), social-evaluative aspects (e.g., rating of participant responses), or anticipation of an uncomfortable task (e.g., cold-pressor test). It is possible that these stress-inducing aspects of the study design resulted in HR arousal that could be inadvertently attributed to the effects of rumination.

Additional study design moderators include publication status, which impacted the significance of angry rumination recovery for SBP and may merely reflect the tendency for significant SBP results to get published; as well as participants of advanced age (over 60 years old), which impacted the significance of angry rumination recovery for DBP and SBP. These findings align with the research revealing that as people age, they potentially develop emotion-self-regulation strategies that allow improved adaptation and resiliency (e.g., less reactivity) to stressors (Schilling \& Diehl, 2015). Thus, when studying physiological reactions, it is important to consider the possibility of developmental influences on biological functions.

Biological Sex. The hypothesis that biological sex would contribute to variance in cardiovascular reactivity and recovery effect sizes was not supported. This was unexpected, given that men have demonstrated greater cardiovascular responses to angering tasks than women (e.g., Shapiro, Goldstein, \& Jamner, 1995; Vögele, Jarvis, \& Cheeseman, 1997), and it was anticipated that a similar pattern would be found for the mental recreation of angering events. Despite the lack of moderating effect of biological sex on induced rumination in the current study, it is possible that biological sex could moderate a relationship between a tendency to ruminate (i.e., trait rumination) and cardiovascular outcome variables. There is some evidence that this may be the case, given that 
people high on trait rumination have been observed to have exaggerated cardiovascular responses to state rumination compared to those low on trait rumination (e.g., Key et al., 2008; Gerin et al., 2006). Furthermore, research indicates that the tendency to ruminate on angering events may be higher for men than women (Rusting \& Nolen-Hoeksema, 1998); while women have a greater tendency to ruminate in response to sad affect (Grant et al., 2004). Thus, men's higher incidence of CVD (Möller-Leimkühler, 2007) could potentially be related to the frequency of exaggerated cardiovascular responses that reflects a propensity for angry rumination.

Race/Ethnicity. The finding that race/ethnicity did not contribute to variability in cardiovascular responses to induced rumination was also unexpected, but does not necessarily contradict the possibility that rumination may play a role in minorities' increased risk for CVD. As noted for biological sex, race/ethnicity may moderate the relationship between trait rumination and cardiovascular responses, which was not explored in the current analysis investigating state rumination. Prior findings allude to such a relationship, with evidence that racial/ethnic minorities may be more likely to ruminate over stressful events than non-minorities (e.g., Hatzenbuehler, NolenHoeksema, \& Dovidio, 2009; Borders \& Liang, 2011). Thus, racial/ethnic minority individuals may simply experience more events to ruminate about (e.g., discriminatory practices) and hence engage in rumination more frequently than non-racial/ethnic minorities. This tendency may translate into a high level of trait rumination that could correspond with accruing cardiovascular health implications from repeated cardiovascular stress-responses associated with chronic rumination. 


\section{Heart Rate Variability}

Limited studies examine the effects of induced rumination in relation to HRV, which constricted the current HRV analyses to angry rumination. Results revealed a large and significant reactivity effect size and indicate a shift in sympathetic dominance of the autonomic system in response to angry rumination. This pattern was also found in a study by Marci et al. (2007) comparing HRV across different emotional recall conditions, in which angry recall resulted in a significant decrease in HRV that was not found for sadness or positive recall. These findings support the notion that angry rumination in particular may be associated with greater autonomic arousal.

The studies included in the current analyses measure HRV using high frequency (HF) domain measures, which is one of a number of ways in which this construct is indirectly measured. Others include time domain methods, statistical methods, and geometric methods; of which comparability is controversial. Even within the frequency

domain methods, comparability of measurements in low and high frequency (HF), as well as $\mathrm{HF} / \mathrm{LF}$ ratio (in which $\mathrm{HF}$ is thought to correspond to parasympathetic activity and $\mathrm{LF}$ to sympathetic activity) is still being examined (Quintana \& Heathers, 2014). Thus, the finding that HF HRV decreased significantly during angry rumination needs to be considered within this context.

Despite issues related to the measurement and understanding of HRV, this construct is promising as an ideal comprehensive biomarker of overall health. As an indicator of autonomic nervous system functioning, HRV represents inhibitory functions of multiple biological pathways, such as immune and inflammatory systems (Thayer \& Sternberg, 2006; Weber et al., 2010); and therefore may be a superior indicator of CVD 
risk than other cardiovascular variables. Furthermore, decreased HRV has been specifically associated with trait rumination (Neumann et al., 2001) and other emotion regulation processes (Thayer \& Sternberg, 2010) revealing that HRV may help elucidate potential mechanisms linking rumination with health implications.

\section{Limitations}

Limitations of the current study include small sample sizes for sadness rumination and rumination on positive emotion due to the few studies investigating cardiovascular responses to these rumination types. Each of the corresponding analyses entailed fewer than 10 studies, which precluded the analyses of some moderator variables.

The research included in the current analyses revealed many inconsistencies in study procedures, including a lack of standardization by which rumination is induced and methods of creating distraction conditions. For example, there were seven different types of distraction conditions in the 10 rumination vs. distraction studies analyzed, which limits the possibility of subgroup analyses to investigate whether certain types of distraction are associated with greater effect sizes than others. Although coding allowed for the identification and sorting of studies based upon various study variables, this subdivision of studies restricted the sample sizes corresponding to certain study design factors. The current meta-analyses may also be missing important data. Despite attempts to identify unpublished studies, $13.6 \%$ of the studies are from unpublished sources, and publication bias was detected in one analysis.

Another limitation of the current analyses corresponds to variations and inconsistencies in exclusion criteria across included studies. Some studies failed to indicate exclusion criteria; and some were more restrictive than others in their exclusion 
criteria. For example, level of fitness can affect cardiovascular reactivity since research reveals that exercise results in decreased reactivity to psychological stressors (Moreira et al., 2014). However, no study controlled or assessed for this variable. Given that various factors can affect cardiovascular functioning, future research can be improved by taking efforts to control for extraneous variables related to participant health. This would allow for any significant physiological findings of the study to be attributable to the study manipulation rather than participant characteristics.

\section{Contributions and Future Directions}

The findings of this study give rise to future directions regarding the investigation of mechanisms connecting psychological constructs to chronic disease states, such as CVD. There is an obvious need for additional studies investigating the physiological implications of different rumination types. Given the inconsistencies among existing studies, standardization across rumination induction conditions is warranted.

Furthermore, more studies are needed that investigate both trait and state rumination to examine not only the magnitude of physiological arousal associated with rumination induction, but also the implications of its chronic use. The latter may be a key process linking depression and hostility with CVD.

Although limited rumination studies include measures of cardiovascular variables; even more scarce are the inclusion of other biological markers. Given that the body's response to stressors (whether actual or mentally recreated) entail the activation of integrated biological systems, cardiovascular indices alone are not sufficient to gain a full understanding of the physiological implications of rumination. Increases in both cortisol and inflammatory markers have been linked to rumination (Zoccola et al., 2014); and are 
considered important components in the development of CVD (Amar et al., 2006). Furthermore, these biomarkers have been linked to depression (Burke, Davis, Otte, \& Mohr, 2005) and hostility (Izawa, Hirata, Kodama, \& Nomura, 2007), revealing the possibility of their role in linking these dispositions to CVD. Since HRV reflects autonomic function that plays a role in regulating multiple stress-response systems (e.g., cardiovascular and immune), this construct may be a better indication of disease risk that can be used to investigate the mind-body connection in light of multifaceted interrelated physiological processes.

Also scarce in the rumination literature are ambulatory studies, which are important given that stress-response systems contributing to CVD risk may respond at different rates. The autonomic nervous system reacts quicker than the hypothalamicpituitary-adrenal axis (Isowa, Ohira, \& Murashima, 2004), which may manifest as quick HR, DBP, and SBP elevations that return to baseline soon after rumination. Meanwhile, the endocrine system may respond slower with prolonged elevations in stress hormones for hours to days following perseveratory processes. For example, Cropley, Rydstedt, Devereux, and Middleton (2015) found that awakening cortisol was significantly higher for those who were ruminating the previous evening compared to those who were not. Thus, long-term effects of rumination captured through measures taken throughout and beyond a 24-hour cycle may reveal resultant ongoing changes in physiology that can potentially lead to CVD.

The current study indicated the possibility of unique cardiovascular response patterns to the rumination types, which could perhaps correspond to cardiovascular response patterns already identified in the stress response literature. Researchers have 
suggested that people tend to react to stress with typical hemodynamic responses (Sherwood, Turner, Light, \& Blumenthal, 1990), in which some individuals are more likely to experience increased blood pressure reactions to stressors, while others have more of an increase in heart rate. This is important, given that elevated blood pressure has been more closely linked to CVD than HR (Stewart, Janicki, \& Kamarck, 2006). Furthermore, these prototypic reactions appear to be relatively stable over time (Kamarck, Jennings, Pogue-Geile, \& Manuck, 1994). Nevertheless, no one has explored whether particular hemodynamic responses are associated with different types of rumination. However, some studies suggest that angering tasks tend to elicit a vascular resistance response pattern (e.g., Davis, Matthews, \& McGrath, 2000; Sinha, Lovallo, \& Parsons, 1992), raising the question of whether vascular responses may be associated with angry rumination. Hemodynamic patterns that comprise greater arterial pressure are associated with CVD risk (Chrysant \& Chrysant, 2014). Future research could explore whether certain hemodynamic responses are associated with angry rumination, bridging the cardiovascular and rumination research; and shedding light on possible pathways in which rumination could increase risk for CVD.

\section{Summary}

The current study investigated rumination as a possible mechanism linking depression and hostility to CVD. Rumination is an emotion regulation strategy common to people with depressed and hostile dispositions (Balsamo, 2010). According to the perseveratory cognition hypothesis (Brosschot, Gerin, \& Thayer, 2006), this repetitive form of thought prolongs sympathetic arousal both immediately following a stressor and through reactivation of the incident weeks to months later; resulting in chronic 
heightened physiological responses that could contribute to poor health outcomes (Brosschot et al., 2006). However, the magnitude of cardiovascular responses to rumination have not before been investigated. Furthermore, little research exists on the reactivation aspect of rumination and the current study aimed to fill this void by drawing upon the stress-response literature using a recall method (Ironson et al., 1992) similar to those used in rumination studies. Results of the analyses indicate that ruminating about a prior event is associated with substantial cardiovascular reactivity regardless of the type of rumination; and that elevated blood pressure indices during recovery to sadness and angry rumination warrant further investigation into the possible role of these rumination types in the link between depression and hostility with CVD.

This study also examined the extent to which distraction can lower cardiovascular responses compared to angry rumination. These analyses revealed a small effect size for DBP, in which publication bias was detected; and no significant effects for HR and SBP. Results suggest a need to investigate alternative emotion coping strategies to mitigate the large and prolonged cardiovascular arousal associated with rumination. 


\section{REFERENCES}

Abela, J., \& Hankin, B. (2011). Rumination as a vulnerability factor to depression during the transition from early to middle adolescence: a multiwave longitudinal study. Journal of Abnormal Psychology, 120, 259-271.

Adler, R., Macritchie, K., \& Engle, G. L. (1971). Psychological processes and ischemic stroke (occlusive cerebrovascular disease). Psychosomatic Medicine, 33, 1-29.

Ahmed, M. A., \& Elosaily, G. M. (2011). Role of Oxytocin in deceleration of early atherosclerotic inflammatory processes in adult male rats. International Journal of Clinical and Experimental Medicine, 4, 169-178.

American Heart Association (2013, May 9). Science News form Quality of Care and Outcomes Research [Website]. Retrieved from http://my.americanheart.org/professional/Sessions/QCOR/ScienceNews/ScienceNews-QCOR-2013-Friday_UCM_440448_Article.jsp

Anderson, S. F., \& Lawler, K. A. (1995). The Anger Recall Interview and cardiovascular reactivity in women: An examination of context and experience. Journal of Psychosomatic Research, 39, 335-343.

Anderson, N., Lane, J., Taguchi, F., Williams, R., \& Houseworth, S. (1989). Race, parental history of hypertension, and patterns of cardiovascular reactivity in women. Psychophysiology, 26, 39-47.

Anderson, N., McNeilly, M., \& Myers, H. (1991). Autonomic reactivity and hypertension in blacks: a review and proposed model. Ethnicity and Disease, 1, 154-170. 
Averill, J. R. (1983). Studies on anger and aggression: Implications for theories of emotion. American Psychologist, 38, 1145-1160.

Ayduk, Ö., \& Kross, E. (2008). Enhancing the pace of recovery: Self-distanced analysis of negative experiences reduces blood pressure reactivity. Psychological Science, 19, 229-231.

Balsamo, M. (2010). Anger and depression: evidence of a possible mediating role for rumination. Psychological Reports, 106, 3-12.

Barefoot, J., \& Schroll, M. (1996). Symptoms of depression, acute myocardial infarction, and total mortality in a community sample. Circulation, 93, 1976-1980.

Beckham, J. C., Vrana, S. R., Barefoot, J. C., Feldman, M. E., Fairbank, J., \& Moore, S. D. (2002). Magnitude and duration of cardiovascular response to anger in Vietnam veterans with and without posttraumatic stress disorder. Journal of Consulting and Clinical Psychology, 70, 228-234.

Benight, C. C., Segall, G. M., Ford, M. E., Goetsch, V. L., Hays, M. T., \& Taylor, C. B. (1997). Psychological stress and myocardial perfusion in coronary disease patients and healthy controls. Journal of Psychosomatic Research, 42, 137-144.

Borders, A., \& Liang, C. H. (2011). Rumination partially mediates the associations between perceived ethnic discrimination, emotional distress, and aggression. Cultural Diversity and Ethnic Minority Psychology, 17, 125-133.

Brosschot, J., Gerin, W., \& Thayer, J. (2006). The perseverative cognition hypothesis: a review of worry, prolonged stress-related physiological activation, and health. Journal of Psychosomatic Research, 60, 113-124. 
Brosschot, J., Pieper, S., \& Thayer, J. (2005). Expanding stress theory: prolonged activation and perseverative cognition. Psychoneuroendocrinology, 30, 10431049.

Brosschot, J., \& Thayer, J. (2003). Heart rate response is longer after negative emotions than after positive emotions. International Journal of Psychophysiology, 50, 181187.

Brown, R. A. (1999, October). Anger, denial, and cardiovascular reactivity in postmenopausal women. Dissertation Abstracts International, 60, 1525.

Brown, J. P., Katzel, L. I., Neumann, S. A., Maier, K. J., \& Waldstein, S. R. (2007). Silent myocardial ischemia and cardiovascular responses to anger provocation in older adults. International Journal of Behavioral Medicine, 14, 134-140.

Brummett, B. H., Boyle, S. H., Kuhn, C. M., Siegler, I. C., \& Williams, R. B. (2009). Positive affect is associated with cardiovascular reactivity, norepinephrine level, and morning rise in salivary cortisol. Psychophysiology, 46, 862-869.

Burke, H. M., Davis, M. C., Otte, C., \& Mohr, D. C. (2005). Depression and cortisol responses to psychological stress: A meta-analysis. Psychoneuroendocrinology, 30, 846-856.

Burns, J. W. (2006). Arousal of negative emotions and symptom-specific reactivity in chronic low back pain patients. Emotion, 6, 309-319.

Burns, J. W., Kubilus, A., \& Bruehl, S. (2003). Emotion induction moderates effects of anger management style on acute pain sensitivity. Pain, 106, 109-118. 
Bushman, B. J. (2002). Does venting anger feed or extinguish the flame? Catharsis, rumination, distraction, anger and aggressive responding. Personality and Social Psychology Bulletin, 28, 724-731.

Butler, L. D., \& Nolen-Hoeksema, S. (1994). Gender differences in responses to depressed mood in a college sample. Sex Roles, 30, 331-346.

Carels, R. A., Szczepanski, R., Blumenthal, J. A., \& Sherwood, A. (1998). Blood pressure reactivity and marital distress in employed women. Psychosomatic Medicine, 60, 639-643.

Carroll, D., Ginty, A., Der, G., Hunt, K., Benzeval, M., \& Phillips, A. (2012). Increased blood pressure reactions to acute mental stress are associated with 16-year cardiovascular disease mortality. Psychophysiology, 49, 1444-1448.

Carroll, D., Ring, C., Hunt, K., Ford, G., \& Macintyre, S. (2003). Blood pressure reactions to stress and the prediction of future blood pressure: effects of sex, age, and socioeconomic position. Psychosomatic Medicine, 65, 1058-1064.

Charlson, F., Stapelberg, N., Baxter, A., \& Whiteford, H. (2011). Should global burden of disease estimates include depression as a risk factor for coronary heart disease? BMC Medicine, 9, 47-52.

Chida, Y., \& Hamer, M. (2008). Chronic psychosocial factors and acute physiological responses to laboratory-induced stress in healthy populations: A quantitative review of 30 years of investigations. Psychological Bulletin, 134, 829-885.

Chida, Y., \& Steptoe, A. (2009). The association of anger and hostility with future coronary heart disease: a meta-analytic review of prospective evidence. Journal of the American College of Cardiology, 53, 936-946. 
Chida, Y. \& Steptoe, A. (2010). Greater cardiovascular responses to laboratory mental stress are associated with poor subsequent cardiovascular risk status: a metaanalysis of prospective evidence. Hypertension, 55, 1026-1032.

Chrysant, S. G., \& Chrysant, G. S. (2014). The age-related hemodynamic changes of blood pressure and their impact on the incidence of cardiovascular disease and stroke: new evidence. Journal of Clinical Hypertension, 16, 87-90.

Cohen, O. (2010). The effects of sociotropy and cognitive rumination on blood pressure recovery. Dissertation Abstracts International, 70, 5224.

Cooney, M. T., Vartiainen, E., Laatikainen, T., Juolevi, A., Dudina, A., \& Graham, I. M. (2010). Elevated resting heart rate is an independent risk factor for cardiovascular disease in healthy men and women. American Heart Journal,159, 612-619.

Cooper, D. C., Thayer, J. F., \& Waldstein, S. R. (2014). Coping with racism: The impact of prayer on cardiovascular reactivity and post-stress recovery in African American women. Annals of Behavioral Medicine, 47, 218-230.

Cropley, M., Rydstedt, L. W., Devereux, J. J., \& Middleton, B. (2015). The relationship between work-related rumination and evening and morning salivary cortisol secretion. Stress and Health: Journal of The International Society for The Investigation of Stress, 31, 150-157.

Cui, L., \& Huang, M. (2007). Effects of rumination and distraction on negative emotion and autobiographical memory. Acta Psychologica Sinica, 39, 78-87.

Davis, M. C., Matthews, K. A., \& McGrath, C. E. (2000). Hostile attitudes predict elevated vascular resistance during interpersonal stress in men and women. Psychosomatic Medicine, 62, 17-25. 
Dawber, T. R., Moore, F. E., \& Mann, G. V. (1957). Coronary heart disease in the Framingham study. American Journal of Public Health and the Nation's Health, 47, 4-24.

Denton, E. D., Rieckmann, N., Davidson, K. W., \& Chaplin, W. F. (2012). Psychosocial vulnerabilities to depression after acute coronary syndrome: The pivotal role of rumination in predicting and maintaining depression. Frontiers in Psychology, 3, 1-9.

Dickson, K., Ciesla, J., \& Reilly, L. (2012). Rumination, worry, cognitive avoidance, and behavioral avoidance: examination of temporal effects. Behavior Therapy, 43, $629-640$.

Ditto, B., Miller, S. B., \& Maurice, S. (1987). Age differences in the consistency of cardiovascular response patterns in healthy women. Biological Psychology, 25(1), 23-31.

Eaton, C. (2005). Traditional and emerging risk factors for cardiovascular disease. Primary Care, 32, 963.

Eckhardt, C., Norlander, B., \& Deffenbacher, J. (2004). The assessment of anger and hostility: A critical review. Aggression and Violent Behavior, 9, 17-43.

Faucheux, B., Lille, F., Baulon, A., Landau, J., Dupuis, C., \& Bourlière, F. (1989). Heart rate and blood pressure reactivity during active coping with a mental task in healthy 18- to 73-year-old subjects. Gerontology, 35, 19-30.

Falkner, B. (1993). Developmental vascular biology and the early phases of essential hypertension in the young. Journal of Human Hypertension, 7, 221-222. 
Feldman, G., Joormann, J., \& Johnson, S. (2008). Responses to positive affect: A selfreport measure of rumination and dampening. Cognitive Therapy and Research, 32, 507-525.

Ford, E., \& Capewell, S. (2007). Coronary heart disease mortality among young adults in the U.S. from 1980 through 2002: concealed leveling of mortality rates. Journal of the American College of Cardiology, 50, 2128-2132.

Foster, P. S., Smith, E. L., \& Webster, D. G. (1998). The psychophysiological differentiation of actual, imagined, and recollected anger. Imagination, Cognition and Personality, 18, 189-203.

Foster, P. S., Webster, D. G., \& Smith, E. L. (1997). The psychophysiological differentiation of emotional memories. Imagination, Cognition and Personality, $17,111-122$.

Fredrickson, B. L., Maynard, K. E., Helms, M. J., Haney, T. L., Siegler, I. C., \& Barefoot, J. C. (2000). Hostility predicts magnitude and duration of blood pressure response to anger. Journal of Behavioral Medicine, 23, 229-243.

Friedberg, J. P., Suchday, S., \& Shelov, D. V. (2007). The impact of forgiveness on cardiovascular reactivity and recovery. International Journal of Psychophysiology, 65, 87-94.

Fryar, C., Hirsch, R., Eberhardt, M., Yoon, S., \& Wright, J. (2010). Hypertension, high serum total cholesterol, and diabetes: racial and ethnic prevalence differences in U.S. adults, 1999-2006, NCHS Data Brief, 36, 1-8. 
Futterman, L. \& Lemberg, L. (1998). Fifty percent of patients with coronary artery disease do not have any of the conventional risk factors. American Journal of Critical Care, 7, 240-244.

Gerin W., Pickering T.G., Glynn L., Christenfeld N., Schwartz A., Carroll D., Davidson K. (2000). An historical context for behavioral models of hypertension. Journal of Psychosomatic Research, 48, 369-77.

Gerin, W., Davidson, K., Christenfeld, N., Goyal, T., \& Schwartz, J. (2006). The role of angry rumination and distraction in blood pressure recovery from emotional arousal. Psychosomatic Medicine, 68, 64-72.

Gerin, W., Zawadzki, M., Brosschot, J., Thayer, J., Christenfeld, N., Campbell, T., \& Smyth, J. (2012). Rumination as a mediator of chronic stress effects on hypertension: a causal model. International Journal of Hypertension, 2012, $453-$ 465.

Girdler, S., Turner, J., Sherwood, A., \& Light, K. (1990). Gender differences in blood pressure control during a variety of behavioral stressors. Psychosomatic Medicine, $52,571-591$.

Glassman, A., \& Shapiro, P. (1998). Depression and the course of coronary artery disease. American Journal of Psychiatry, 155, 4-11.

Glynn, L., Christenfeld, N., \& Gerin, W. (2007). Recreating cardiovascular responses with rumination: the effects of a delay between harassment and its recall. International Journal of Psychophysiology, 66, 135-140. 
Glynn, L., Christenfeld, N., \& Gerin, W. (2002). The role of rumination in recovery from reactivity: cardiovascular consequences of emotional states. Psychosomatic Medicine, 64, 714-726.

Grant, K., Lyons, A., Finkelstein, J., Conway, K., Reynolds, L., O'Koon, J., Waitkoff, J.R., \& Hicks, K. J. (2004). Gender differences in rates of depressive symptoms among low-income, urban, African American youth: A test of two mediational hypotheses. Journal of Youth and Adolescence, 33, 523-533.

Greeson, J. M., Lewis, J. G., Achanzar, K., Zimmerman, E., Young, K. H., \& Suarez, E. C. (2009). Stress-induced changes in the expression of monocytic $\beta_{2}$-integrins: The impact of arousal of negative affect and adrenergic responses to the Anger Recall Interview. Brain, Behavior, and Immunity, 23, 251-256.

Gruber, J., Eidelman, P., Johnson, S., Smith, B., \& Harvey, A. (2011). Hooked on a feeling: rumination about positive and negative emotion in inter-episode bipolar disorder. Journal of Abnormal Psychology, 120, 956-961.

Haas, D., Davidson, K., Schwartz, D., Rieckmann, N., Roman, M., Pickering, T., Gerin, W., \& Schwartz, J. (2005). Depressive symptoms are independently predictive of carotid atherosclerosis. American Journal of Cardiology, 95, 547-550.

Haensel, A., Mills, P. J., Nelesen, R. A., Ziegler, M. G., \& Dimsdale, J. E. (2008). The relationship between heart rate variability and inflammatory markers in cardiovascular diseases. Psychoneuroendocrinology, 33, 1305-1312.

Hatzenbuehler, M. L., Nolen-Hoeksema, S., \& Dovidio, J. (2009). How does stigma 'get under the skin'?: The mediating role of emotion regulation. Psychological Science, 20, 1282-1289. 
Hedges, L. V. (1981). Distribution theory for Glass's estimator of effect size and related estimators. Journal of Educational Statistics, 6, 107-128.

Henninger, M. L. (2001, March). The effects of defensiveness and hostility on cardiovascular reactivity during an anger-recall interview. Dissertation Abstracts International, 61, 5044.

Herrald, M., \& Tomaka, J. (2002). Patterns of emotion-specific appraisal, coping, and cardiovascular reactivity during an ongoing emotional episode. Journal of Personality and Social Psychology, 83, 434-450.

Hidaka, B. H. (2012). Depression as a disease of modernity: Explanations for increasing prevalence. Journal of Affective Disorders, 140, 205-214.

Huisman, H., Schutte, A., Schutte, R., van Rooyen, J., Fourie, C., Mels, C., Smith, W., Malan N.T., \& Malan, L. (2013). Exploring the link between cardiovascular reactivity and end-organ damage in African and Caucasian men: the SABPA study. American Journal of Hypertension, 26, 68-75.

Ironson, G., Taylor, C., Boltwood, M., Bartzokis, T., Dennis, C., Chesney, M., Spitzer, S., \& Segall, G. (1992). Effects of anger on left ventricular ejection fraction in coronary artery disease. American Journal of Cardiology, 70, 281-285.

Isowa, T., Ohira, H., \& Murashima, S. (2004). Reactivity of immune, endocrine and cardiovascular parameters to active and passive acute stress. Biological Psychology, 65, 101-120.

Izawa, S., Hirata, U., Kodama, M., \& Nomura, S. (2007). Effect of hostility on salivary cortisol levels in university students. Japanese Journal of Psychology, 78, 277283. 
James, G., Yee, L., Harshfield, G., Blank, S., \& Pickering, T. (1986). The influence of happiness, anger, and anxiety on the blood pressure of borderline hypertensives. Psychosomatic Medicine, 48, 502-508.

Jonassaint, C. R., Why, Y. P., Bishop, G. D., Tong, E. M., Diong, S. M., Enkelmann, H. C., Khader, M., \& Ang, J. (2009). The effects of neuroticism and extraversion on cardiovascular reactivity during a mental and an emotional stress task. International Journal of Psychophysiology, 74, 274-279.

Kamarck, T. W., Jennings, J. R., Pogue-Geile, M., \& Manuck, S. B. (1994). A multidimensional measurement model for cardiovascular reactivity: Stability and cross-validation in two adult samples. Health Psychology, 13, 471-478.

Kaplan, G., \& Keil, J. (1993). Socioeconomic factors and cardiovascular disease: a review of the literature. Circulation, 88, 1973-1998.

Kario, K., Schwartz, J. E., Gerin, W., Robayo, N., Maceo, E., \& Pickering, T. G. (2002). Psychological and physical stress-induced cardiovascular reactivity and diurnal blood pressure variation in women with different work shifts. Hypertension Research, 25, 543-551.

Kassinove, H., \& Sukhodolsky, D. G. (1995). Anger disorders: Basic science and practice issues. Issues in Comprehensive Pediatric Nursing, 18, 173-205.

Kawachi, I., Sparrow, D., Spiro, A., Vokonas, P., \& Weiss, S. (1996). A prospective study of anger and coronary heart disease. The Normative Aging Study. Circulation, 94, 2090-2095. 
Kelishadi, R., \& Poursafa, P. (2014). A review on the genetic, environmental, and lifestyle aspects of the early-life origins of cardiovascular disease. Current Problems in Pediatric and Adolescent Health Care, 44, 54-72.

Kessler, R. C., Petukhova, M., Sampson, N. A., Zaslavsky, A., \& Wittchen, H. (2012). Twelve-month and lifetime prevalence and lifetime morbid risk of anxiety and mood disorders in the United States. International Journal of Methods in Psychiatric Research, 21, 169-184.

Key, B. (2011). The influence of rumination, distraction and mindfulness on cardiovascular recovery from stress. Dissertation Abstracts International, 72.

Kross, E., Ayduk, O., \& Mischel, W. (2005). When asking 'why' does not hurt: Distinguishing rumination from reflective processing of negative emotions. Psychological Science, 16, 709-715.

Larsen, B., \& Christenfeld, N. (2009). Cardiovascular disease and psychiatric comorbidity: the potential role of perseverative cognition. Cardiovascular Psychiatry and Neurology, 2009, 1-8.

Labelle, L. E., Campbell, T. S., \& Carlson, L. E. (2010). Mindfulness-based stress reduction in oncology: Evaluating mindfulness and rumination as mediators of change in depressive symptoms. Mindfulness, 1, 28-40.

Lawler, K., Wilcox, Z., \& Anderson, S. (1995). Gender differences in patterns of dynamic cardiovascular regulation. Psychosomatic Medicine, 57, 357-365.

Lepore, S., Revenson, T., Weinberger, S., Weston, P., Frisina, P., Robertson, R., \& ... Cross, W. (2006). Effects of social stressors on cardiovascular reactivity in Black and White women. Annals of Behavioral Medicine, 31, 120-127. 
Lespérance, F., Frasure-Smith, N., \& Talajic, M. (1996). Major depression before and after Myocardial Infarction: Its nature and consequences. Psychosomatic Medicine, 58, 99-110.

Lewington, S., \& MacMahon, S. (1999). Blood pressure, cholesterol, and common causes of death: a review. American Journal of Hypertension, 12, 96-98.

Lineberger, M. D. (2005). Habituation of anger revisited: Magnitude and duration of cardiovascular response following repeated emotional activation. Dissertation Abstracts International, 65, 6052.

Lipsey, M. W., \& Wilson, D. B. (2001). Practical meta-analysis. Thousand Oaks, CA US: Sage Publications, Inc.

Lloyd-Jones, D., Hong, Y., Labarthe, D., Mozaffarian, D., Appel, L., Van Horn, L., \& ... Rosamond, W. (2010). Defining and setting national goals for cardiovascular health promotion and disease reduction: the American Heart Association's strategic Impact Goal through 2020 and beyond. Circulation, 121, 586-613.

Lovallo, W. (2010). Cardiovascular responses to stress and disease outcomes: a test of the reactivity hypothesis. Hypertension, 55, 842-843.

Lyubomirsky, S., Caldwell, N.D., \& Nolen-Hoeksema, S. (1998). Effects of ruminative and distracting responses to depressed mood on retrieval of autobiographical memories. Journal of Personality and Social Psychology, 75, 166-177.

Manuck, S. B., Kasprowicz, A. L., \& Muldoon, M. F. (1990). Behaviorally-evoked cardiovascular reactivity and hypertension: Conceptual issues and potential associations. Annals of Behavioral Medicine, 12, 17-29. 
Marci, C. D., Glick, D. M., Loh, R., \& Dougherty, D. D. (2007). Autonomic and prefrontal cortex responses to autobiographical recall of emotions. Cognitive, Affective \& Behavioral Neuroscience, 7, 243-250.

Martin, L. L., \& Tesser, A. (1996). Some ruminative thoughts. In R. r. Wyer (Ed.). Ruminative thoughts (pp. 1-47). Hillsdale, NJ England: Lawrence Erlbaum Associates, Inc.

Mauss, I. B., Cook, C. L., Cheng, J. J., \& Gross, J. J. (2007). Individual differences in cognitive reappraisal: Experiential and physiological responses to an anger provocation. International Journal of Psychophysiology, 66, 116-124.

McEwen, B. (1998). Stress, adaptation, and disease. Allostasis and allostatic load. Annals of the New York Academy of Sciences, 840, 33-44.

McLain, M. K. (2010). The effects of rumination, hostility, and distraction on cardiovascular reactivity and recovery from anger recall in healthy women. Dissertation Abstracts International, 71, 3940.

Merritt, M., Bennett, G., Williams, R., Edwards, C., \& Sollers, J. (2006). Perceived racism and cardiovascular reactivity and recovery to personally relevant stress. Health Psychology, 25, 364-369.

Meyer, C. (2004). Depressive disorders were the fourth leading cause of global disease burden in the year 2000. Evidence Based Mental Health, 7, 123.

Miller, S., Dolgoy, L., Friese, M., \& Sita, A. (1996). Dimensions of hostility and cardiovascular response to interpersonal stress. Journal of Psychosomatic Research, 41, 81-95. 
Miller, T., Smith, T., Turner, C., Guijarro, M., \& Hallet, A. (1996). A meta-analytic review of research on hostility and physical health. Psychological Bulletin, 119, $322-348$.

Möller-Leimkühler, A. (2007). Gender differences in cardiovascular disease and comorbid depression. Dialogues in Clinical Neuroscience, 9, 71-83.

Montoya, P., Campos, J. J., \& Schandry, R. (2005). See red? Turn pale? Unveiling Emotions through Cardiovascular and Hemodynamic Changes. The Spanish Journal of Psychology, 8, 79-85.

Moreira, S. R., Lima, R. M., Silva, K. S., \& Simões, H. G. (2014). Combined exercise circuit session acutely attenuates stress-induced blood pressure reactivity in healthy adults. Brazilian Journal of Physical Therapy, 18, 38-46.

Neumann, S., \& Waldstein, S. (2001). Similar patterns of cardiovascular response during emotional activation as a function of affective valence and arousal and gender. Journal of Psychosomatic Research, 50, 245-253.

Neumann, S. A., Waldstein, S. R., Sellers, J. I., Thayer, J. F., \& Sorkin, J. D. (2004). Hostility and Distraction Have Differential Influences on Cardiovascular Recovery From Anger Recall in Women. Health Psychology, 23, 631-640.

Nolen-Hoeksema, S. (1991). Responses to depression and their effects on the duration of depressive episodes. Journal of Abnormal Psychology, 100, 569-582.

Nolen-Hoeksema, S. \& Jackson, B. (2001). Mediators of the gender difference in rumination. Psychology of Women Quarterly, 25, 37-47. 
Nolen-Hoeksema, S., Larson, J., \& Grayson, C. (1999). Explaining the gender difference in depressive symptoms. Journal of Personality and Social Psychology, 77, 10611072.

Nolen-Hoeksema, S., \& Morrow, J. (1993). Effects of rumination and distraction on naturally occurring depressed mood. Cognition and Emotion, 7, 561-570.

Nolen-Hoeksema, S., Wisco, B., \& Lyubomirsky, S. (2008). Rethinking rumination. Perspectives on Psychological Science, 3, 400-424.

Ong, A. D., \& Allaire, J. C. (2005). Cardiovascular Intraindividual Variability in Later Life: The Influence of Social Connectedness and Positive Emotions. Psychology and Aging, 20, 476-485.

Ottaviani, C., \& Shapiro, D. (2011). Do we need a stressor to be stressed? Insights from cardiac regulation. Japanese Psychological Research, 53, 155-162.

Ottaviani, C., Shapiro, D., Davydov, D., Goldstein, I., \& Mills, P. (2009). The autonomic phenotype of rumination. International Journal of Psychophysiology, 72, 267275.

Ottaviani, C., Shapiro, D., \& Fitzgerald, L. (2011). Rumination in the laboratory: What happens when you go back to everyday life? Psychophysiology, 48, 453-461.

Palatini, P. (2011). Role of elevated heart rate in the development of cardiovascular disease in hypertension. Hypertension, 58, 745-750.

Pedersen, W., Denson, T., Goss, R., Vasquez, E., Kelley, N., \& Miller, N. (2011). The impact of rumination on aggressive thoughts, feelings, arousal, and behaviour. British Journal of Social Psychology, 50, 281-301. 
Peled, M., \& Moretti, M. M. (2010). Ruminating on rumination: Are rumination on anger and sadness differentially related to aggression and depressed mood? Journal of Psychopathology and Behavioral Assessment, 32, 108-117.

Peters, S. E., Huxley, R. R., \& Woodward, M. (2013). Comparison of the sex-specific associations between systolic blood pressure and the risk of cardiovascular disease: a systematic review and meta-analysis of 124 cohort studies, including 1.2 million individuals. Stroke; A Journal of Cerebral Circulation, 44, 23942401.

Porges, S. (2009). The polyvagal theory: new insights into adaptive reactions of the autonomic nervous system. Cleveland Clinic Journal of Medicine, 76, 86-90.

Pössel, P., Mitchell, A. M., Ronkainen, K., Kaplan, G. A., Kauhanen, J., \& Valtonen, M. (2013). Do depressive symptoms predict the incidence of myocardial infarction independent of hopelessness? Journal of Health Psychology, 20, 60-68.

Pratt, L. A., Ford, D. E., Crum, R. M., Armenian, H. K., Gallo, J. J., \& Eaton, W. W. (1996). Depression, psychotropic medication, and risk of myocardial infarction.

Prospective data from the Baltimore ECA follow-up. Circulation, 94, 3123-3129.

Prkachin, K., Williams-Avery, R., Zwaal, C., \& Mills, D. (1999). Cardiovascular changes during induced emotion: an application of Lang's theory of emotional imagery. Journal of Psychosomatic Research, 47, 255-267.

Quintana, D. S., \& Heathers, J. J. (2014). Considerations in the assessment of heart rate variability in biobehavioral research. Frontiers in Psychology, 5805. 
Radstaak, M., Geurts, S., Brosschot, J., Cillessen, A., \& Kompier, M. (2011). The role of affect and rumination in cardiovascular recovery from stress. International Journal of Psychophysiology, 81, 237-244.

Radstaak, M., Geurts, S. E., Brosschot, J. F., \& Kompier, M. J. (2014). Music and psychophysiological recovery from stress. Psychosomatic Medicine, 76, 529-537.

Raes, F., Daems, K., Feldman, G. C., Johnson, S. L., \& Van Gucht, D. (2009). A psychometric evaluation of the Dutch version of the Responses to Positive Affect Questionnaire. Psychologica Belgica, 49, 293-310.

Rainville, P., Bechara, A., Naqvi, N., \& Damasio, A. (2006). Basic emotions are associated with distinct patterns of cardiorespiratory activity. International Journal of Psychophysiology, 61, 5-18.

Ratnasingam, P., \& Bishop, G. D. (2007). Social support schemas, trait anger, and cardiovascular responses. International Journal of Psychophysiology, 63, 308316.

Ray, R. D., Wilhelm, F. H., \& Gross, J. J. (2008). All in the mind's eye? Anger rumination and reappraisal. Journal of Personality and Social Psychology, 94, $133-145$.

Richman, L. S., Bennett, G. G., Pek, J., Siegler, I., \& Williams, R. J. (2007). Discrimination, dispositions, and cardiovascular responses to stress. Health Psychology, 26, 675-683.

Rimes, K., \& Watkins, E. (2005). The effects of self-focused rumination on global negative self-judgements in depression. Behaviour Research and Therapy, 43, 1673-1681. 
Roberts, R., \& Weerts, T. (1982). Cardiovascular responding during anger and fear imagery. Psychological Reports, 50, 219-230.

Rugulies, R. (2002). Depression as a predictor for coronary heart disease. A review and meta-analysis. American Journal of Preventive Medicine, 23, 51-61.

Ruiz, J. M. (2003, April). Anger expression as social influence: Effects on cardiovascular reactivity and recovery, and the impact of rumination. Dissertation Abstracts International, 63, 4957.

Rusting, C., \& Nolen-Hoeksema, S. (1998). Regulating responses to anger: effects of rumination and distraction on angry mood. Journal of Personality and Social Psychology, 74, 790-803.

Rutledge, T., Linden, W., \& Paul, D. (2001). The stability of cardiovascular reactivity: Effects of task-type and family history over a 3-yr interval. International Journal of Behavioral Medicine, 8, 293-303.

Rutledge, T., Reis, V. A., Linke, S. E., Greenberg, B. H., \& Mills, P. J. (2006). Depression in Heart Failure: A Meta-Analytic Review of Prevalence, Intervention Effects, and Associations with Clinical Outcomes. Journal of the American College of Cardiology, 48, 1527-1537.

Schilling, O. K., \& Diehl, M. (2015). Psychological vulnerability to daily stressors in old age: Results of short-term longitudinal studies. Zeitschrift Für Gerontologie Und Geriatrie, 48, 517-523.

Schwartz, A., Gerin, W., Davidson, K., Pickering, T., Brosschot, J., Thayer, J., \& ... Linden, W. (2003). Toward a causal model of cardiovascular responses to stress 
and the development of cardiovascular disease. Psychosomatic Medicine, 65, 2235.

Shapiro, D., Goldstein, I. B., \& Jamner, L. D. (1995). Effects of anger/hostility, defensiveness, gender, and family history of hypertension on cardiovascular reactivity. Psychophysiology, 32, 425-435.

Sherwood, A., Turner, J. R., Light, K. C., \& Blumenthal, J. A. (1990). Temporal stability of the hemodynamics of cardiovascular reactivity. International Journal of Psychophysiology, 10, 95-98.

Sinha, R., Lovallo, W., \& Parsons, O. (1992). Cardiovascular differentiation of emotions. Psychosomatic Medicine, 54, 422-435.

Smeijers, L., Szabó, B. M., van Dammen, L., Wonnink, W., Jakobs, B. S., Bosch, J. A., \& Kop, W. J. (2015). Emotional, neurohormonal, and hemodynamic responses to mental stress in Tako-Tsubo cardiomyopathy. American Journal of Cardiology, $115,1580-1586$.

Stewart, J. C., Janicki, D. L., \& Kamarck, T. W. (2006). Cardiovascular reactivity to and recovery from psychological challenge as predictors of 3-year change in blood pressure. Health Psychology, 25, 111-118.

Strike, P., \& Steptoe, A. (2004). Psychosocial factors in the development of coronary artery disease. Progress in Cardiovascular Diseases, 46, 337-347.

Suarez, E. C., Saab, P. G., Llabre, M. M., Kuhn, C. M., \& Zimmerman, E. (2004). Ethnicity, gender, and age effects on adrenoceptors and physiological responses to emotional stress. Psychophysiology, 41, 450-460. 
Synowski, S. J. (2008). The effects of an oral glucose challenge on cardiovascular responses to mental stress. Dissertation Abstracts International, 68, 7016.

Taylor, S., \& Tweedie, R. (2000). A nonparametric "trim and fill" method of accounting for publication bias in meta-analysis. Journal of the American Statistical Association, 95, 89-98.

Thayer, R. E., Newman, J. R., \& McClain, T. M. (1994). Self-regulation of mood: Strategies for changing a bad mood, raising energy, and reducing tension. Journal of Personality and Social Psychology, 67, 910-925.

Thayer, J. F., \& Sternberg, E. M. (2010). Neural aspects of immunomodulation: Focus on the vagus nerve. Brain, Behavior, and Immunity, 24, 1223-1228.

Treiber, F. A., Kamarck, T., Schneiderman, N., Sheffield, D., Kapuku, G., \& Taylor, T. (2003). Cardiovascular reactivity and development of preclinical and clinical disease states. Psychosomatic Medicine, 65, 46-62.

Van der Kooy, K., van Hout, H., Marwijk, H., Marten, H., Stehouwer, C., \& Beekman, A. (2007). Depression and the risk for cardiovascular diseases: Systematic review and meta analysis. International Journal of Geriatric Psychiatry, 22, 613-626.

Vaughn, A. (2008). The effects of relationship quality and distraction on cardiovascular reactivity and recovery in a social support context. Dissertation Abstracts International, 69, 3903.

Velasco, C., \& Bond, A. (1998). Personal relevance is an important dimension for visceral reactivity in emotional imagery. Cognition and Emotion, 12, 231-242. 
Verkuil, B., Brosschot, J. F., Gebhardt, W. A., \& Thayer, J. F. (2010). When worries make you sick: A review of perseverative cognition, the default stress response and somatic health. Journal of Experimental Psychopathology, 1, 87-118.

Vickers, K. S., \& Vogeltanz-Holm, N. D. (2003). The Effects of Rumination and Distraction Tasks on Psychophysiological Responses and Mood in Dysphoric and Nondysphoric Individuals. Cognitive Therapy and Research, 27, 331-348.

Vögele, C., Jarvis, A., \& Cheeseman, K. (1997). Anger suppression, reactivity, and hypertension risk: Gender makes a difference. Annals of Behavioral Medicine, 19, 61-69.

Vogeltanz-Holm, N. D., \& Vickers, K. S. (2003). The effects of rumination and distraction tasks on psychophysiological responses and mood in dysphoric and nondysphoric individuals. Cognitive Therapy and Research, 27, 331-348.

Vrana, S. R., Hughes, J. W., Dennis, M. F., Calhoun, P. S., \& Beckham, J. C. (2009). Effects of posttraumatic stress disorder status and covert hostility on cardiovascular responses to relived anger in women with and without PTSD. Biological Psychology, 82, 274-280.

Waldstein, S. R., Kauhanen, J., Neumann, S. A., \& Katzel, L. I. (2002). Alexithymia and cardiovascular risk in older adults: Psychosocial, psychophysiological, and biomedical correlates. Psychology \& Health, 17, 597-610.

Waldstein, S., Kop, W., Schmidt, L., Haufler, A., Krantz, D., \& Fox, N. (2000). Frontal electrocortical and cardiovascular reactivity during happiness and anger. Biological Psychology, 55, 3-23. 
Weber, C. S., Thayer, J. F., Rudat, M., Wirtz, P. H., Zimmermann-Viehoff, F., Thomas, A., \& ... Deter, H. C. (2010). Low vagal tone is associated with impaired post stress recovery of cardiovascular, endocrine, and immune markers. European Journal of Applied Physiology, 109, 201-211.

Why, Y. P., Bishop, G. D., Tong, E. W., Diong, S. M., Enkelmann, H. C., Khader, M., \& Ang, J. (2003). Cardiovascular reactivity of Singaporean male police officers as a function of task, ethnicity and hostility. International Journal of Psychophysiology, 49, 99-110.

Why, Y. P., \& Johnston, D. W. (2008). Cynicism, anger and cardiovascular reactivity during anger recall and human-computer interaction. International Journal of Psychophysiology, 68, 219-227.

Wilkowski, B. M., \& Robinson, M. D. (2010). The Anatomy of Anger: An Integrative Cognitive Model of Trait Anger and Reactive Aggression. Journal of Personality, 78, 9-38.

Winkeljohn Black, S. \& Pössel, P. (2013). The combined effects of self-referent information processing and ruminative responses on adolescent depression. Journal of Youth and Adolescence, 42, 1145-1154.

Yusuf, S., Hawken, S., Ounpuu, S., Dans, T., Avezum, A., Lanas, F., \& ... Lisheng, L. (2004). Effect of potentially modifiable risk factors associated with myocardial infarction in 52 countries (the INTERHEART study): case-control study. Lancet, $364,937-952$.

Zhang, Z., \& Hayward, M. D. (2006). Gender, the marital life course, and cardiovascular disease in late midlife. Journal of Marriage and Family, 68, 639-657. 
Zoccola, P. M., Figueroa, W. S., Rabideau, E. M., Woody, A., \& Benencia, F. (2014). Differential effects of poststressor rumination and distraction on cortisol and Creactive protein. Health Psychology, 33, 1606-1609. 
APPENDIX: CODING MANUAL

\section{Rumination Induction Method}

1. Imagery: Instructed to imagine a personally- experienced situation/event.

2. Interview: Prompted to talk about a personally-experienced situation/event.

3. Co-rumination: Discuss personally-experienced stressor/event with a friend.

4. Write: Write about a personally-experienced situation/event.

5. Other

\section{Emotion Induced by Rumination}

1. Anger

2. Sadness

3. Positive Emotion/Joy

4. Anxiety

5. Other

\section{Study Design}

1. Between Subjects Design

2. Within Subjects Design

\section{Rumination Duration}

1. Less than 3 minutes

2. 3 - 5 minutes

3. 5- 10 minutes

4. $11-15$ minutes

5. $16-20$ minutes

6. Over 20 minutes

\section{Recovery Duration}

1. Under 10 minutes

2. $10-15$ minutes 
3. 16 - 30 minutes

4. 31 - 45 minutes

5. $46-60$ minutes

6. Over 60 minutes

\section{Laboratory Stressor}

1. Blood draw

2. Recall recorded

3. Pain condition

\section{Publication Status}

1. Published in peer reviewed journal

1. Not published in peer reviewed journal 


\section{CURRICULUM VITA \\ Lona Busch \\ 79 Crestview Drive \\ Pittsford NY, 14534}

\section{EDUCATION:}

Ph.D. in Counseling Psychology (2015)

University of Louisville

M.Ed. in Counseling Psychology (2011)

University of Louisville

M.S. in Applied Psychology (2002)

University of Baltimore

B.A. in Psychology (1995)

State University of New York at Buffalo

\section{TEACHING EXPERIENCE:}

STATE UNIVERSITY OF NEW YORK AT GENESEO

Geneseo, NY

Social Psychology (PSYC 350) Fall 2015

Psychology of Personality (PSYC 355) Fall 2015

\section{ROCHESTER INSTITUTE OF TECHNOLOGY}

Rochester, NY

Career Development (SSP 011) Spring 2014

Motivation and Wellness (CRPG 92.04) Spring 2014

YearOne Freshman Transition (ACSC 010) Fall 2013

\section{UNIVERSITY OF LOUISVILLE}

Louisville, KY

Learning and Human Development (ECPY 507/607) Fall 2011 


\section{CLINICAL EXPERIENCE:}

UNIVERSITY OF ROCHESTER MEDICAL CENTER

APA Accredited Doctoral Internship

Rochester, NY

\section{Doctoral Psychology Intern (Adult Track)}

Outpatient Rotation (July 2014 - June 2015)

Provide clinical services at Strong Behavioral Health, including intake assessments, treatment planning, individual and group therapy, crisis intervention, psychological testing, and consultation with medical providers.

Urgent Care Rotation (July 2014 - December 2014)

Provide short-term therapy (approximately six sessions) through the Urgent Care Clinic at Strong Behavioral Health to individuals experiencing acute mental health issues.

Anxiety Disorders Rotation (July 2014 - June 2015)

Receive extensive training and supervision in the assessment and treatment for anxiety disorders, including Obsessive Compulsive Disorder, Panic Disorder, Generalized Anxiety Disorder, and Social Phobia.

Inpatient Rotation, Rochester Psychiatric Center (January 2015 - June 2015) Provide individual and group interventions appropriate for severely mentally ill patients, using rehabilitative skill modules, Dialectical Behavioral Therapy (DBT) interventions, and behavioral techniques.

\section{COMMUNICARE MENTAL HEALTH CLINIC}

Radcliffe, KY

Psychology Intern (August 2011 - August 2012)

Provided clinical services to include intake assessments, treatment planning, parent behavioral management training, and evidence-based treatment (individual, family, and group counseling) in an outpatient clinic in a rural community.

\section{UNIVERSITY OF LOUISVILLE COUNSELING CENTER}

Louisville, KY

Psychology Intern (July 2010 - August 2011)

Provided clinical, outreach, and administrative services within a college counseling center serving undergraduate and graduate students in a large midwestern university. 


\section{LOUISVILLE VA MEDICAL CENTER}

Louisville, KY

Psychological Assessment Intern (January 2010 - June 2010)

Conducted comprehensive and integrated neuropsychological assessments.

\section{PROFESSIONAL EXPERIENCE:}

\section{ROCHESTER INSTITUTE OF TECHNOLOGY}

Rochester, NY

Spectrum Support Program (December 2013 - July 2014)

Planned a practitioners' conference for higher education professionals who deliver targeted programs for college students on the autism spectrum; and assisted in the development of a corresponding resource guide.

College Restoration Program (January 2014 - June 2014)

Provided individualized targeted interventions to students facing suspension, monitored progress, and addressed barriers to academic success.

Academic Support Center (July 2013 - December 2013)

Provided individual coaching to over 100 freshmen to support student development and address issues of transition.

\section{UNIVERSITY OF LOUISVILLE}

Louisville, KY

Academic Intervention Specialist (July 2008 - July 2010)

Provided individualized support to at-risk students and assisted in enrollment management initiatives.

\section{UNIVERSITY OF BALTIMORE}

\section{Baltimore, MD}

Transfer Specialist and Counselor (May 2005 - December 2007)

Provided services to improve outcomes for at-risk students, devised assessment procedures to gauge student needs, and assisted with academic advising initiatives.

Advisor, Counselor, and Coordinator (December 2003 - April 2005) Coordinated various academic programs and scholarships, reviewed student grievances, oversaw faculty and course evaluations, supported at-risk students, developed and implemented efficient academic advising processes, and served as expert on transfer policies. 
Assistant Director of Admissions (January 1998 - March 2000)

Successfully reached enrollment goals, streamlined recruitment to enrollment

processes, provided supportive leadership, managed the admissions' mailing center, helped develop articulation agreements with community colleges, and fostered professional relationships with internal and external colleagues.

\section{RESEARCH EXPERIENCE:}

\section{UNIVERSITY OF LOUISVILLE}

Louisville, KY

Depression and Physical Health Research Team (2008-present)

Principal Researcher: Dr. Patrick Pössel

Conduct research on the association between depression and cardiovascular disease, and assist with grant proposals. Grant proposal submitted on 11/2015 for National Institute of Health (NIH) R03 grant.

Adolescent Depression Research Team (2008 - 2012)

Principal Researcher: Dr. Patrick Pössel

Developed and administered assessments to high school students, analyzed data, performed literature searches, assisted in writing proposals, and presented research results.

\section{UNIVERSITY OF BALTIMORE}

Baltimore, MD

Adolescent Anxiety Disorders Research Team (1998 - 2000)

Principal Researcher: Dr. Golda Ginsburg

Presented workshops on coping with stress and anxiety to students in urban high schools; administered self-report assessments to classrooms of students; assisted in the recruitment, diagnosis, and treatment of clients from urban underserved communities; facilitated group sessions; conducted research; and presented results at conferences.

\section{PRESENTATIONS:}

Busch, L. (March, 2013). A Meta-Analysis of Cardiovascular Responses to Rumination. Paper presentation at Kentucky Psychological Association Spring Academic Conference. Louisville, KY. 
Busch, L. (February, 2012). Cardiovascular Implications of Rumination. Oral research presentation to the Department of Education and Counseling Psychology at the University of Louisville. Louisville, KY.

Wooldridge, D. T., Rudasill, K. M., Pössel, P., Rhyne, E. P., Busch, L. Y., \& Bjerg, A. C. (August, 2010). The Teacher Behavior Questionnaire: Facilitating Interventions for Student Mental Health. Poster presentation at the $118^{\text {th }}$ Annual American Psychological Association Convention. San Diego, CA.

Busch, L., Page, C., \& Pyle, J. (May, 2010). Harnessing Graduate Assistants' Talents to Improve Advising Services: A Mutually Beneficial Relationship. Training session conducted at the National Academic Advising Association MidSouth Regional Conference. Lexington, KY.

Busch, L. Pössel, P., Rudasill, K., Wooldridge, D., \& Pickering, N. (November, 2009). Psychometric Properties of the Evaluative Feedback Questionnaire: A Preliminary Study. Poster presentation at the $43^{\text {rd }}$ Annual Convention of the Association of Behavioral and Cognitive Therapies. New York, NY.

Busch, L. Psychometric Properties of the Evaluative Feedback Questionnaire. (April, 2009). Poster presentation at the Kentucky Psychological Association for Graduate Students Annual Convention. Lexington, KY.

Hills (Busch), L., Ginsburg, G.S., Drake, K.L., \& Vandenbosch, D. (November, 1998). Relation between Anxiety and Self-Perceptions among African American Adolescents. Poster presentation at the Annual Convention of the Association for Advancement of Behavioral Therapy. Washington, DC.

Drake, K.L., Ginsburg, G.S., Vandenbosch, D. \& Hills (Busch), L. (November, 1998). Attributional Style among High- and Low-Anxious African-American Adolescents. Poster presentation at the Annual Convention of the Association for Advancement of Behavioral Therapy. Washington, D.C.

\section{PROFESSIONAL AFFILIATIONS \& SERVICE:}

New York State Psychological Association (January 2015 - present)

Division 15 of the American Psychological Association, Educational Psychology (2010-present)

Division 17 of the American Psychological Association, Society for Counseling Psychology (2010-present) 
Judge, Kentucky Psychological Association Foundation, Spring Academic Conferences (2010-2013)

Kentucky Psychological Association of Graduate Students (2008-2012)

Doctoral Student Organization, College of Education and Human Development, University of Louisville (2008-2014)

Association for Behavioral and Cognitive Therapy, Student Member (2009-2011)

Program Committee, Registration Committee, and Technology Committee, Student Research Conferences, University of Louisville (2009)

Inter-Institutional Graduate and Professional Studies Committee, Maryland Higher Education Commission (2002)

Women's Forum, University System of Maryland (2001-2004)

National Academic Advising Association (2001-2004; 2008-2011)

Association for Women in Psychology (1998-2000)

Partners in Continuing Education, University System of Maryland (1998-2000)

National Association for College Admissions Counseling (1997-2000) 